\title{
Silylpyrrole Oxidation en route to Saxitoxin Congeners including 11-Saxitoxinethanoic Acid
}

Doris T. Y. Tang ${ }^{\dagger}$, Jeffrey E. Merit ${ }^{\dagger}$, T. Aaron Bedell ${ }^{\ddagger}$ and J. Du Bois*

Department of Chemistry, Stanford University, 333 Campus Dr., Stanford, CA 94305

\section{Table of Contents}

Tabulated spectral data for 11-SEA

${ }^{1} \mathrm{H},{ }^{13} \mathrm{C}$, and 2D NMR Spectra

Comparison of spectral data for synthetic and natural 11-saxitoxinethanoic acid:

\begin{tabular}{|c|c|c|c|c|}
\hline \multirow[t]{2}{*}{ Position } & \multicolumn{2}{|c|}{ Synthetic 11-SEA* } & \multicolumn{2}{|c|}{ Natural 11-SEA } \\
\hline & ${ }^{13} C^{* *}$ & ${ }^{1} \mathrm{H}^{* * *}$ & ${ }^{13} \mathrm{C}$ & ${ }^{1} \mathrm{H}$ \\
\hline 2 & 156.1 & - & 156.2 & - \\
\hline 4 & 85.5 & - & 83.5 & - \\
\hline 5 & 57.4 & $4.80(\mathrm{~s}, 1 \mathrm{H})$ & 57.5 & $4.73(\mathrm{~s}, 1 \mathrm{H})$ \\
\hline 6 & 53.7 & 3.83 (ddd, $1 \mathrm{H}, J=9.1,5.3,1.4 \mathrm{~Hz})$ & 53.5 & $3.81(\mathrm{dd}, 1 \mathrm{H}, J=9.7,5.1 \mathrm{~Hz})$ \\
\hline 8 & 159.5 & - & 158.3 & - \\
\hline 10 & 48.0 & $\begin{array}{l}3.95(\mathrm{t}, 1 \mathrm{H}, J=9.4 \mathrm{~Hz}) \\
3.26-3.19(\mathrm{~m}, 1 \mathrm{H})\end{array}$ & 48.2 & $\begin{array}{l}3.91(\mathrm{dd}, 1 \mathrm{H}, J=10,9 \mathrm{~Hz}) \\
3.18(\mathrm{dd}, 1 \mathrm{H}, J=10,10 \mathrm{~Hz})\end{array}$ \\
\hline 11 & 39.8 & $2.80(\mathrm{ddd}, 1 \mathrm{H}, J=16.6,9.8,6.8 \mathrm{~Hz})$ & 39.9 & $2.76(\mathrm{~m}, 1 \mathrm{H})$ \\
\hline 12 & 99.4 & - & 99.3 & - \\
\hline 13 & 63.6 & $\begin{array}{l}4.28(\mathrm{dd}, 1 \mathrm{H}, J=11.7,9.1 \mathrm{~Hz}) \\
4.06(\mathrm{dd}, 1 \mathrm{H}, J=11.7,5.3 \mathrm{~Hz})\end{array}$ & 63.6 & $\begin{array}{l}4.24(\mathrm{dd}, 1 \mathrm{H}, J=12,9 \mathrm{~Hz}) \\
4.02(\mathrm{dd}, 1 \mathrm{H}, J=12,9 \mathrm{~Hz})\end{array}$ \\
\hline 14 & 159.2 & - & 159.3 & - \\
\hline 15 & 34.2 & $\begin{array}{l}2.75-2.66(\mathrm{~m}, 1 \mathrm{H}) \\
2.54(\mathrm{dd}, 1 \mathrm{H}, J=16.3,6.3 \mathrm{~Hz})\end{array}$ & 33.9 & $\begin{array}{l}2.68(\mathrm{dd}, 1 \mathrm{H}, J=16,7 \mathrm{~Hz}) \\
2.51(\mathrm{dd}, 1 \mathrm{H}, J=16,6 \mathrm{~Hz})\end{array}$ \\
\hline 16 & 180.9 & - & 180.6 & - \\
\hline
\end{tabular}

${ }^{*} \mathrm{H}$ and ${ }^{13} \mathrm{C}$ NMR signals are sensitive to solution $\mathrm{pH}$.

** ${ }^{13} \mathrm{C}$ NMR data were obtained by HSQC and HMBC on a sample that was allowed to stand for $15 \mathrm{~h}$ in $\mathrm{D}_{2} \mathrm{O}$. The ${ }^{1} \mathrm{H}$ signal at $\mathrm{H}-11$ was completely exchanged with deuterium.

*** ${ }^{1} \mathrm{H}$ NMR spectrum was recorded immediately after dissolving a solid sample of 11-SEA in $\mathrm{D}_{2} \mathrm{O}$; the $\mathrm{H}-11$ signal appears at $2.80 \mathrm{ppm}$. 
${ }^{1} \mathrm{H}$ NMR for $\mathbf{S 1}, 400 \mathrm{MHz}, \mathrm{CDCl}_{3}$

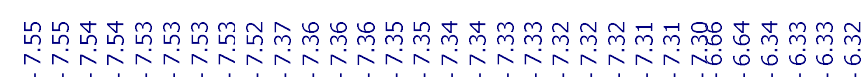

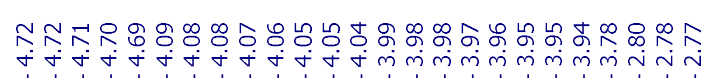

等,

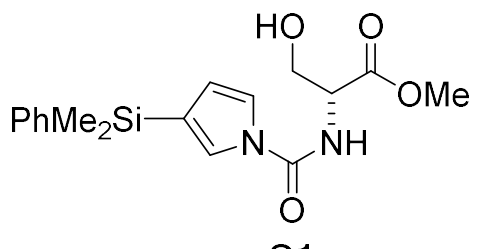

S1

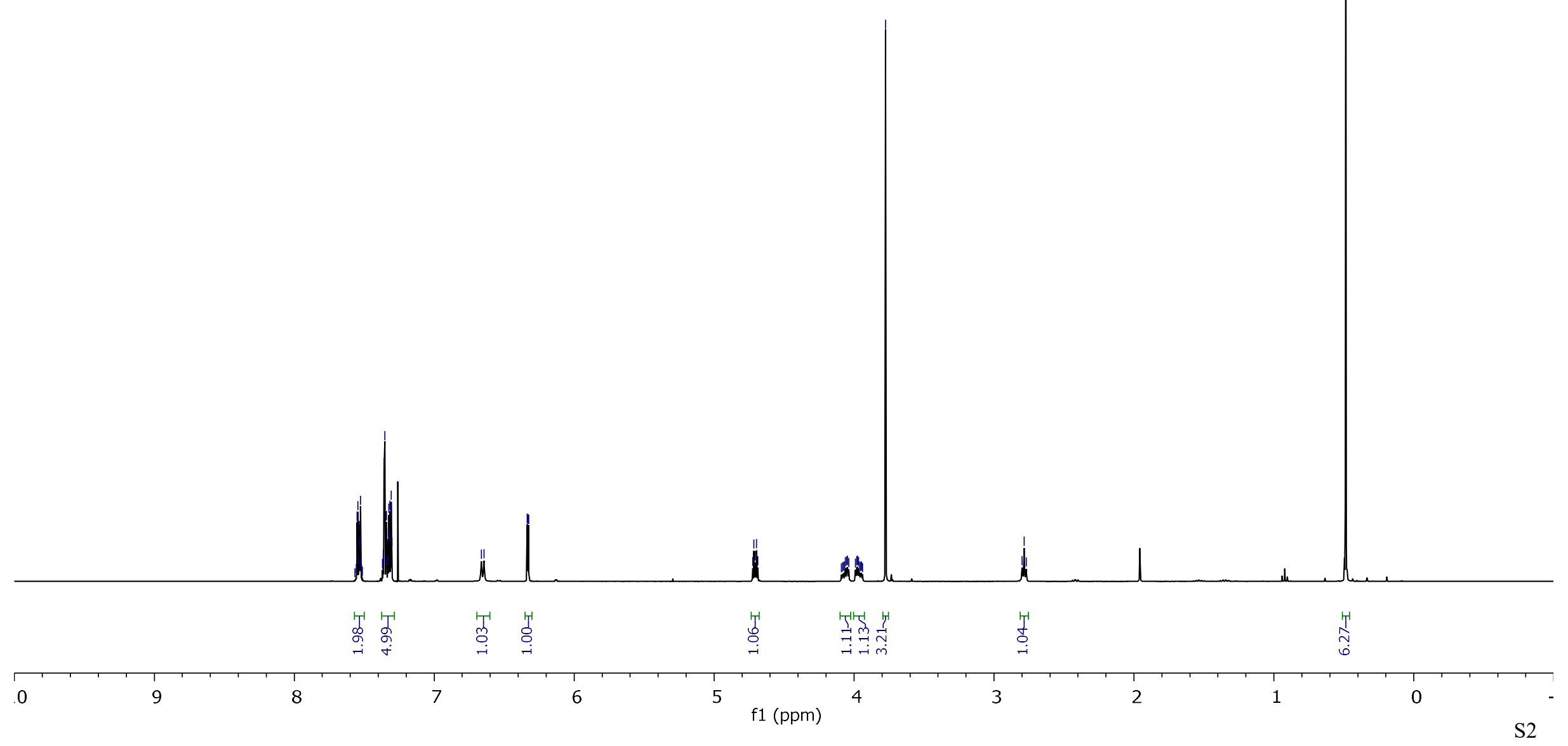


${ }^{13} \mathrm{C}\left\{{ }^{1} \mathrm{H}\right\}$ NMR for $\mathbf{S} 1,100 \mathrm{MHz}, \mathrm{CDCl}_{3}$

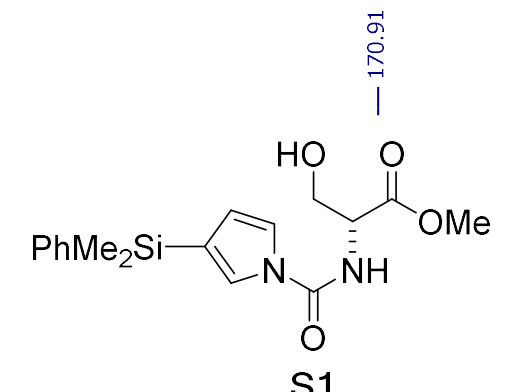

S1

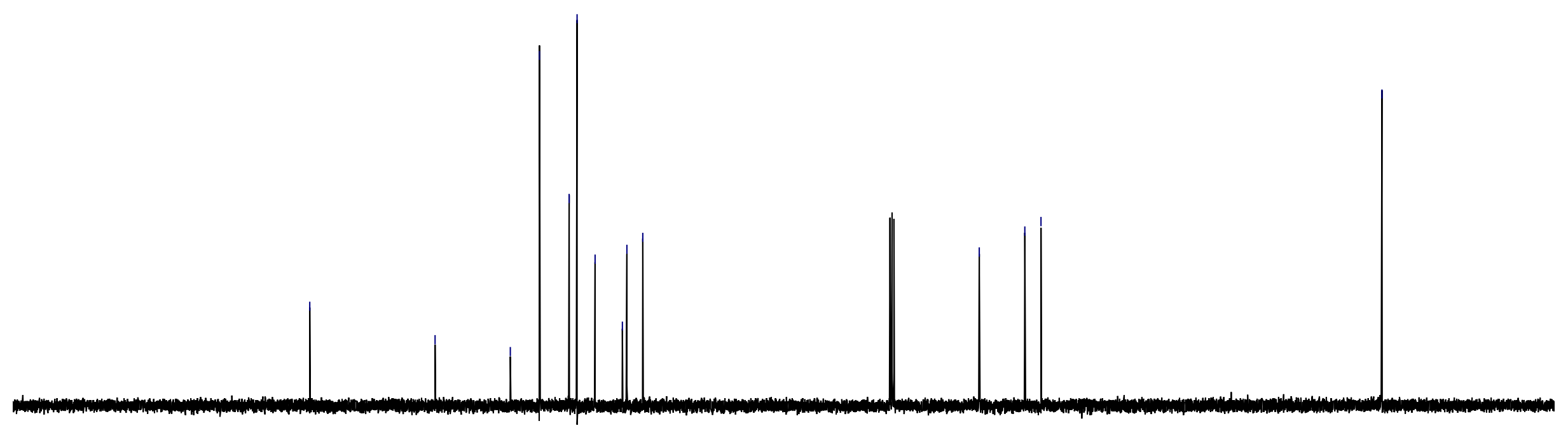

\begin{tabular}{|c|c|c|c|c|c|c|c|c|c|c|c|c|c|c|c|c|c|c|c|c|c|c|}
\hline 1 & 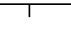 & 1 & 1 & 1 & 1 & 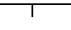 & 1 & 1 & 1 & 1 & $1+1$ & 1 & 1 & 1 & $T$ & 1 & 1 & 1 & 1 & $T$ & 1 & 1 \\
\hline 210 & 200 & 190 & 180 & 170 & 160 & 150 & 140 & 130 & 120 & 110 & $\begin{array}{r}100 \quad 90 \\
\mathrm{f} 1(\mathrm{ppm})\end{array}$ & 80 & 70 & 60 & 50 & 40 & 30 & 20 & 10 & 0 & -10 & -20 \\
\hline
\end{tabular}


${ }^{1} \mathrm{H}$ NMR for $11,400 \mathrm{MHz}, \mathrm{CDCl}_{3}$

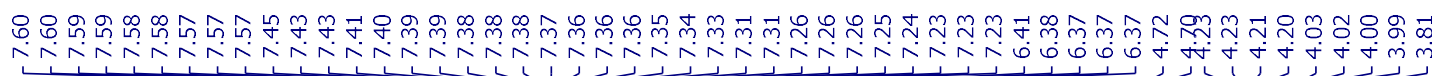
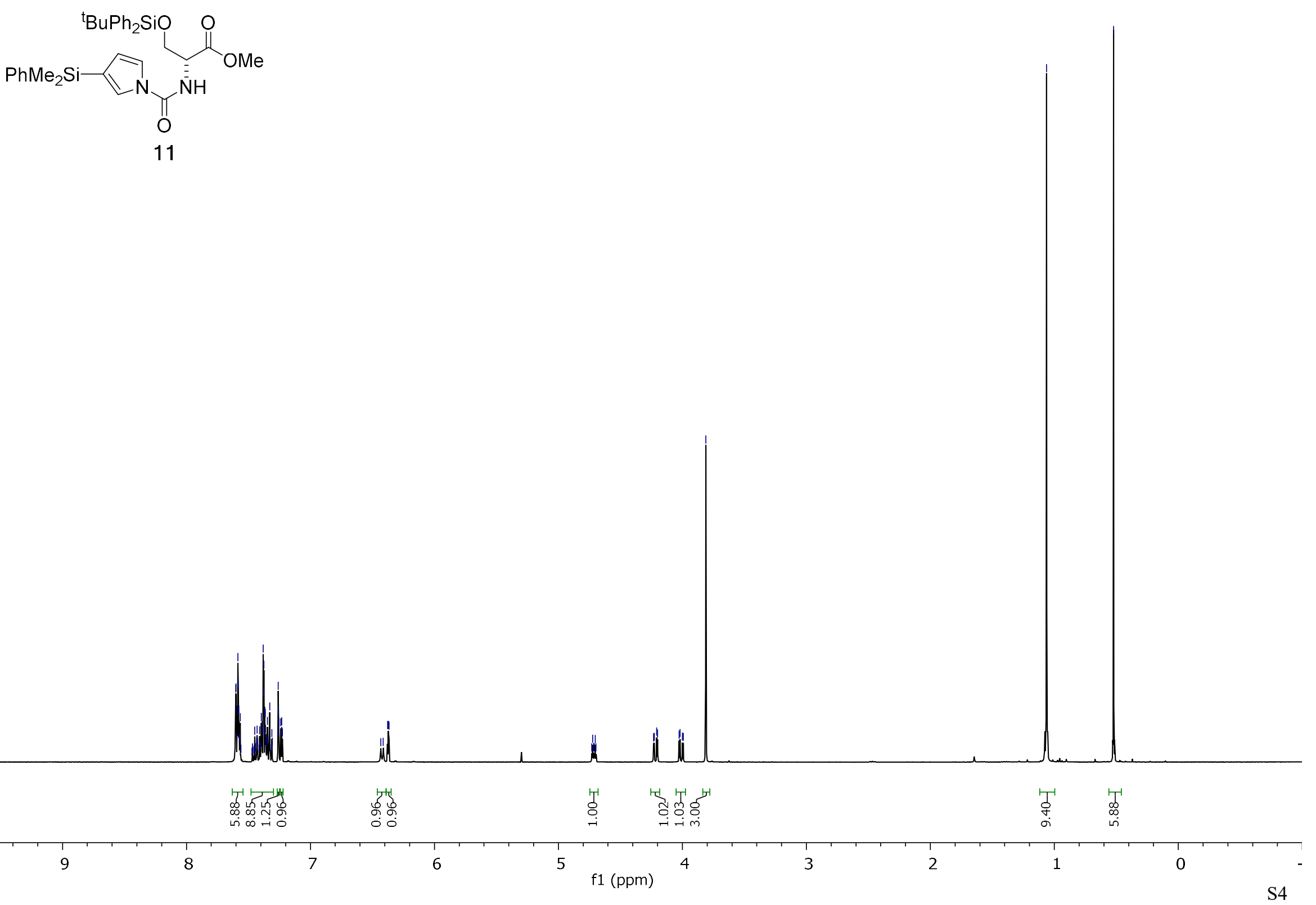
${ }^{13} \mathrm{C}\left\{{ }^{1} \mathrm{H}\right\}$ NMR for $\mathbf{1 1}, 100 \mathrm{MHz}, \mathrm{CDCl}_{3}$

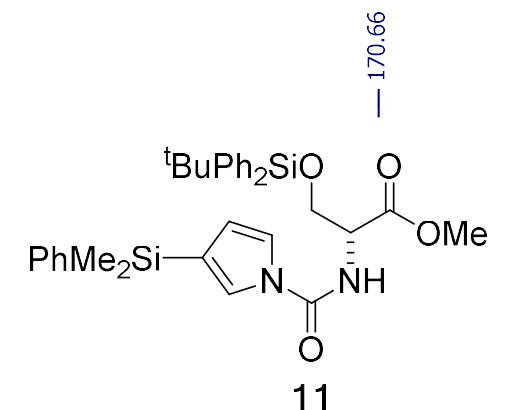

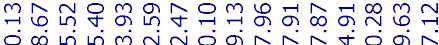

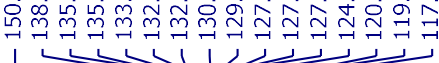

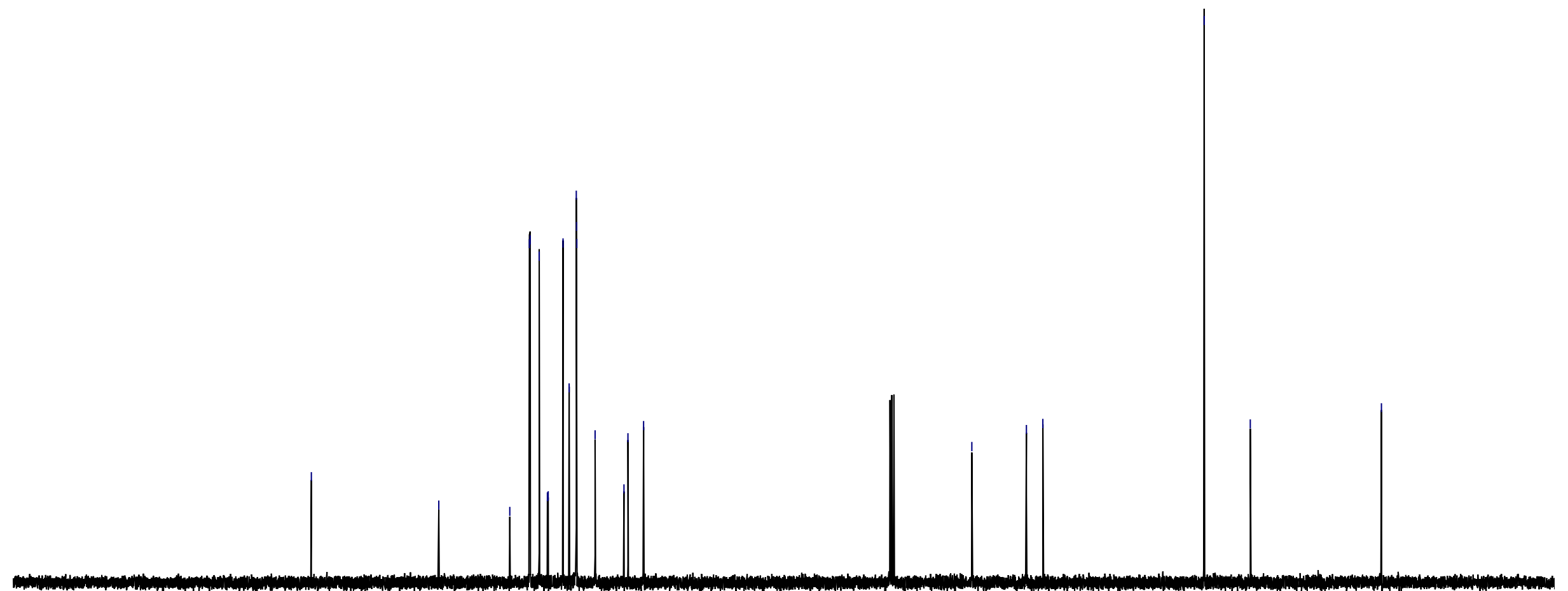


${ }^{1} \mathrm{H}$ NMR for $12,400 \mathrm{MHz}, \mathrm{CDCl}_{3}$

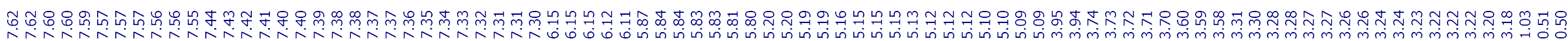
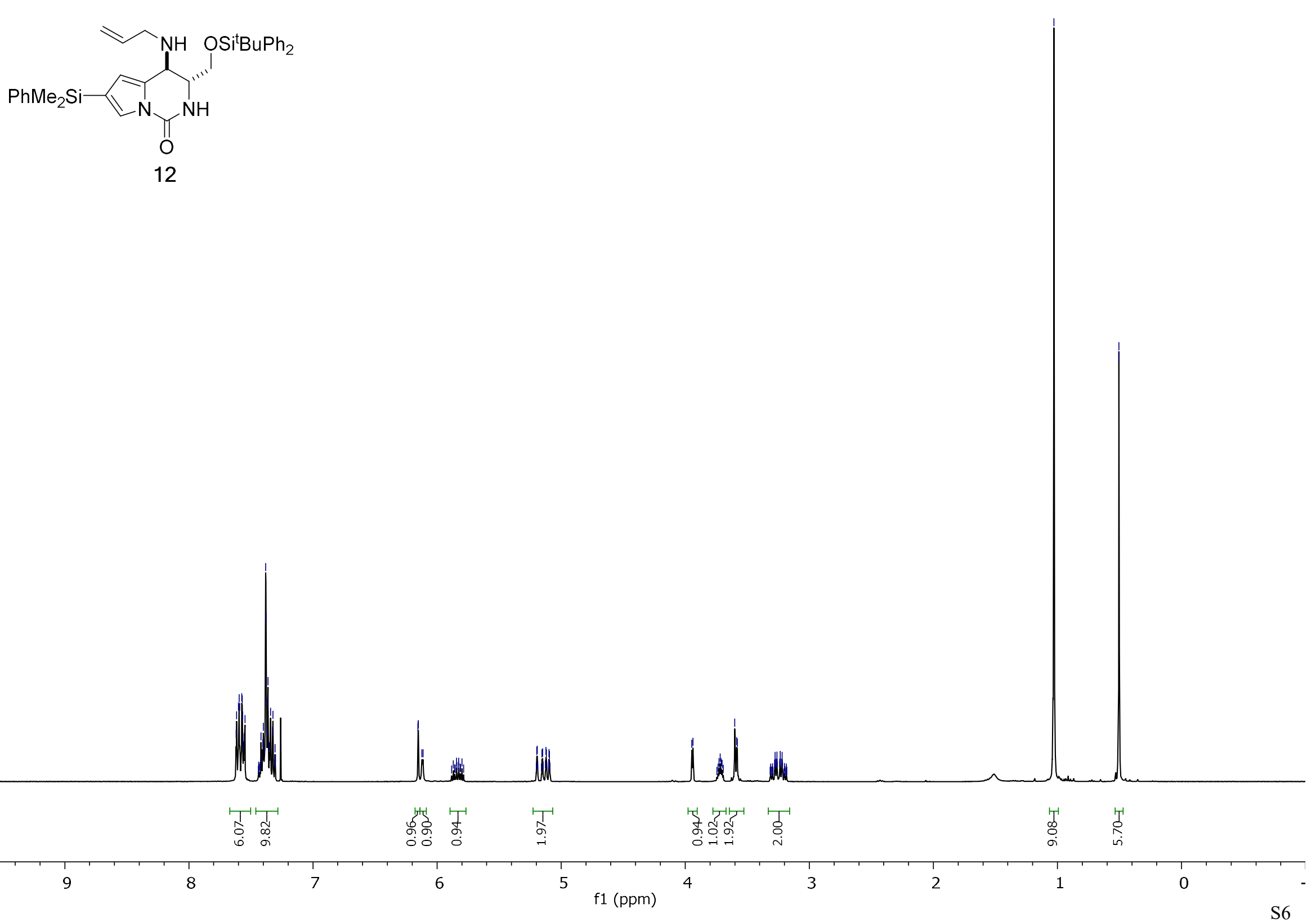
${ }^{13} \mathrm{C}\left\{{ }^{1} \mathrm{H}\right\}$ NMR for $12,100 \mathrm{MHz}, \mathrm{CDCl}_{3}$
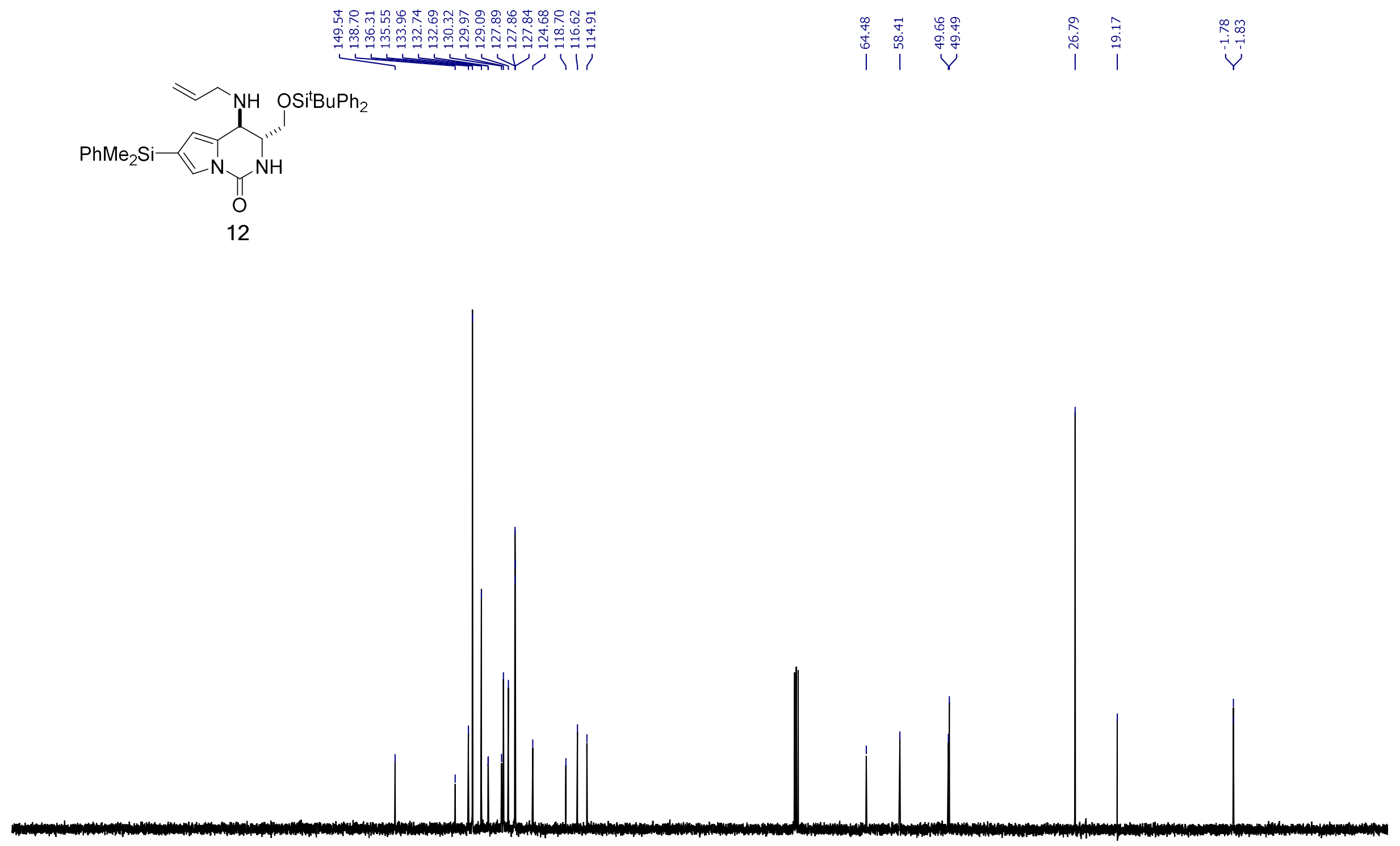
${ }^{1} \mathrm{H}$ NMR for $\mathbf{S 2}, 400 \mathrm{MHz}, \mathrm{CDCl}_{3}$

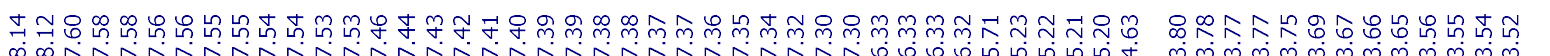

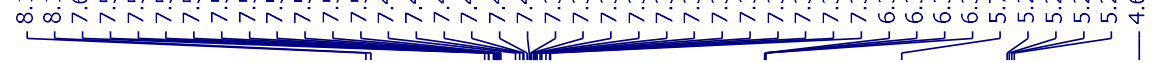
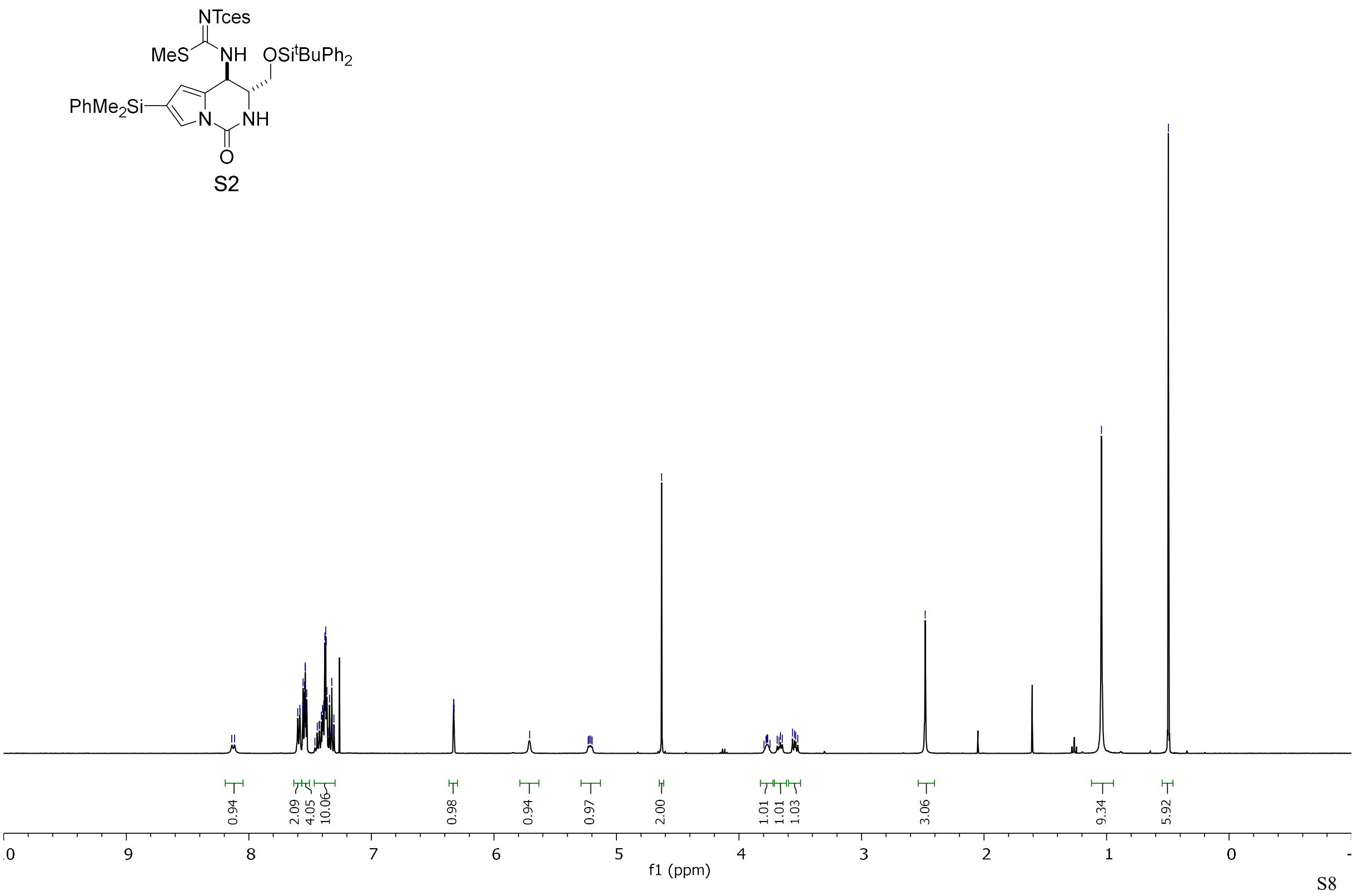
${ }^{13} \mathrm{C}\left\{{ }^{1} \mathrm{H}\right\}$ NMR for S2, $100 \mathrm{MHz}, \mathrm{CDCl}_{3}$

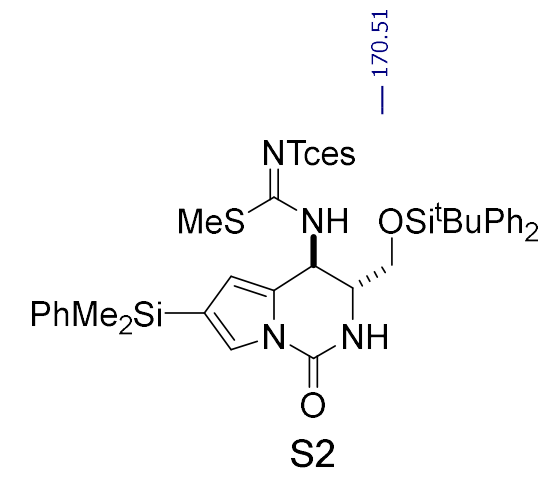

|

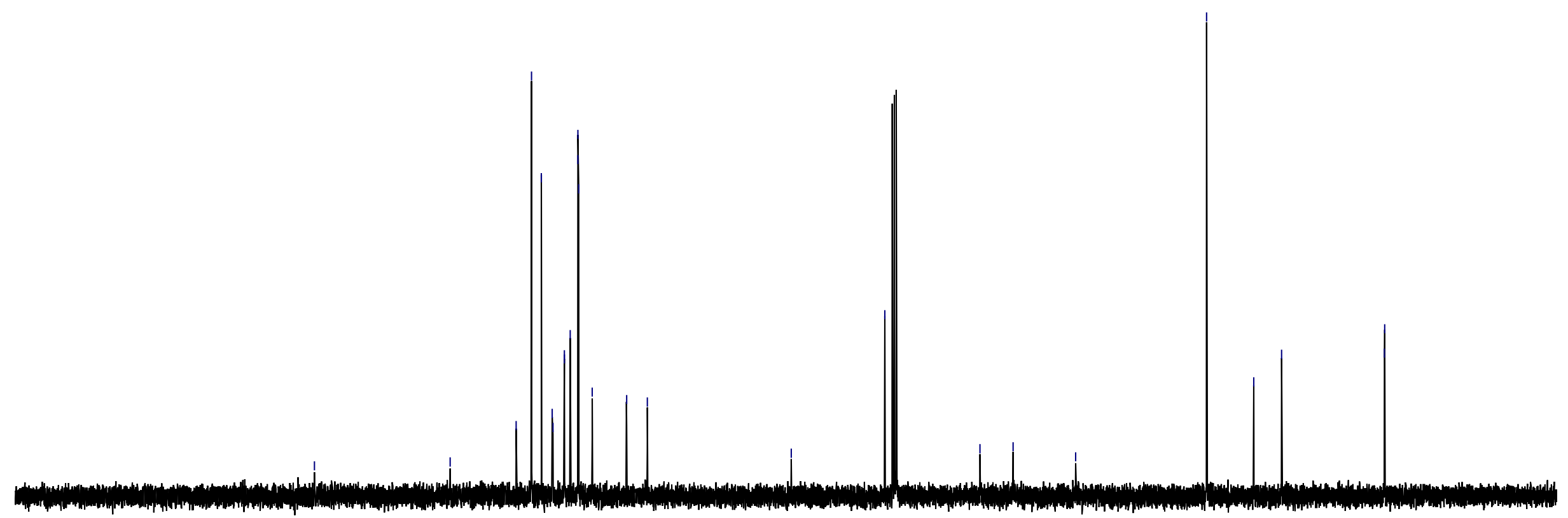


${ }^{1} \mathrm{H}$ NMR for $14,500 \mathrm{MHz}, \mathrm{CDCl}_{3}$

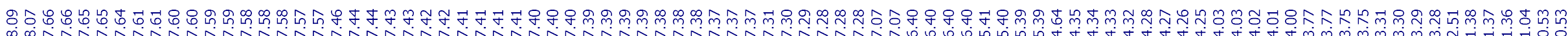

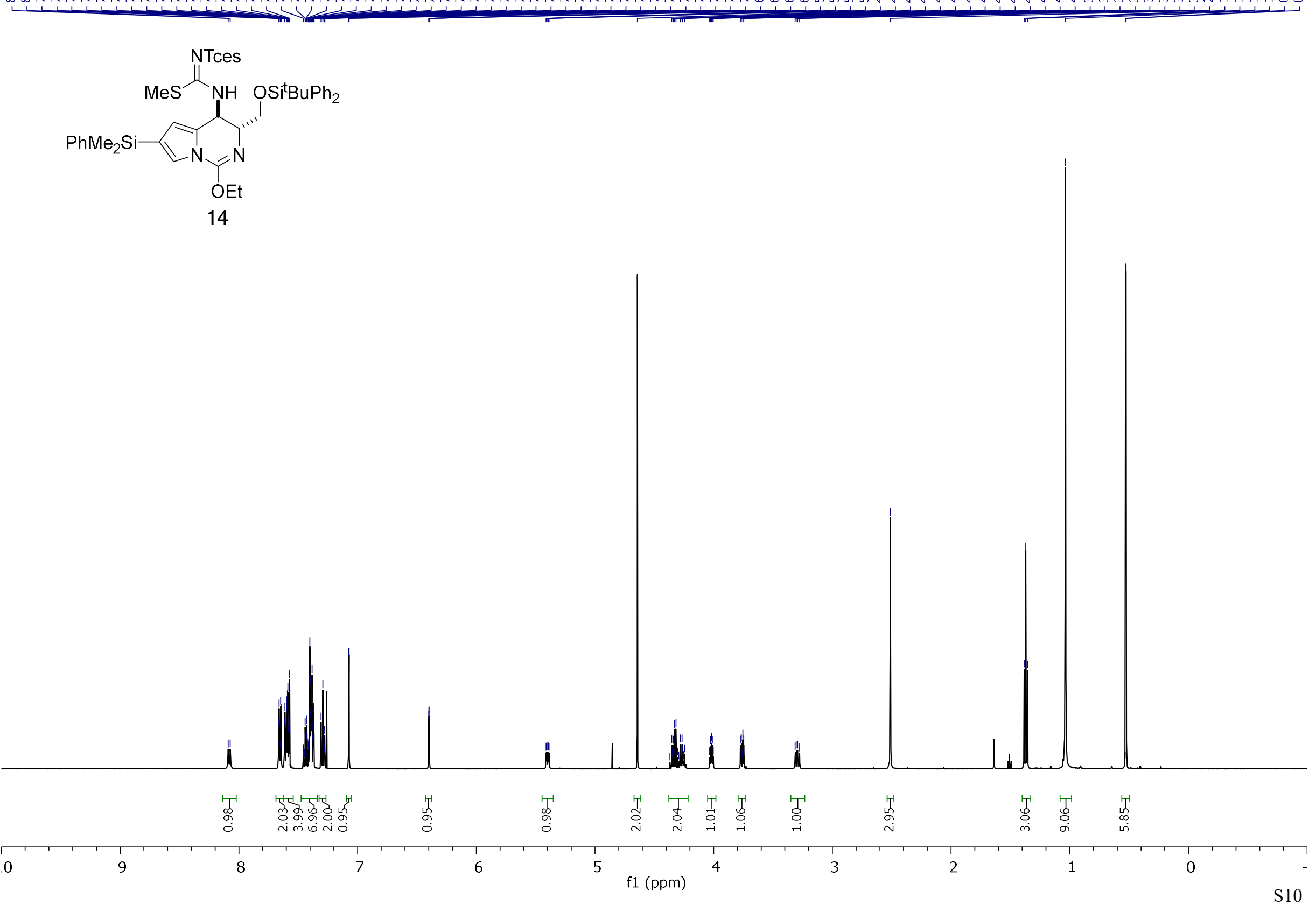


${ }^{13} \mathrm{C}\left\{{ }^{1} \mathrm{H}\right\}$ NMR for $14,125 \mathrm{MHz}, \mathrm{CDCl}_{3}$
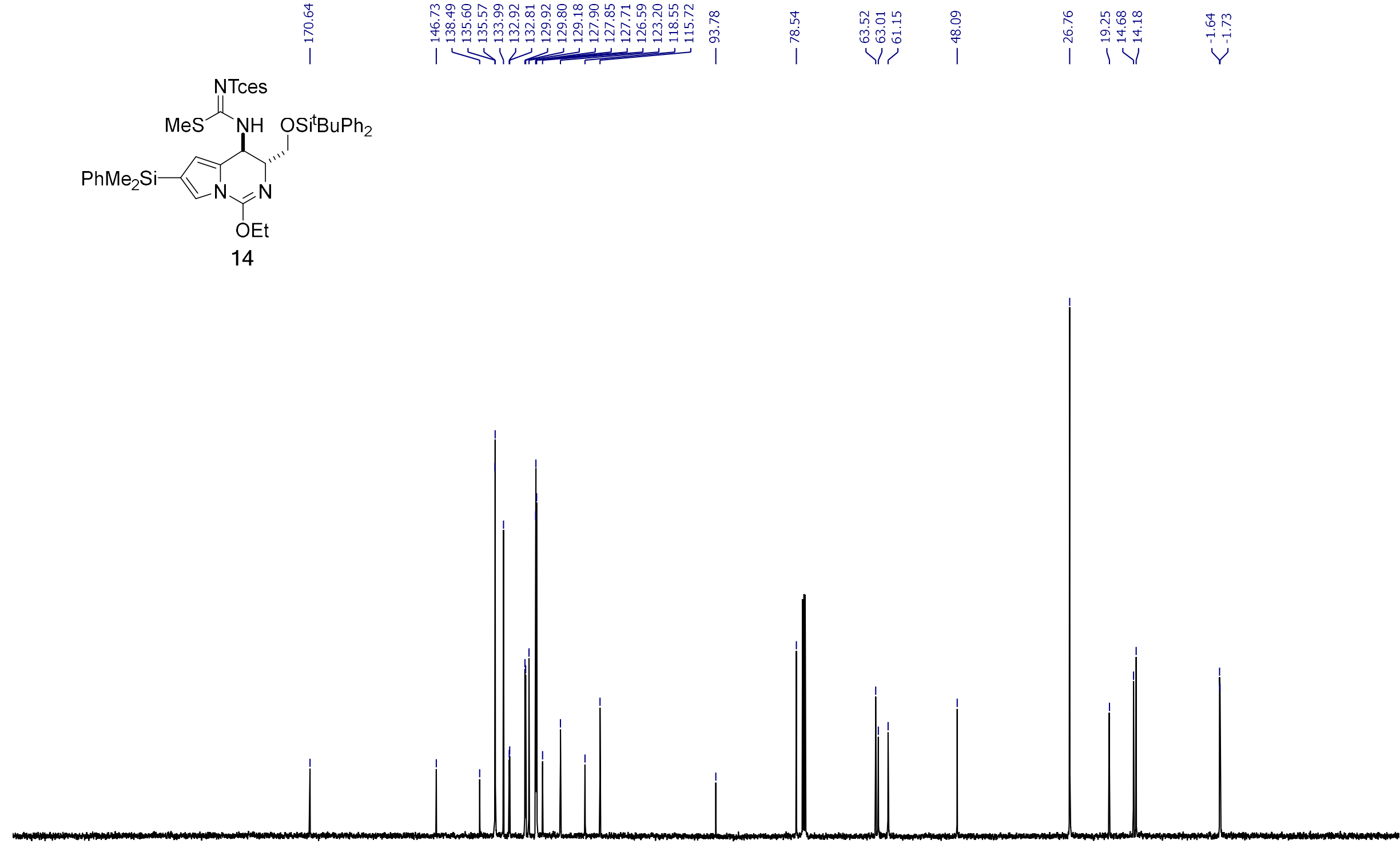
${ }^{1} \mathrm{H}$ NMR for $\mathbf{S} 3,400 \mathrm{MHz}, \mathrm{CD}_{3} \mathrm{OD}$

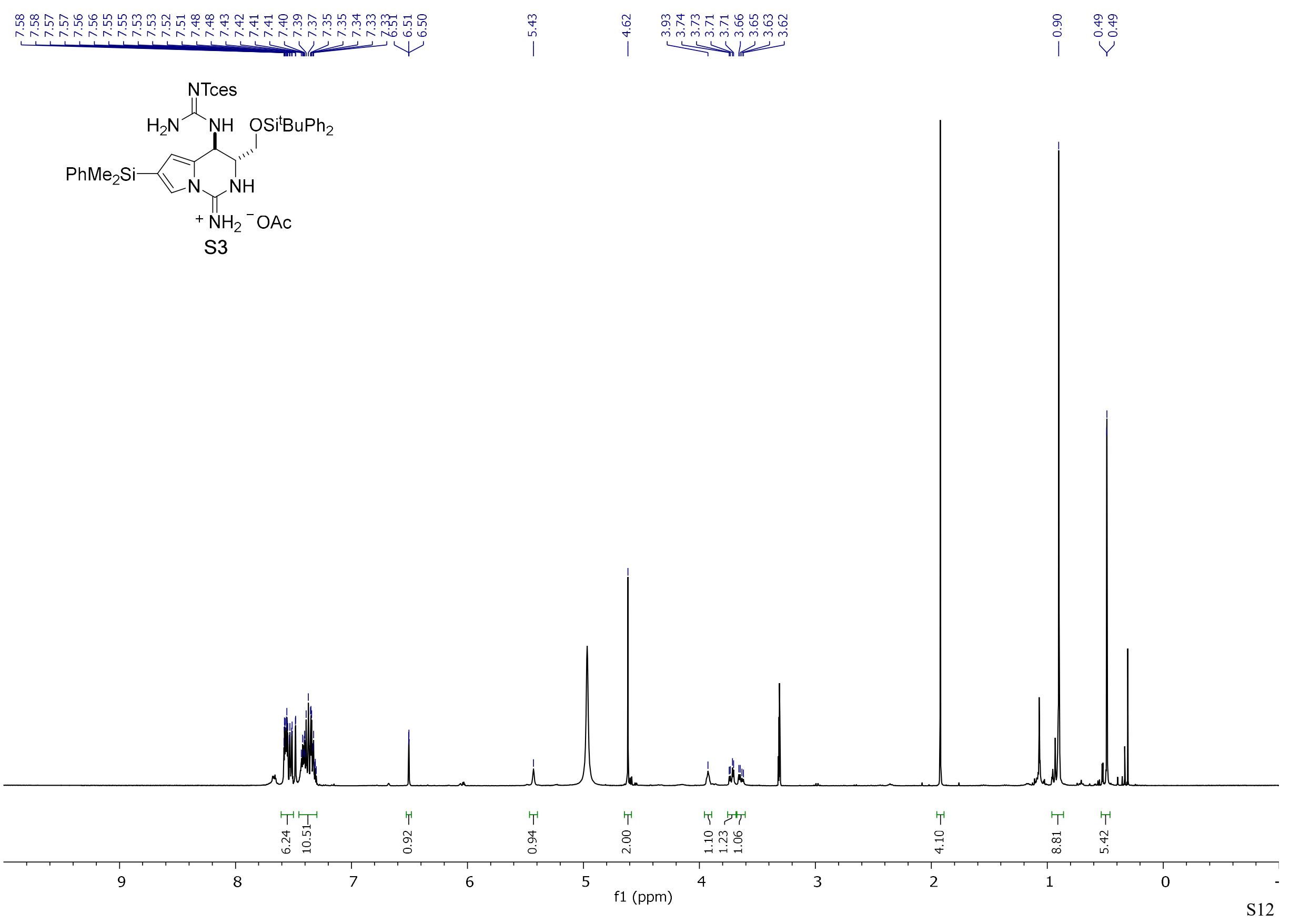


${ }^{13} \mathrm{C}\left\{{ }^{1} \mathrm{H}\right\}$ NMR for S3, $100 \mathrm{MHz}, \mathrm{CD}_{3} \mathrm{OD}$

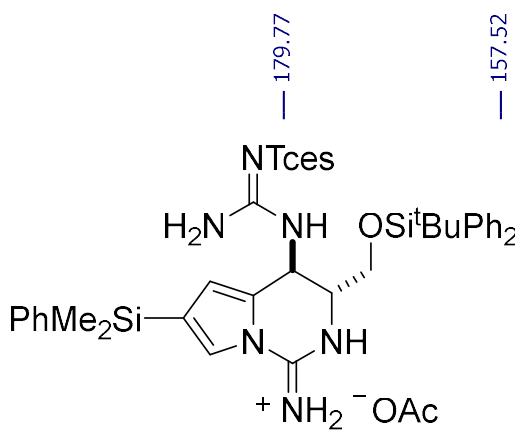

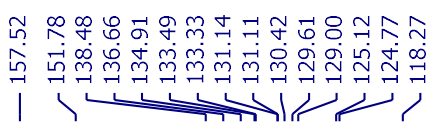

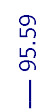

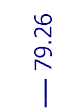

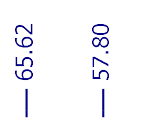

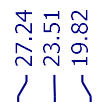

Ỹ

S3

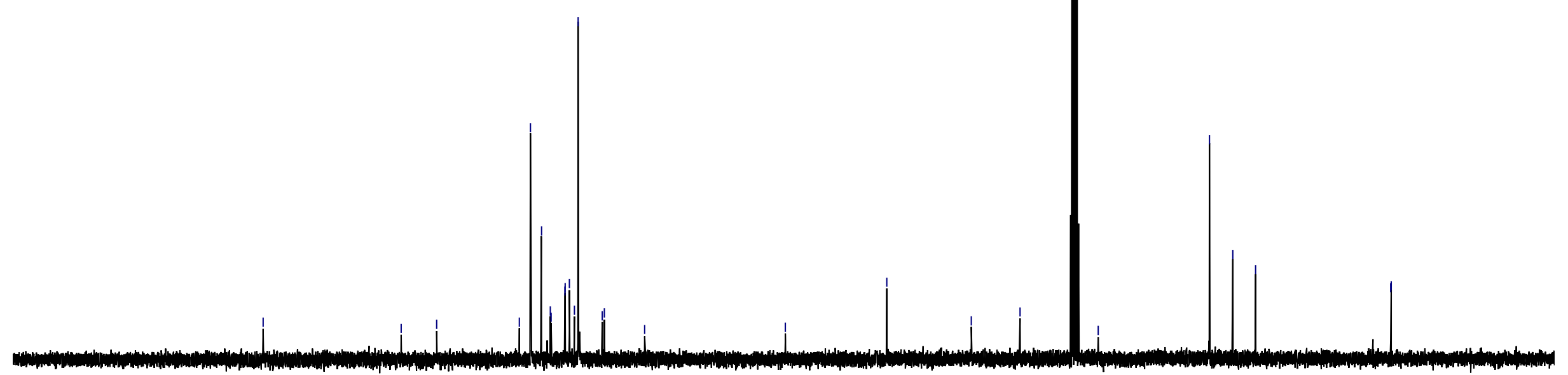

$20 \quad 210$ 


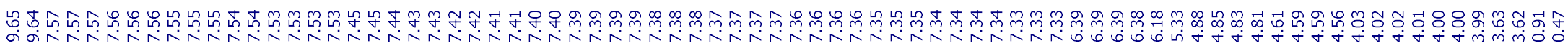

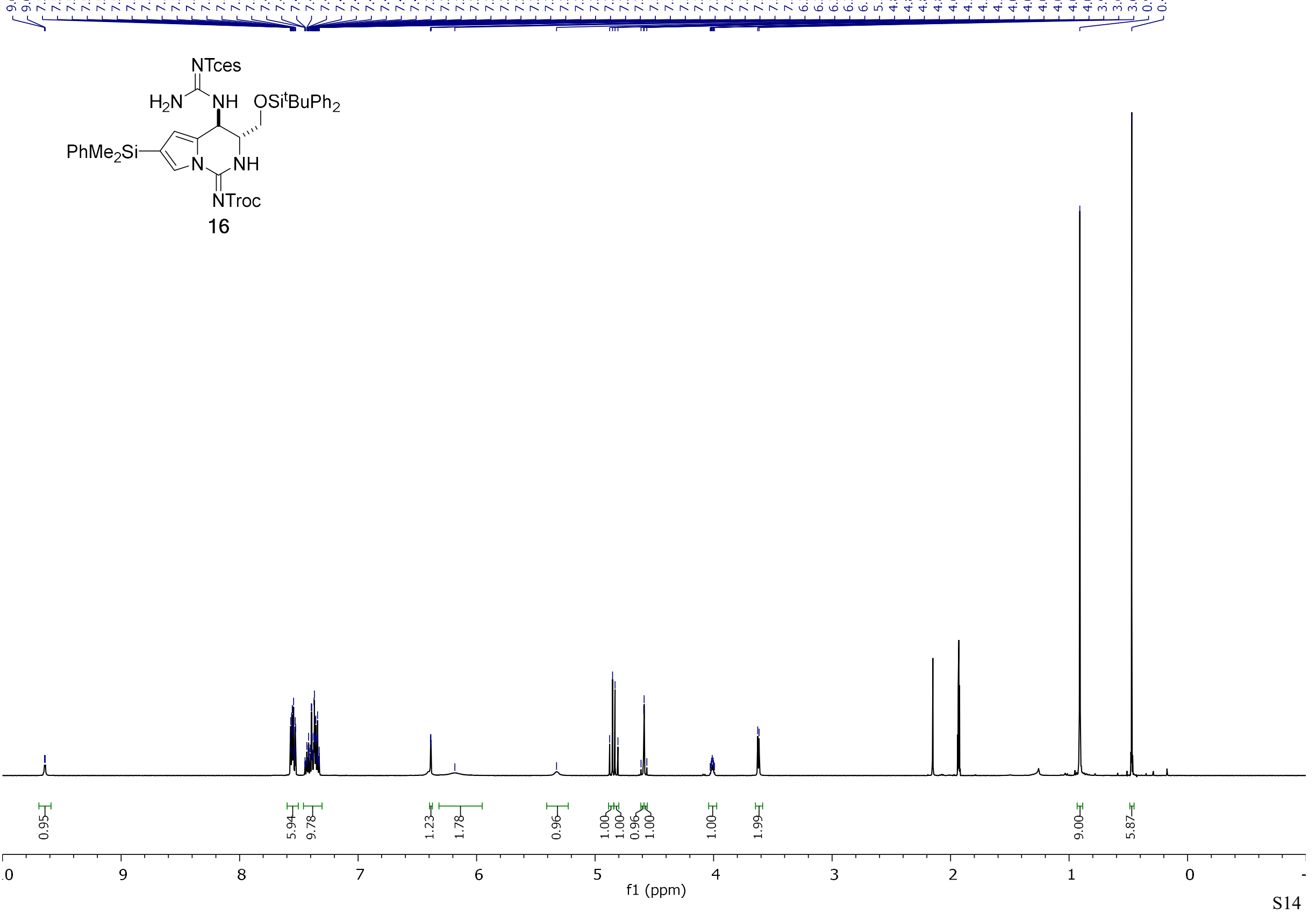


${ }^{13} \mathrm{C}\left\{{ }^{1} \mathrm{H}\right\} \mathrm{NMR}$ for $16,125 \mathrm{MHz}, \mathrm{CD}_{3} \mathrm{CN}$

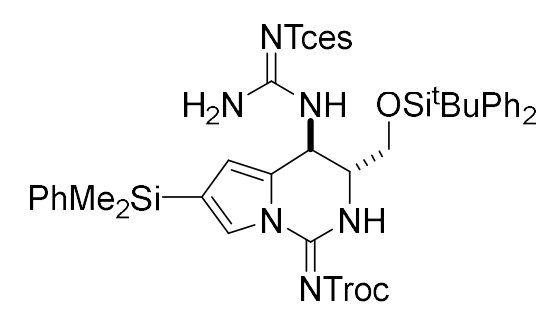

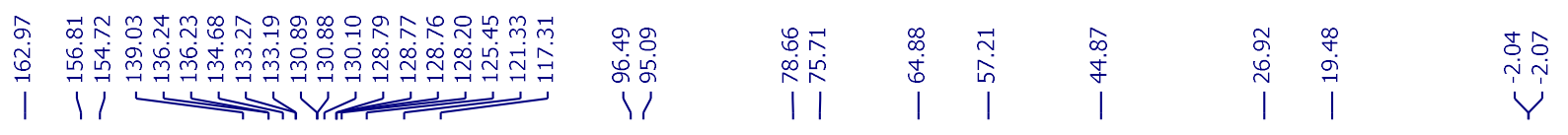

16

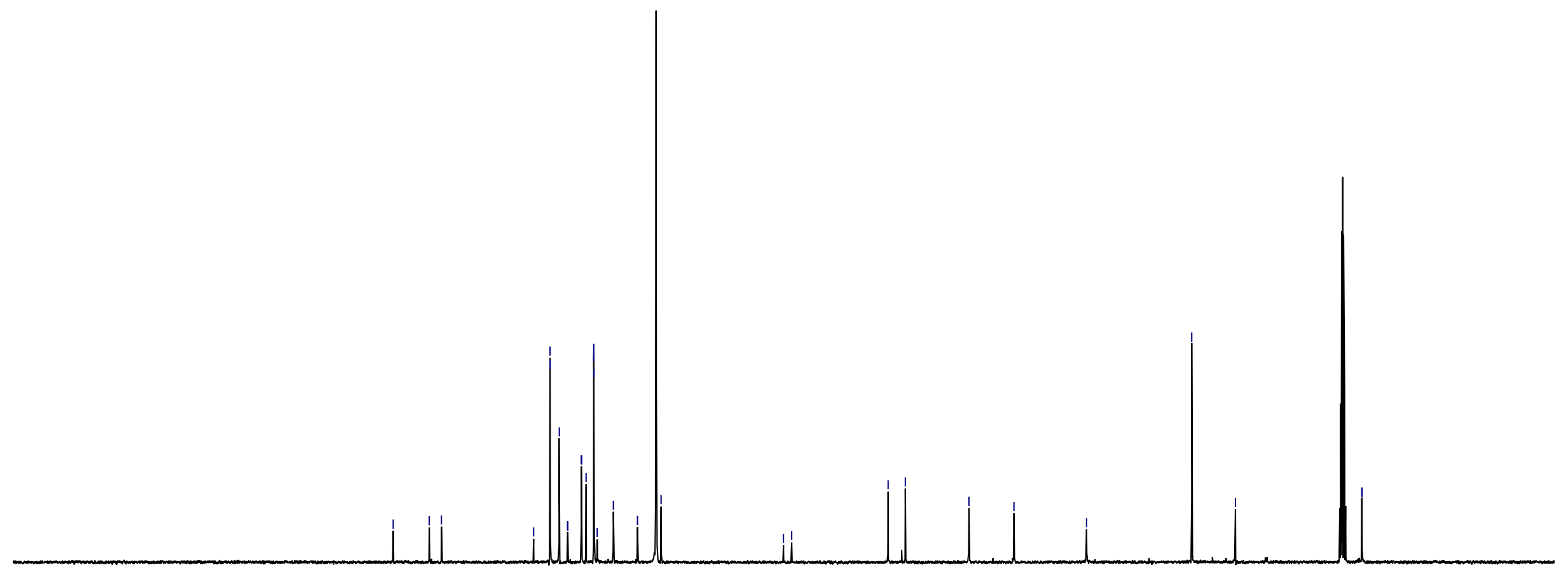




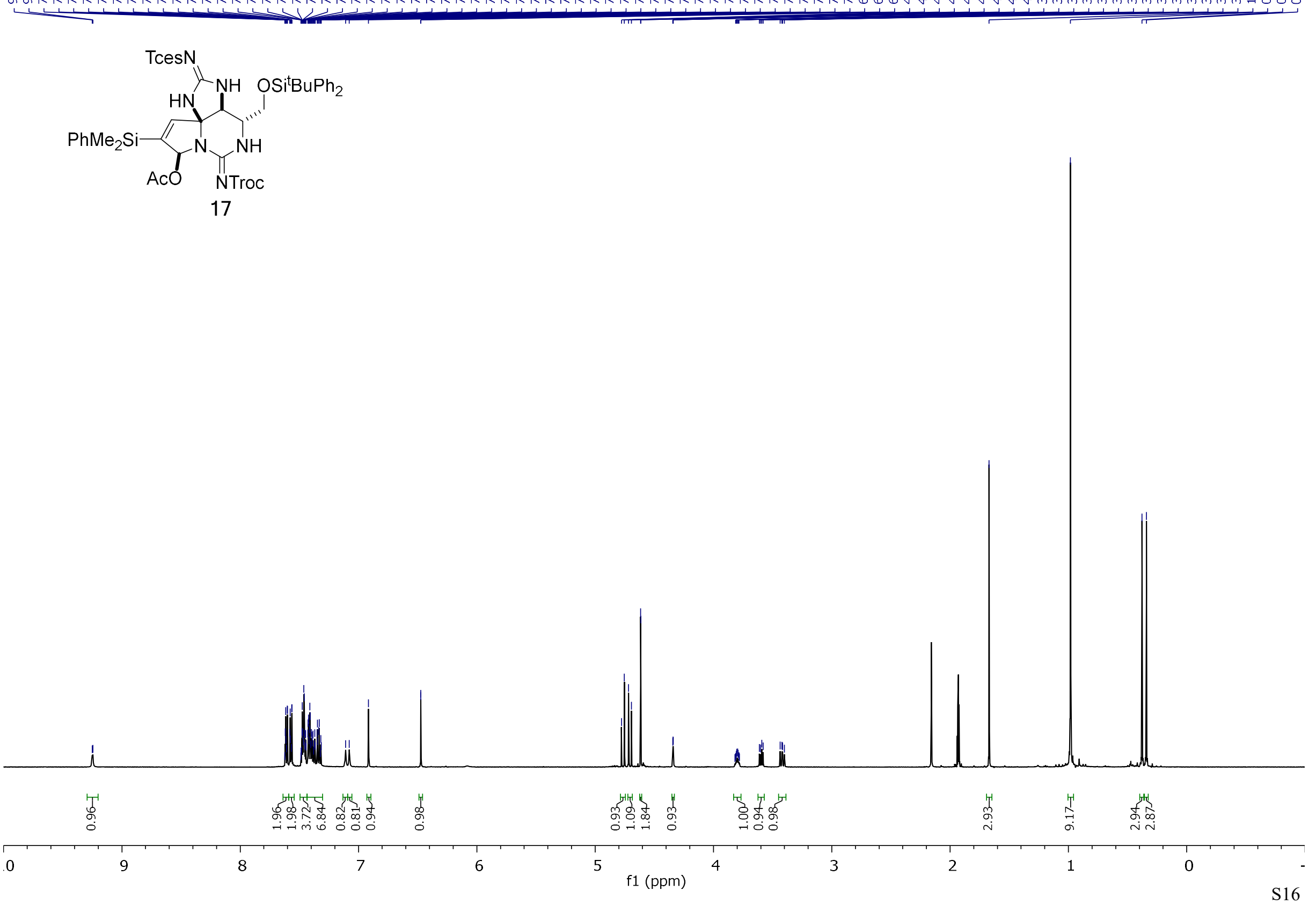


${ }^{13} \mathrm{C}\left\{{ }^{1} \mathrm{H}\right\}$ NMR for $17,125 \mathrm{MHz}, \mathrm{CD}_{3} \mathrm{CN}$

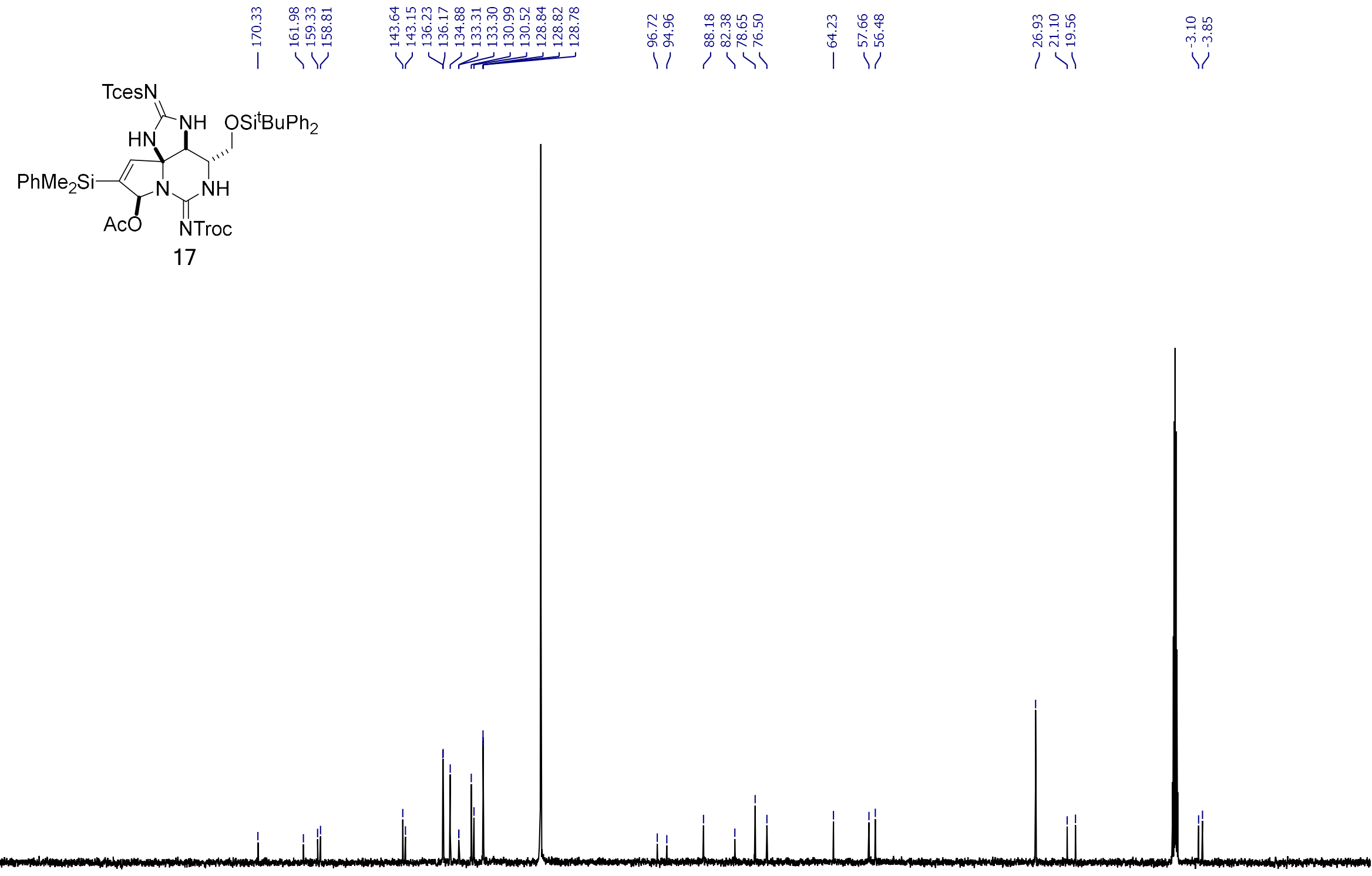




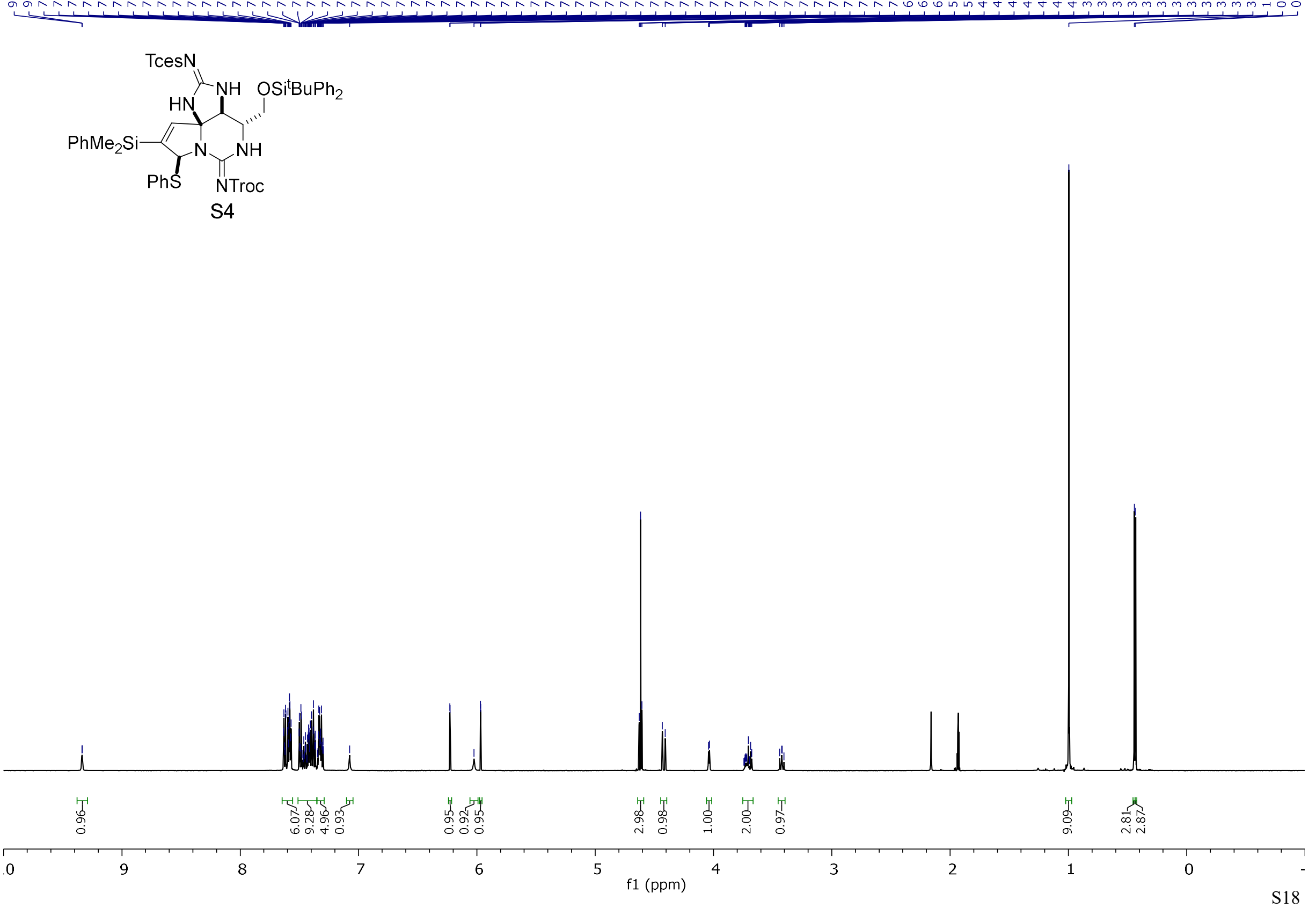


${ }^{13} \mathrm{C}\left\{{ }^{1} \mathrm{H}\right\} \mathrm{NMR}$ for $\mathbf{S 4}, 125 \mathrm{MHz}, \mathrm{CD}_{3} \mathrm{CN}$
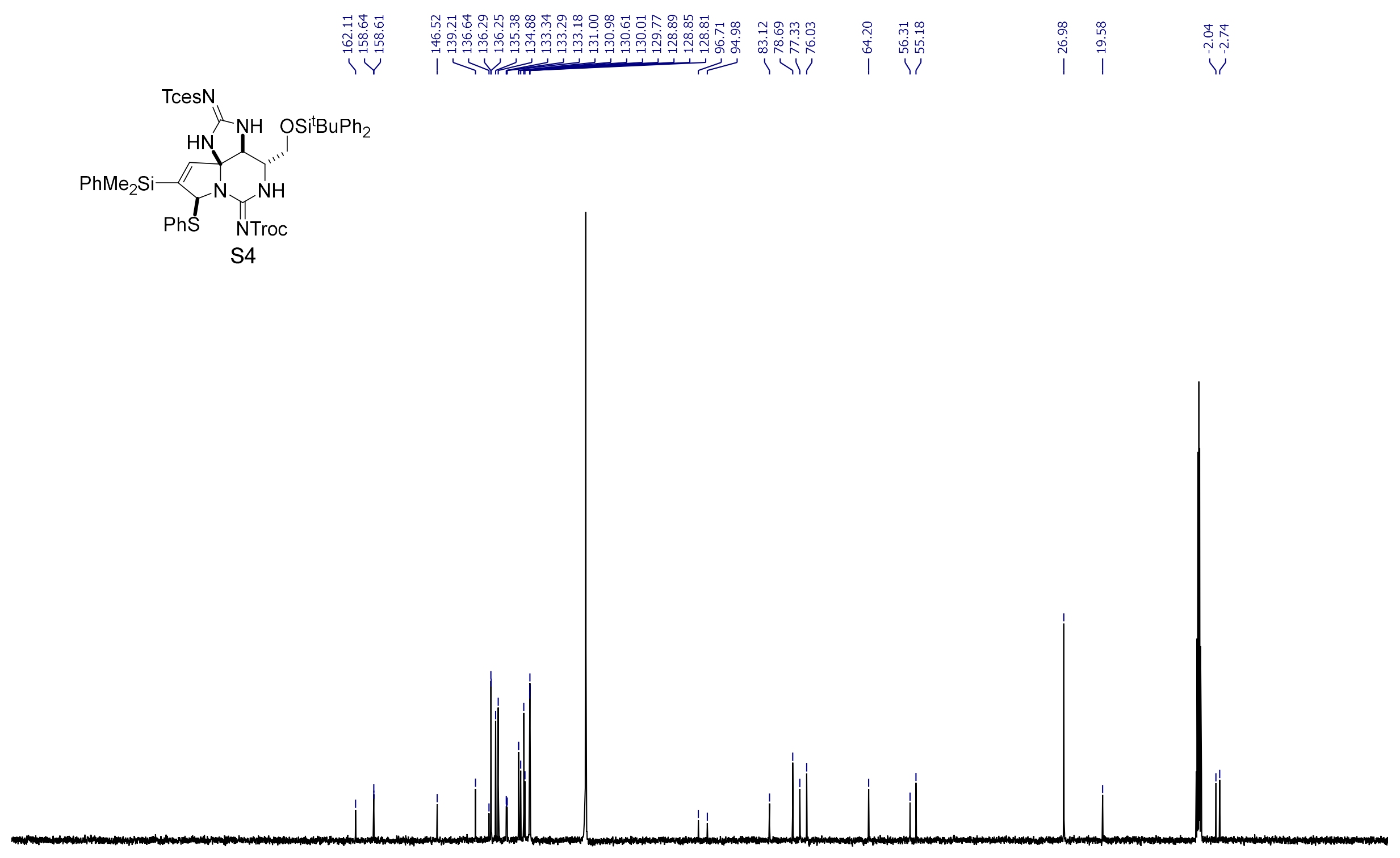


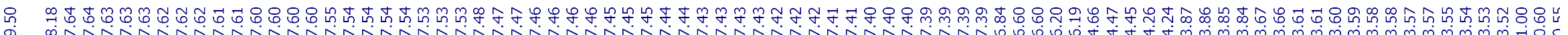
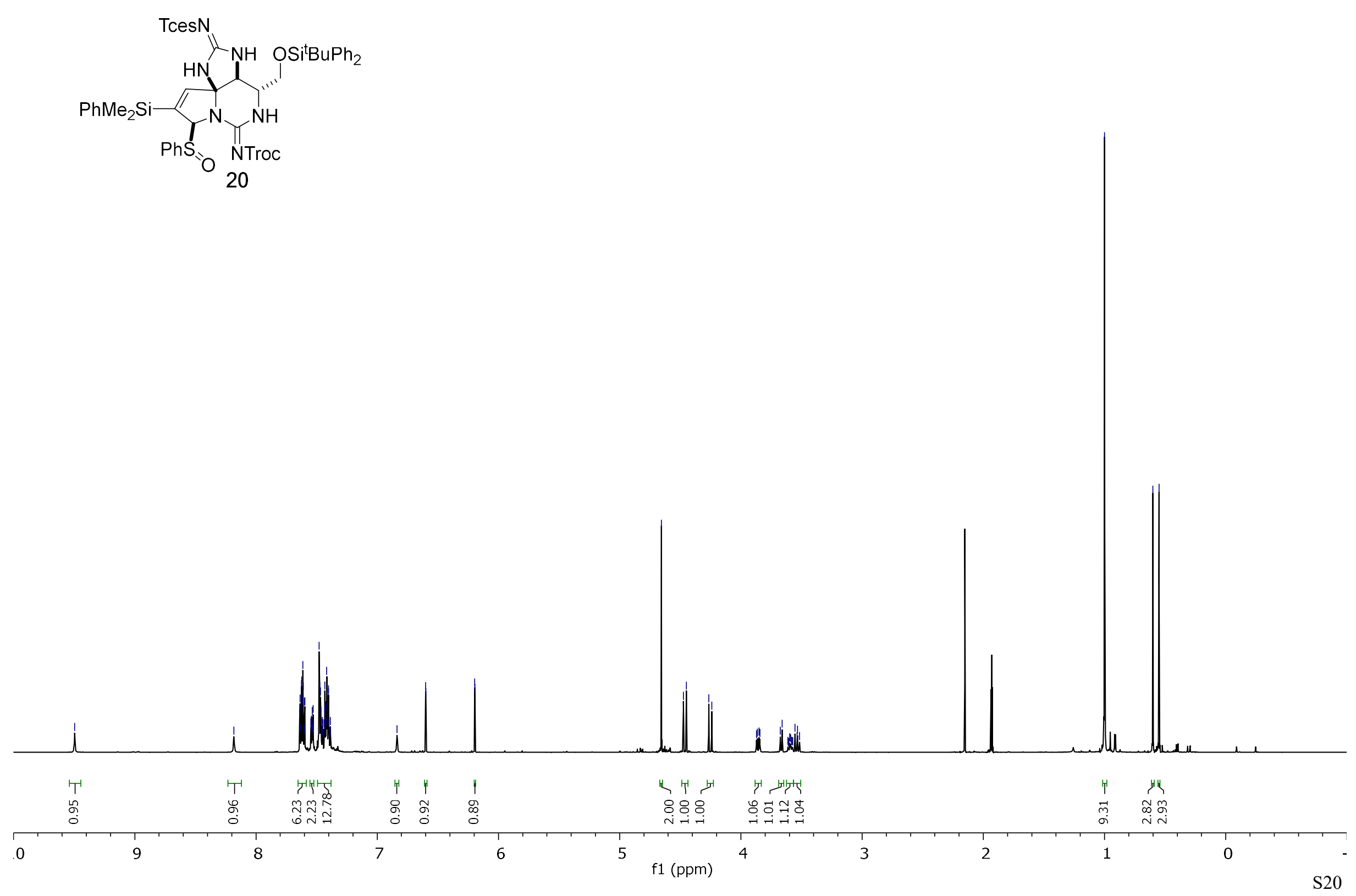
${ }^{13} \mathrm{C}\left\{{ }^{1} \mathrm{H}\right\}$ NMR for $20,125 \mathrm{MHz}, \mathrm{CD}_{3} \mathrm{CN}$

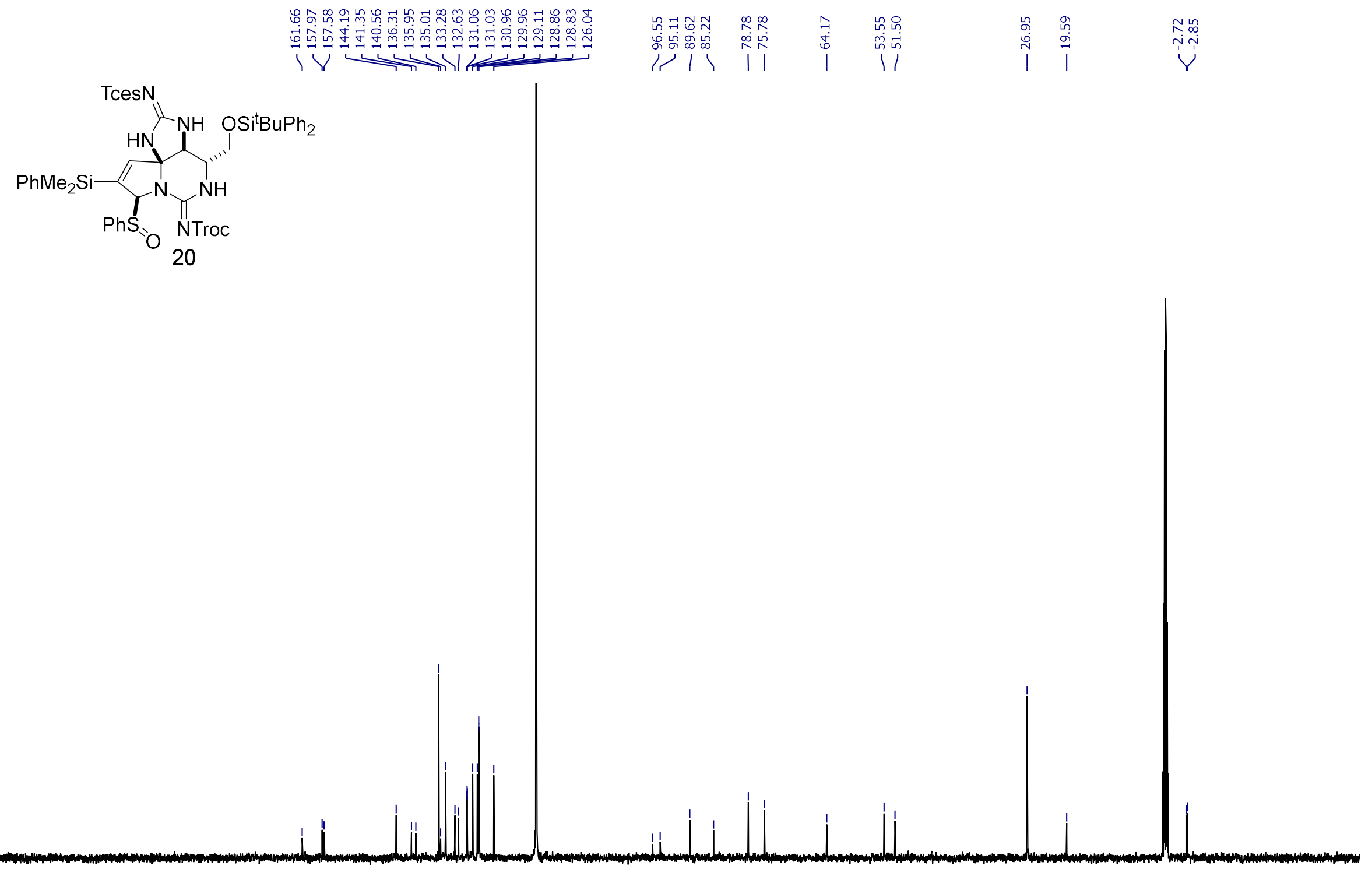




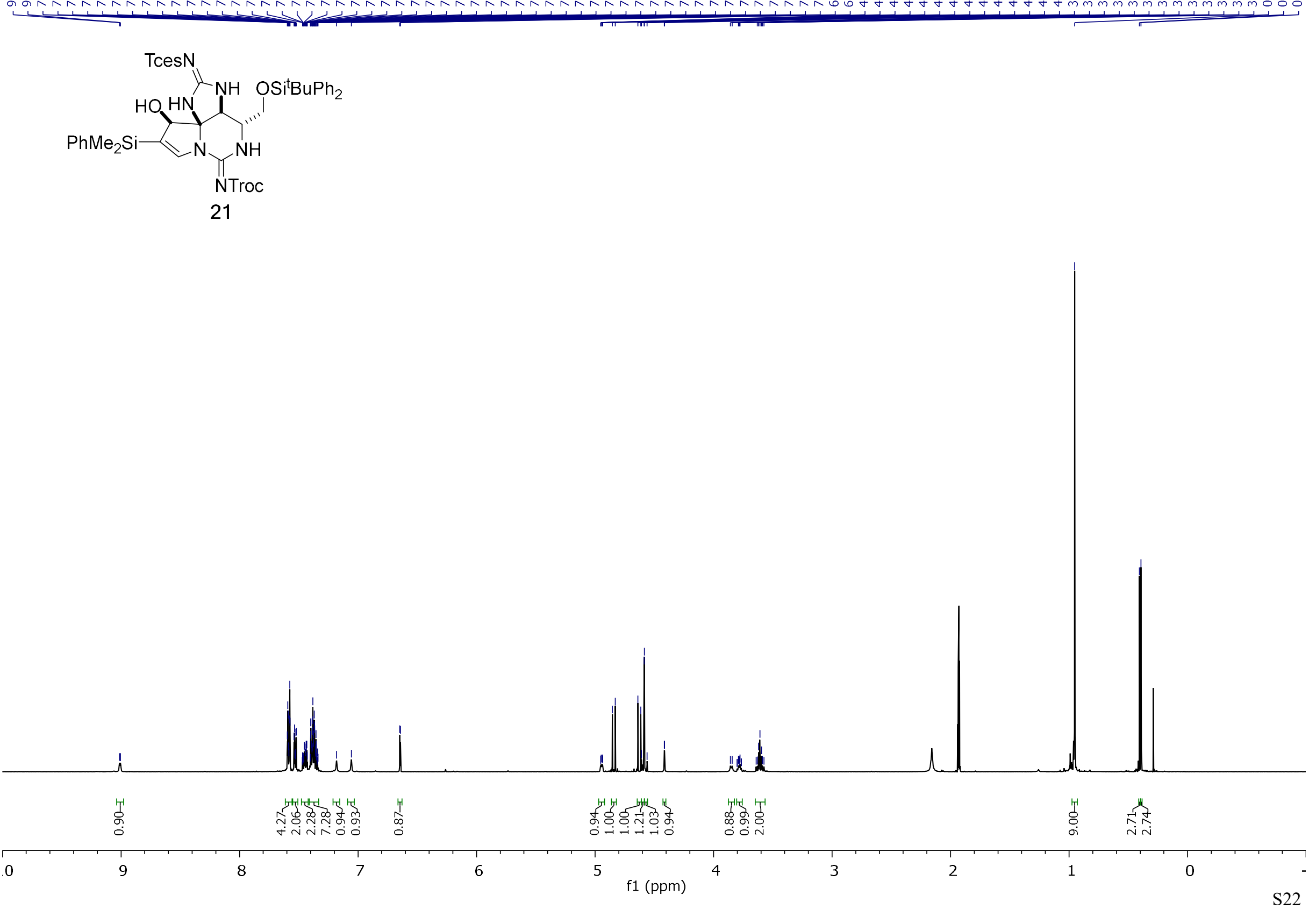


${ }^{13} \mathrm{C}\left\{{ }^{1} \mathrm{H}\right\}$ NMR for $21,125 \mathrm{MHz}, \mathrm{CD}_{3} \mathrm{CN}$

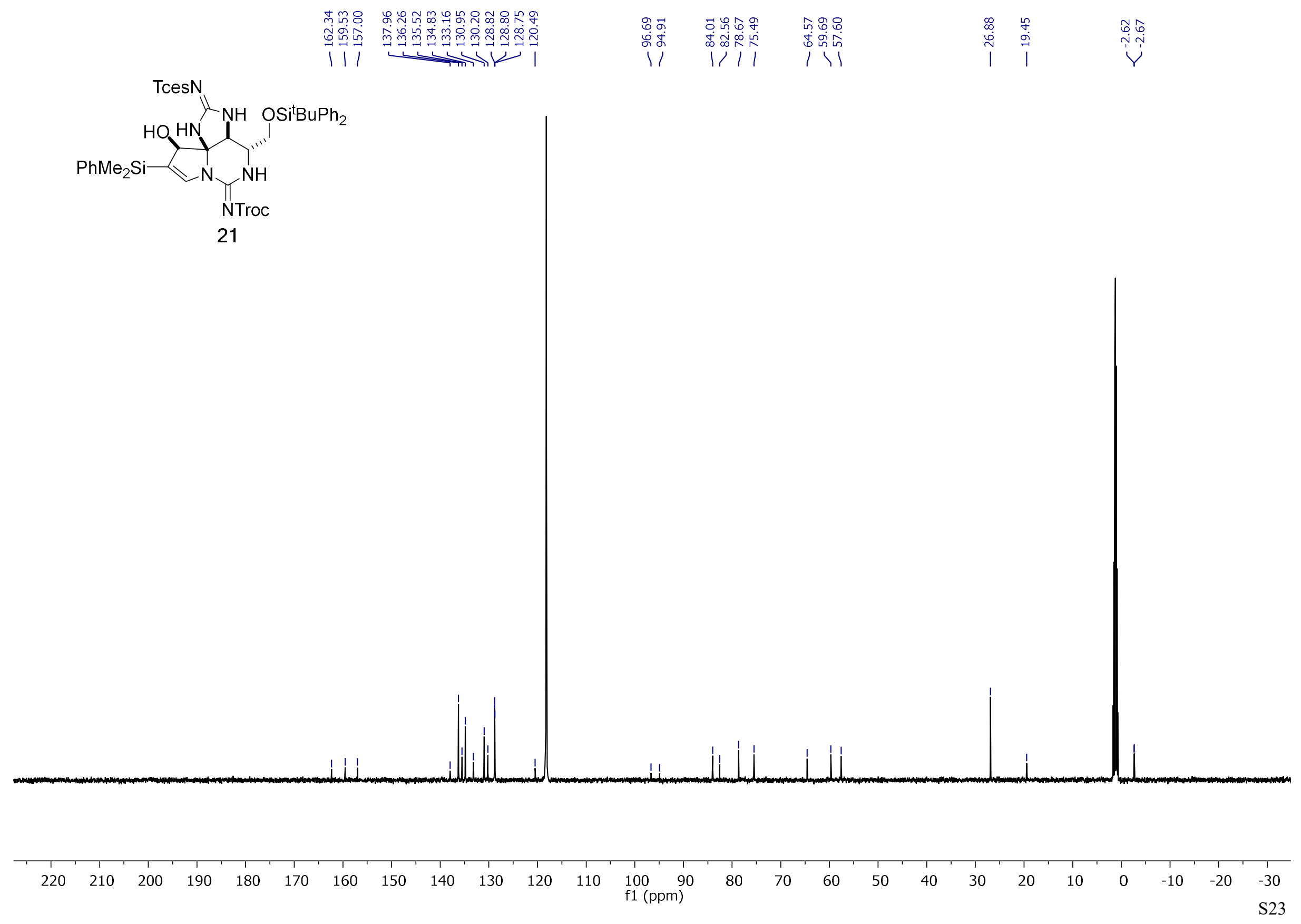




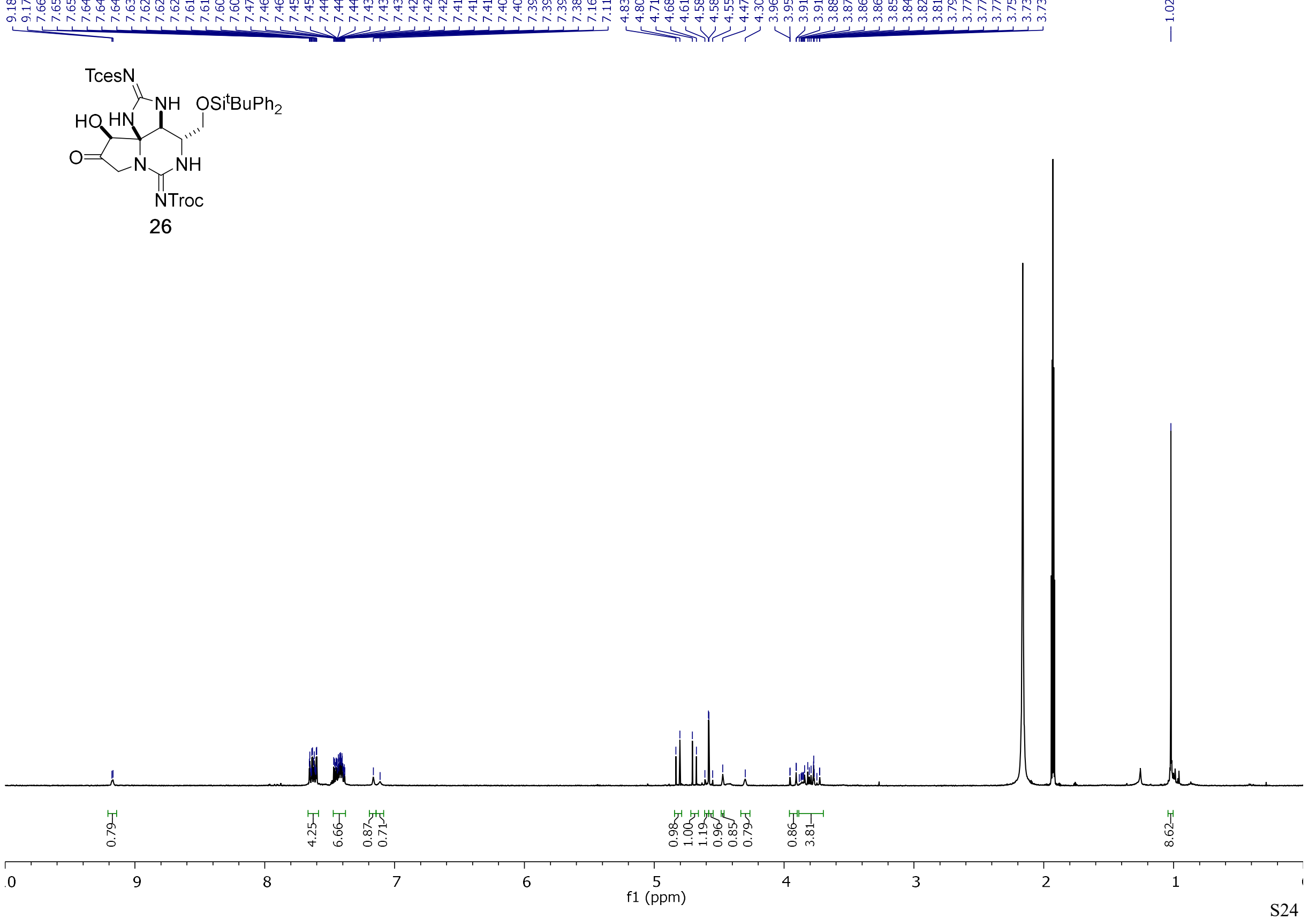


${ }^{1} \mathrm{H}$ NMR for $\mathbf{S 5}, 500 \mathrm{MHz}, \mathrm{CDCl}_{3}$

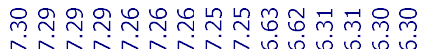

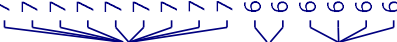

${ }_{\mathrm{BuMe}_{2} \mathrm{Si}}^{\mathrm{S} 5}$

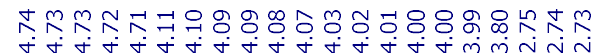

$\sqrt{10060}$

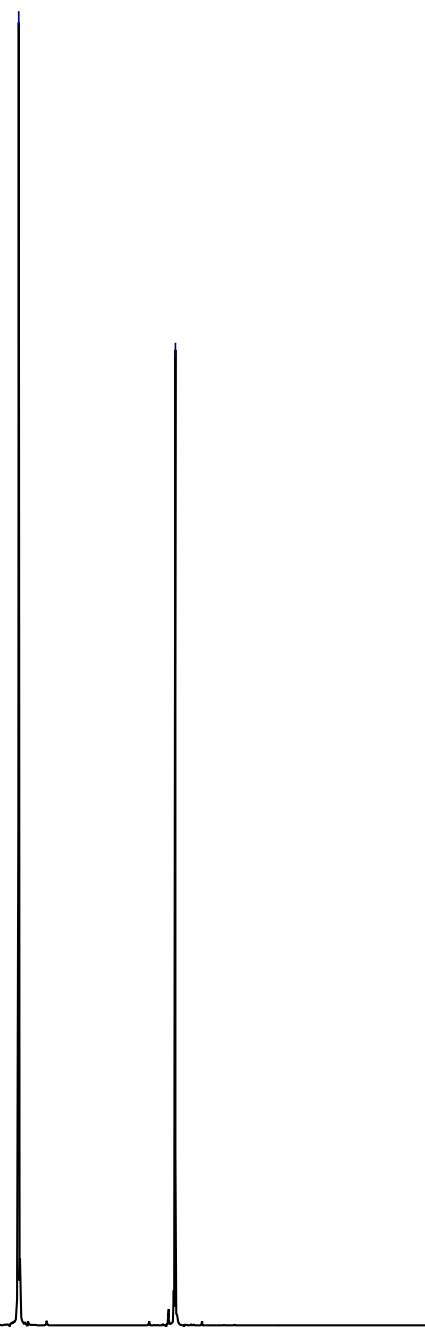

黛

预

6

5

f1 (ppm)

宨

$\begin{aligned} & \\ & 1 \\ & 1\end{aligned}, 1$

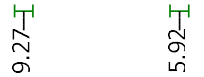

更

0 
${ }^{13} \mathrm{C}\left\{{ }^{1} \mathrm{H}\right\}$ NMR for S5, $125 \mathrm{MHz}, \mathrm{CDCl}_{3}$
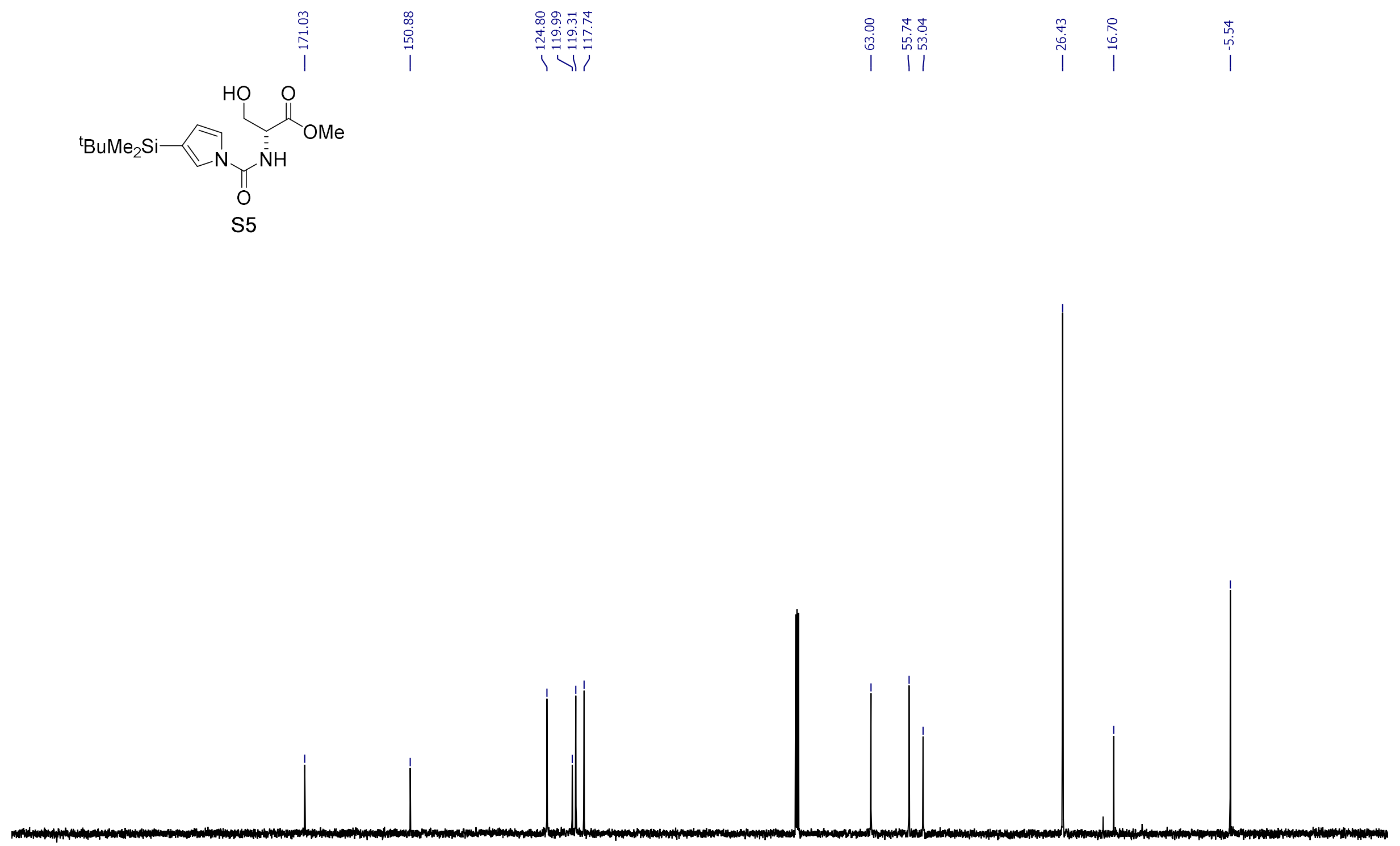

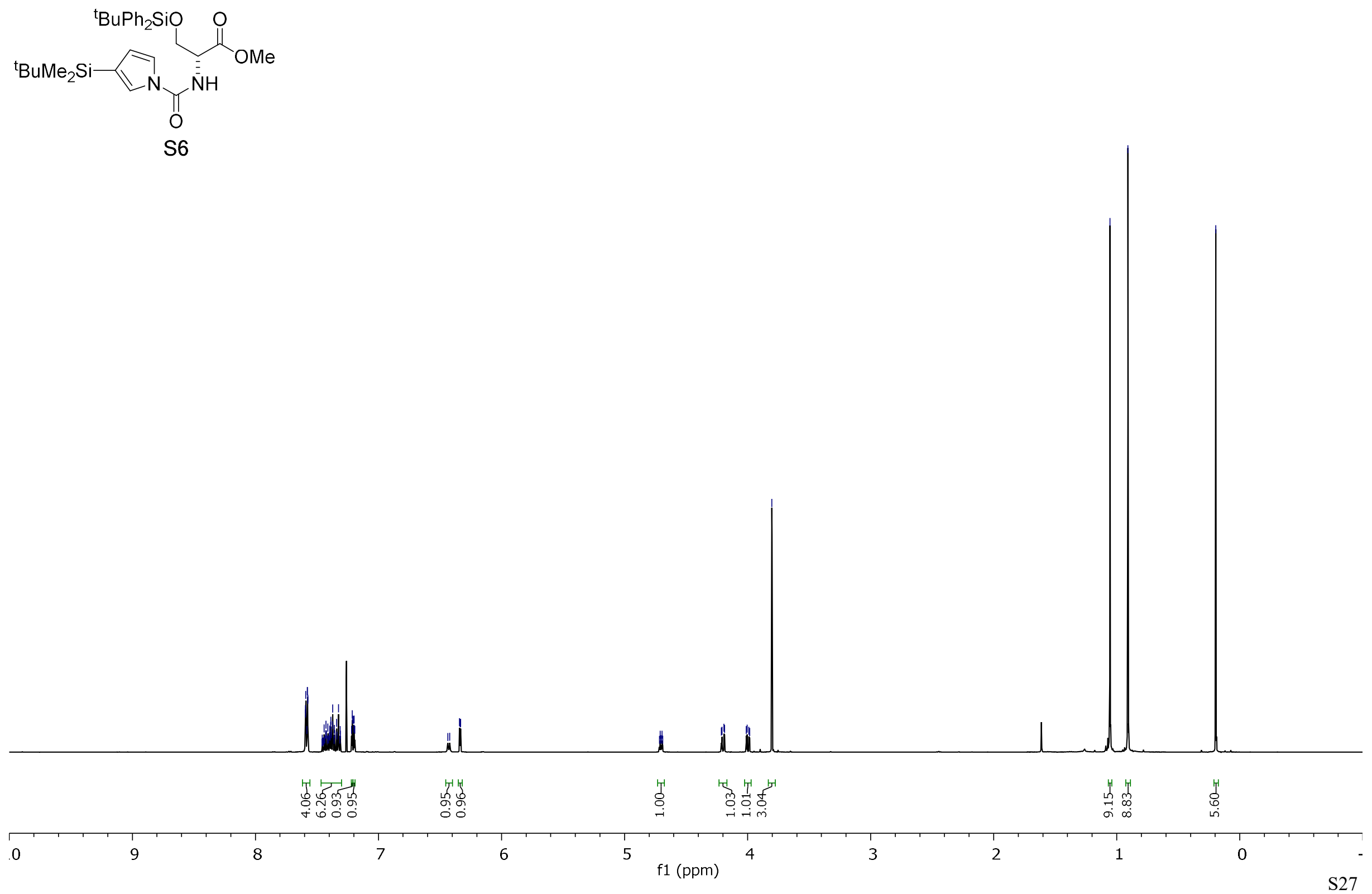
${ }^{13} \mathrm{C}\left\{{ }^{1} \mathrm{H}\right\} \mathrm{NMR}$ for $\mathbf{S 6}, 100 \mathrm{MHz}, \mathrm{CDCl}_{3}$

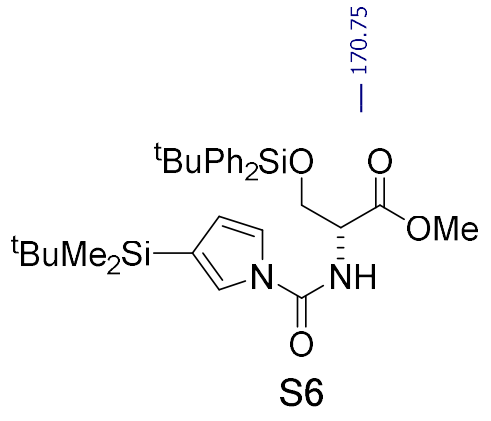

空

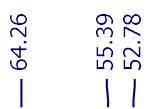

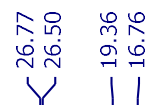

Yن

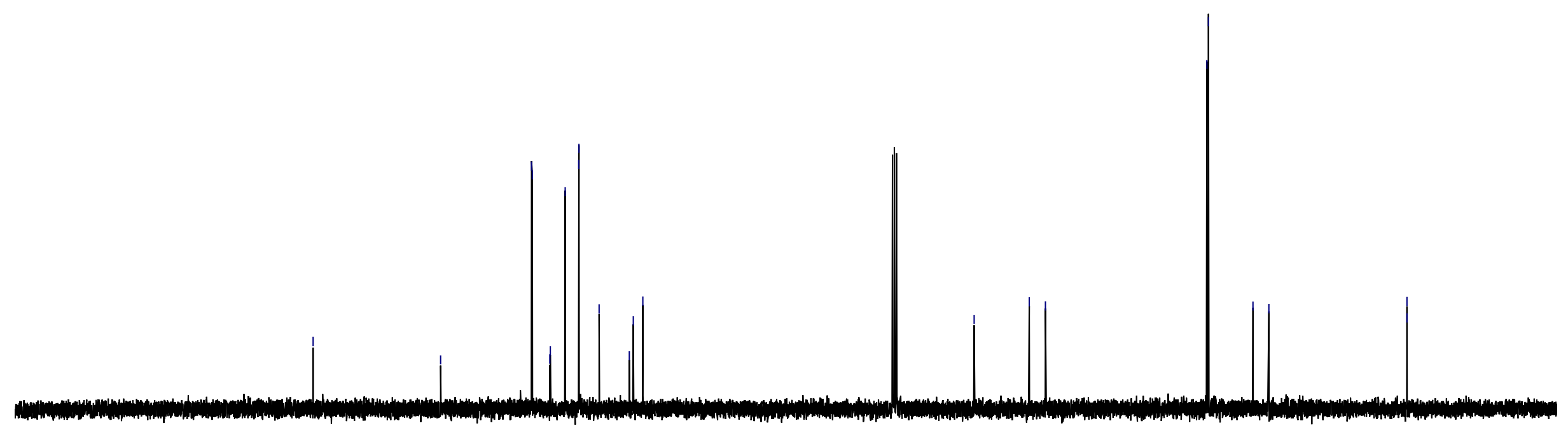




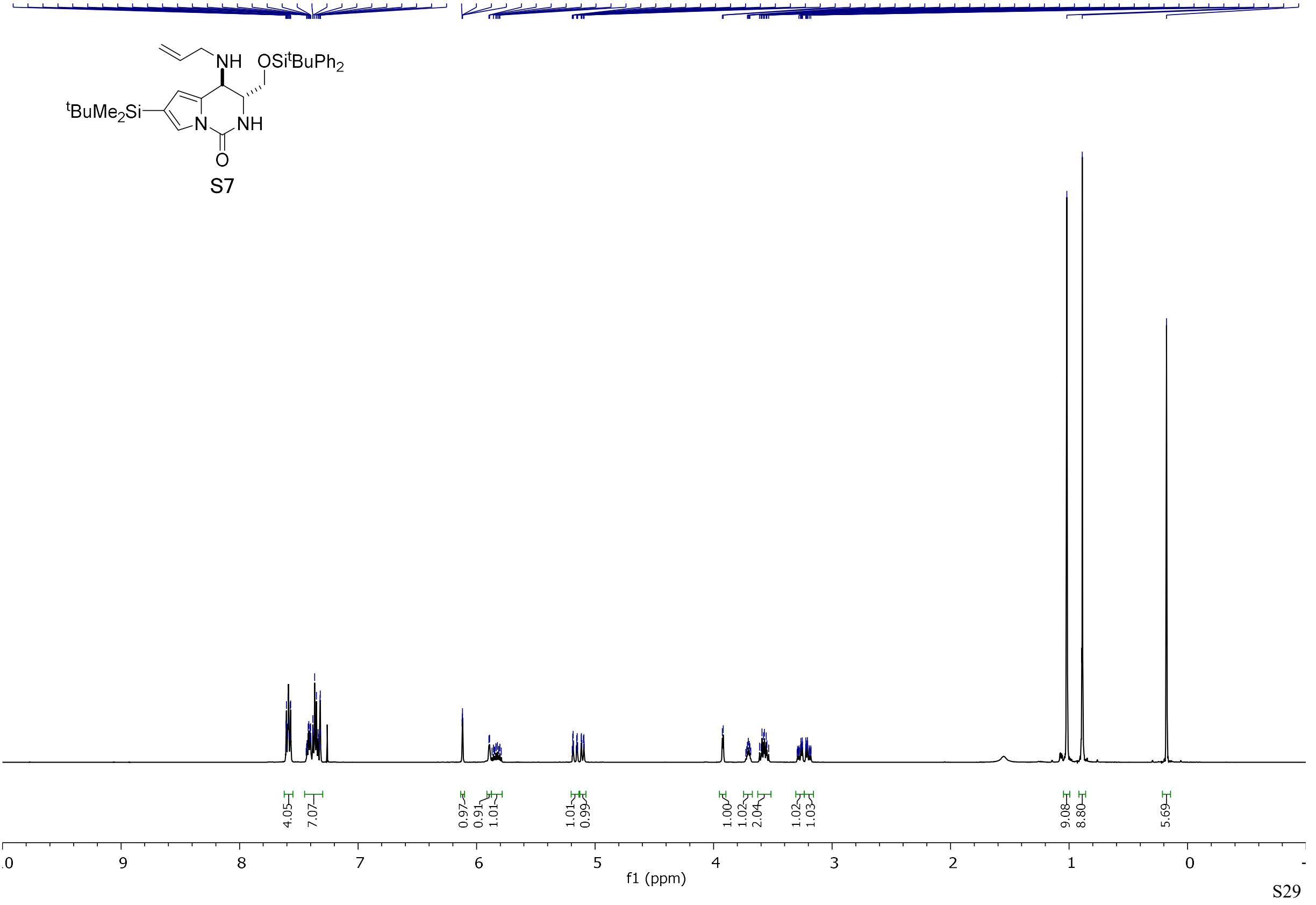


${ }^{13} \mathrm{C}\left\{{ }^{1} \mathrm{H}\right\} \mathrm{NMR}$ for $\mathbf{S} 7,125 \mathrm{MHz}, \mathrm{CDCl}_{3}$
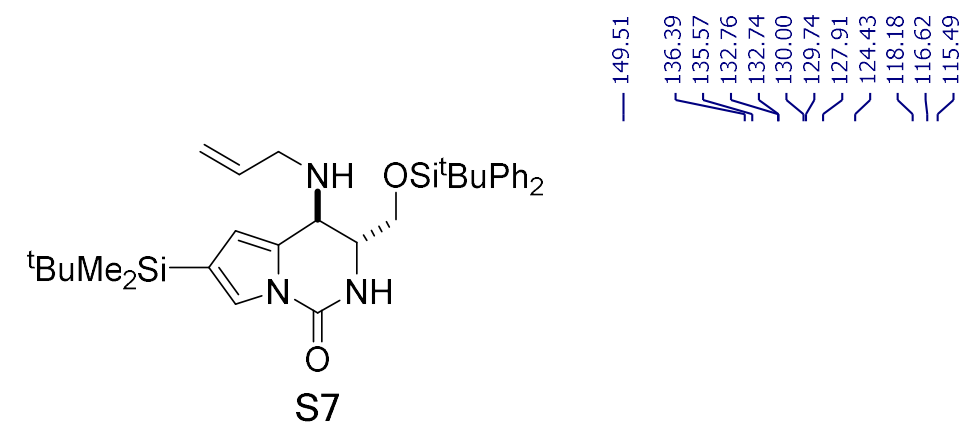

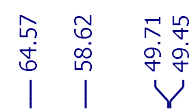

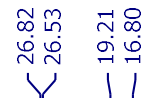

ن่

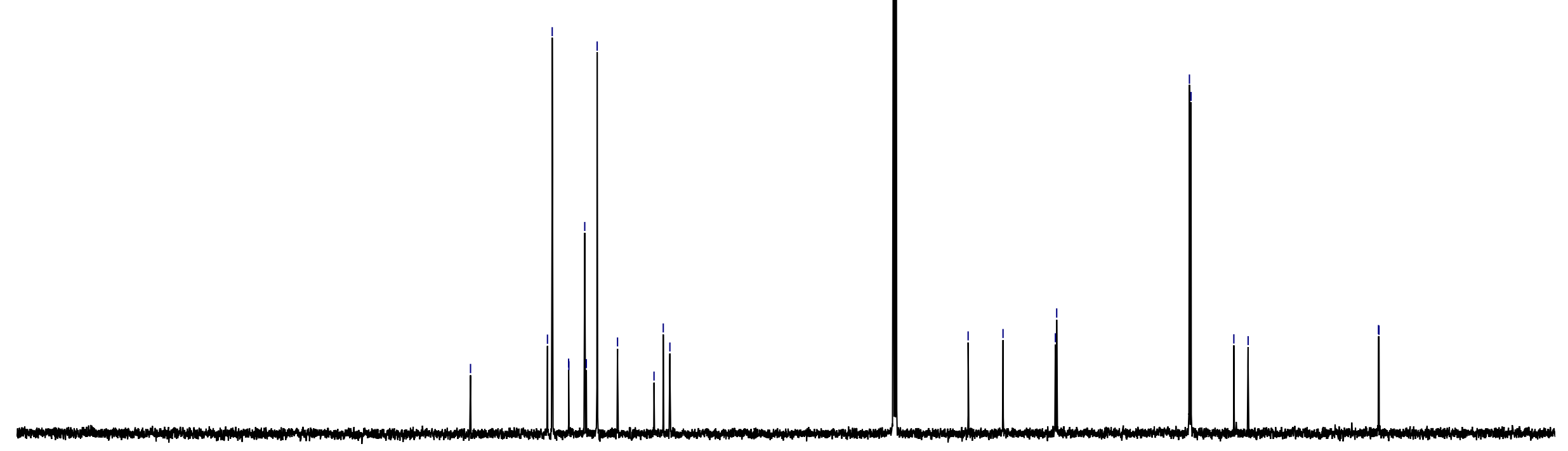


${ }^{1} \mathrm{H}$ NMR for $\mathbf{S 8}, 400 \mathrm{MHz}, \mathrm{CDCl}_{3}$

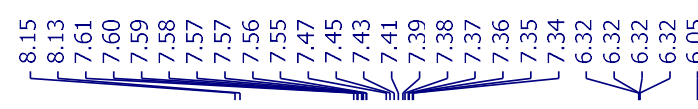

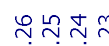

ถู่

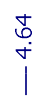

œळ

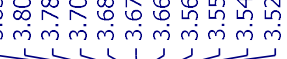

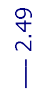

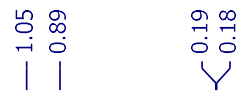

NTces

S8

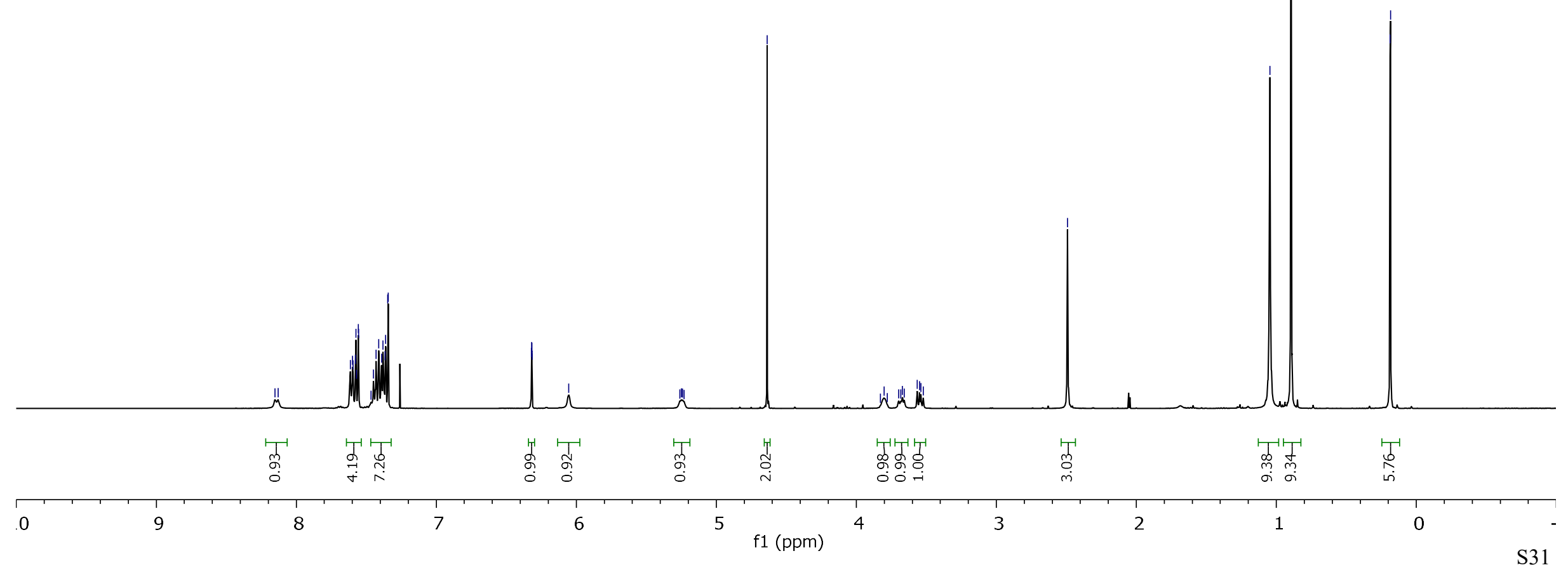


${ }^{13} \mathrm{C}\left\{{ }^{1} \mathrm{H}\right\}$ NMR for $\mathbf{S} 8,100 \mathrm{MHz}, \mathrm{CDCl}_{3}$
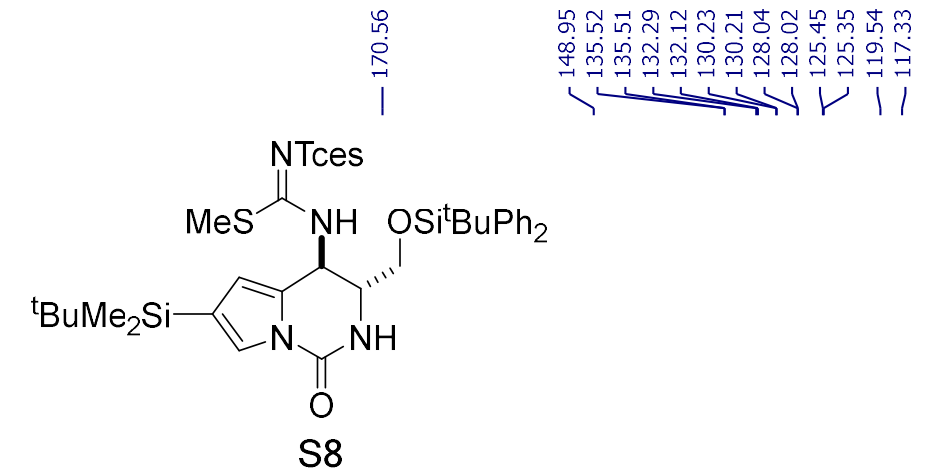

$\begin{array}{ll}i & 0 \\ \dot{m} & \infty \\ 0 & \infty\end{array}$

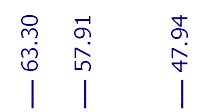

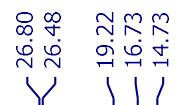

Y

S8

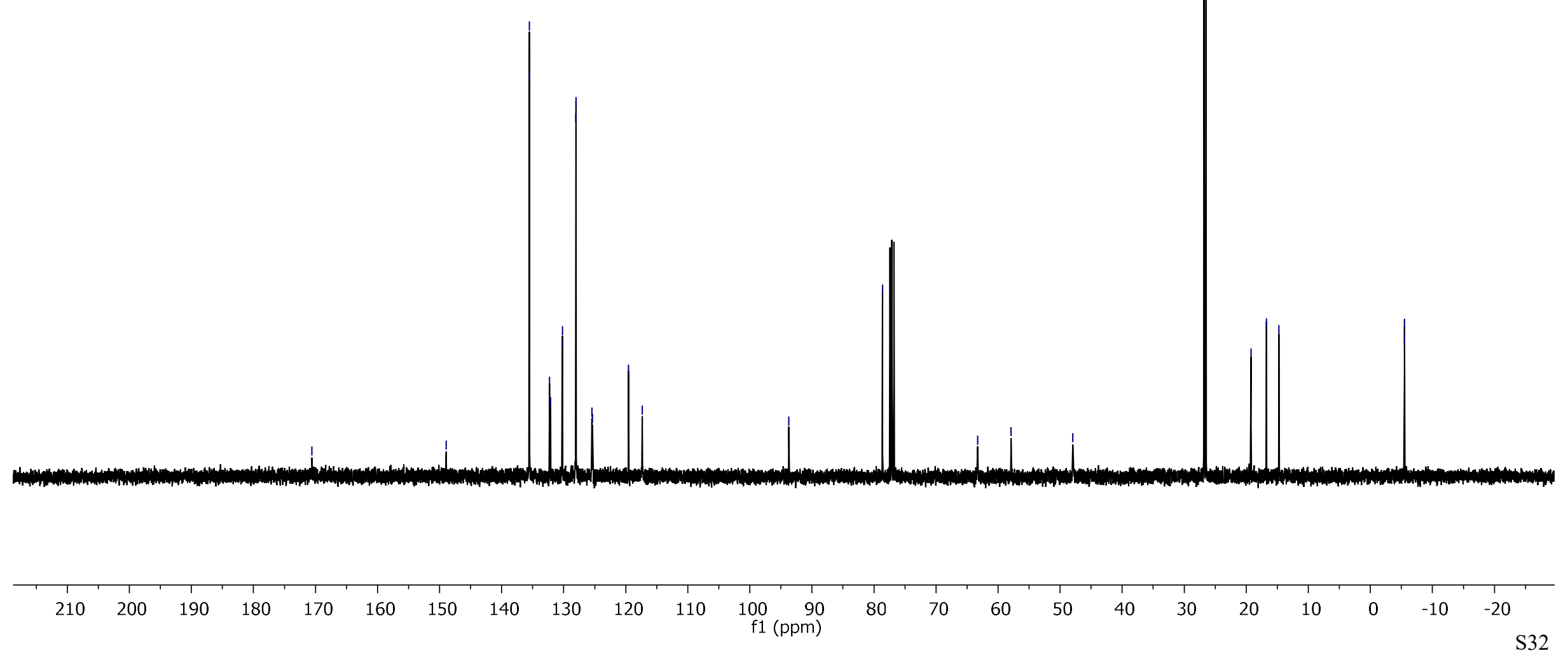


${ }^{1} \mathrm{H}$ NMR for $\mathbf{S 9}, 400 \mathrm{MHz}, \mathrm{CDCl}_{3}$

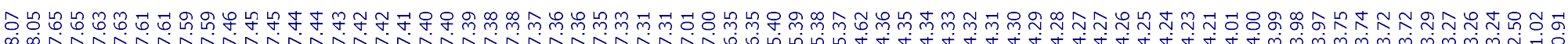

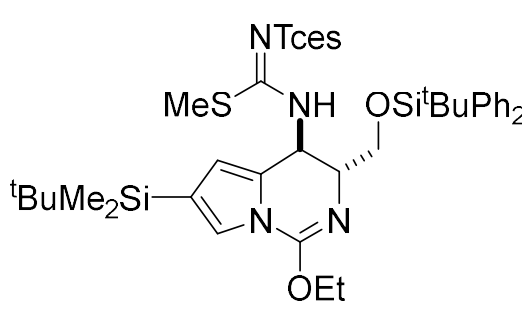

S9

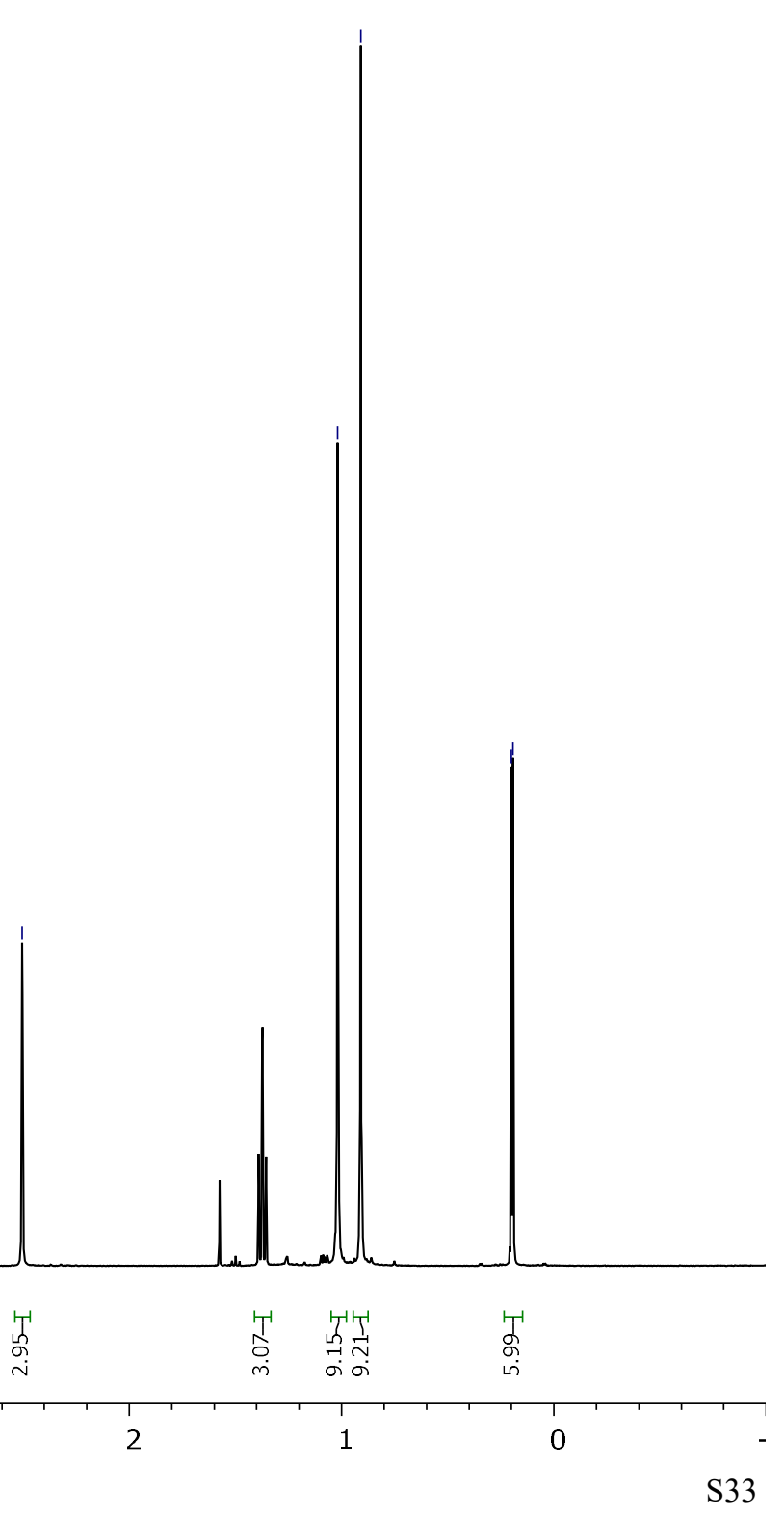


${ }^{13} \mathrm{C}\left\{{ }^{1} \mathrm{H}\right\}$ NMR for S9, $100 \mathrm{MHz}, \mathrm{CDCl}_{3}$

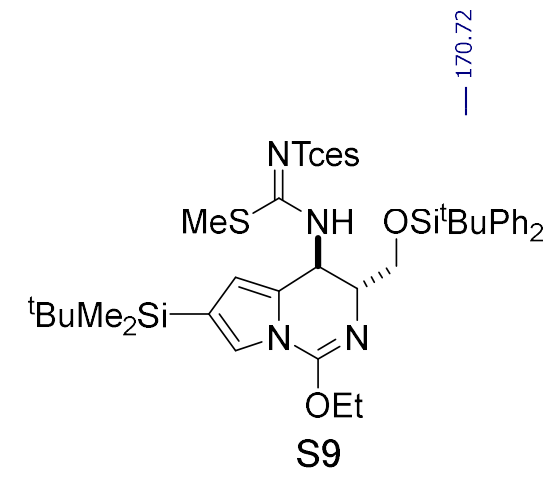

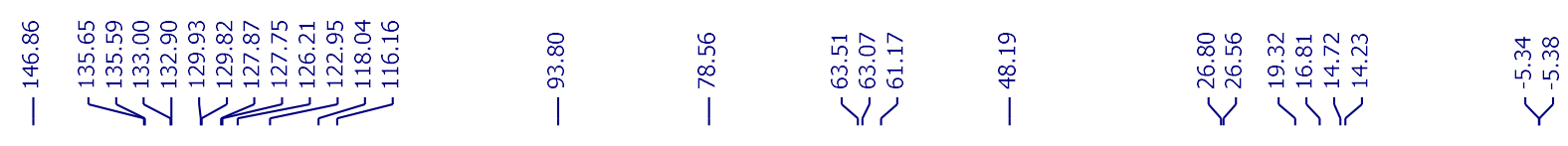

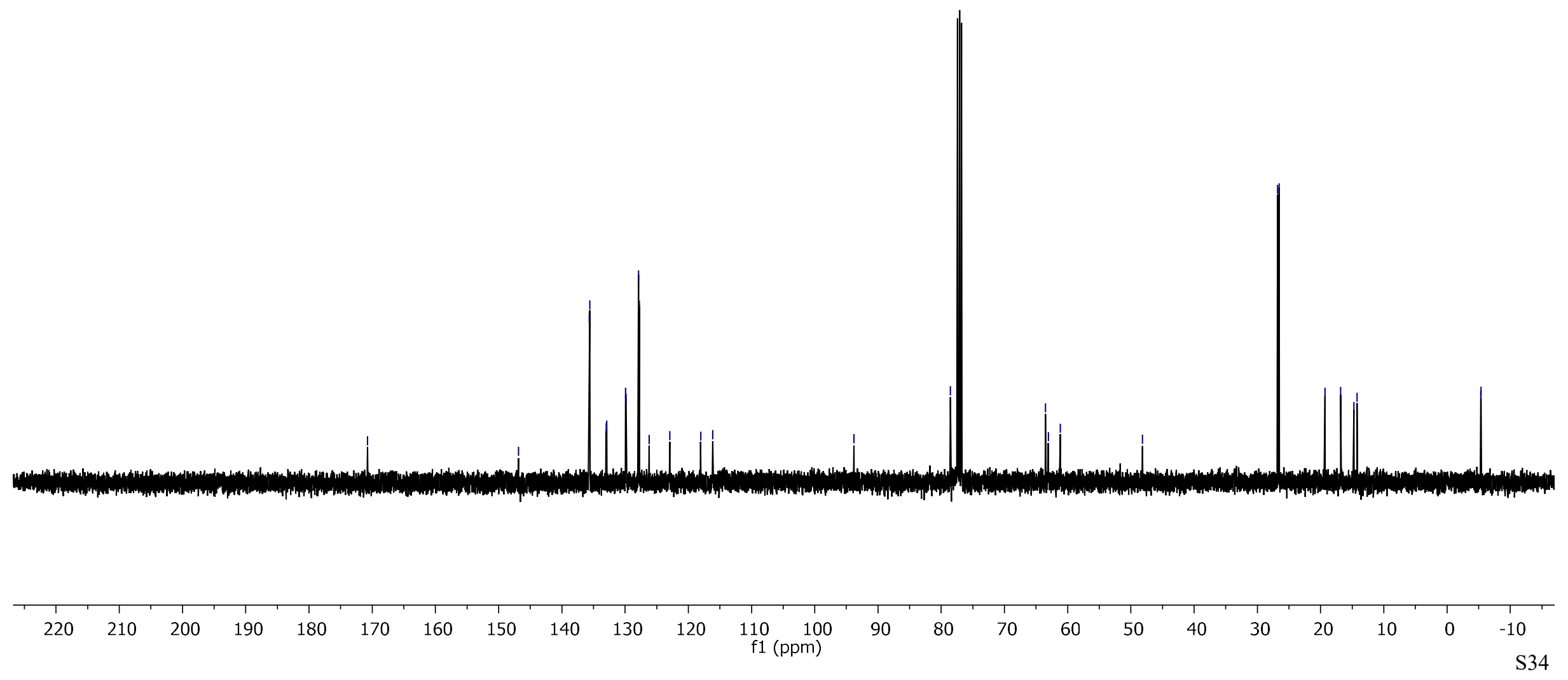


${ }^{1} \mathrm{H}$ NMR for $\mathbf{S} 10,400 \mathrm{MHz}, \mathrm{CD}_{3} \mathrm{OD}$

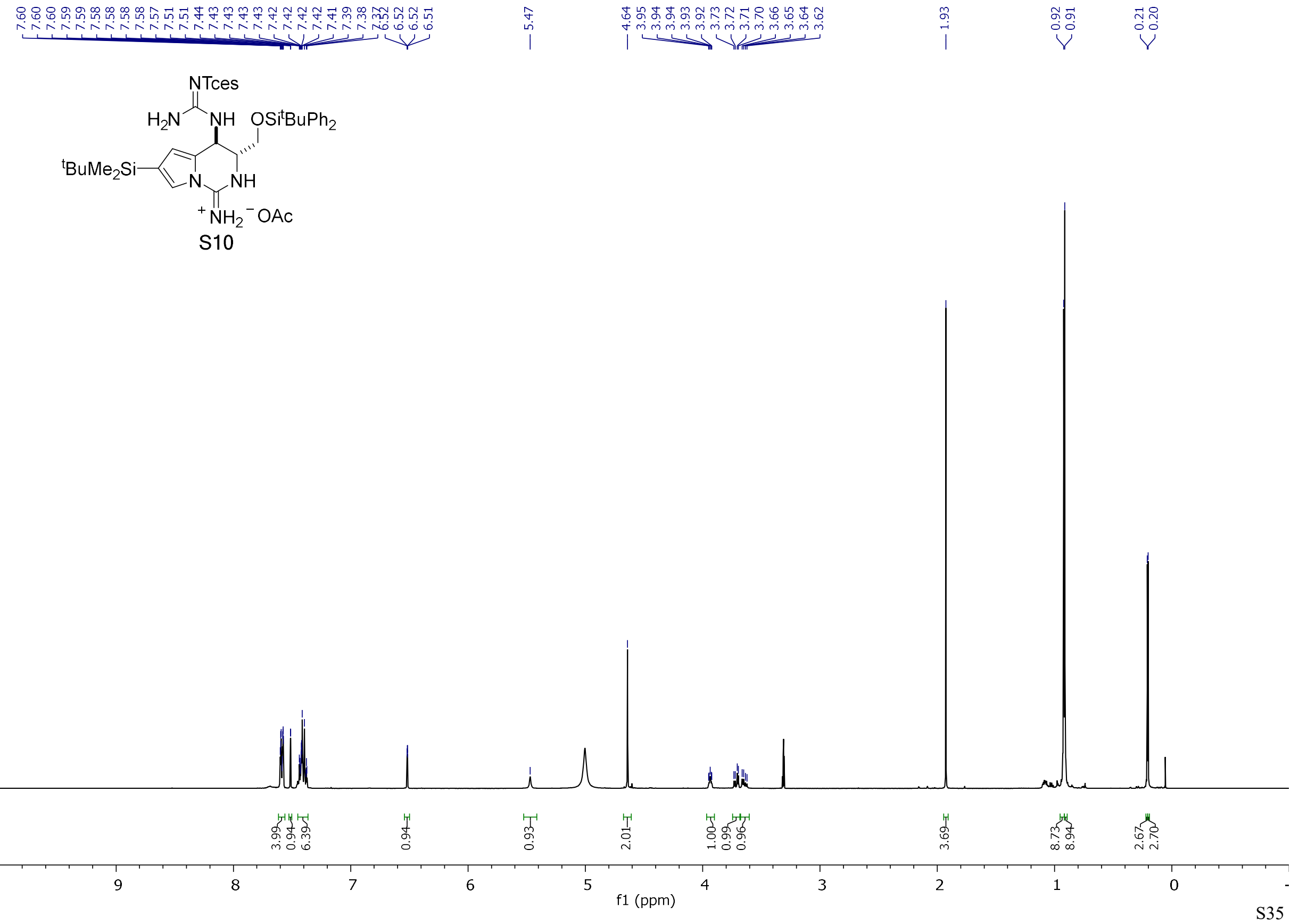


${ }^{13} \mathrm{C}\left\{{ }^{1} \mathrm{H}\right\}$ NMR for $\mathbf{S 1 0}, 100 \mathrm{MHz}, \mathrm{CD}_{3} \mathrm{OD}$

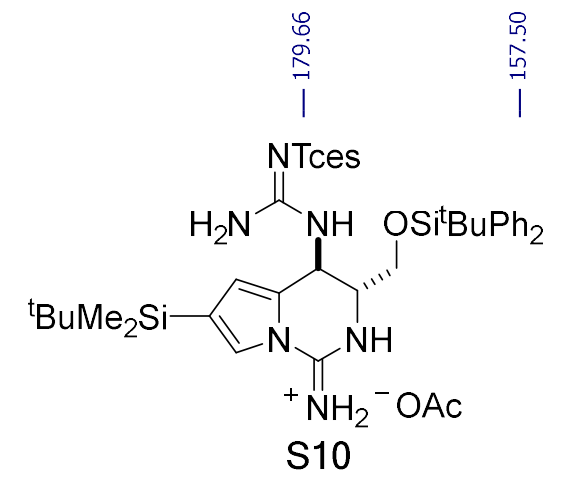

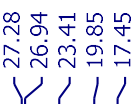

认̀

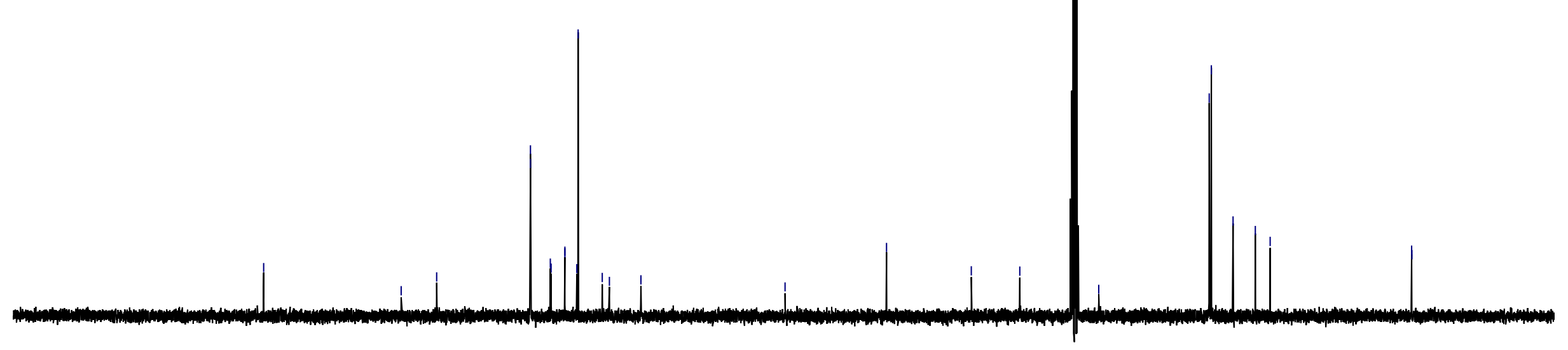

$20 \quad 210$ 


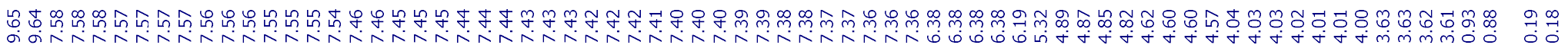
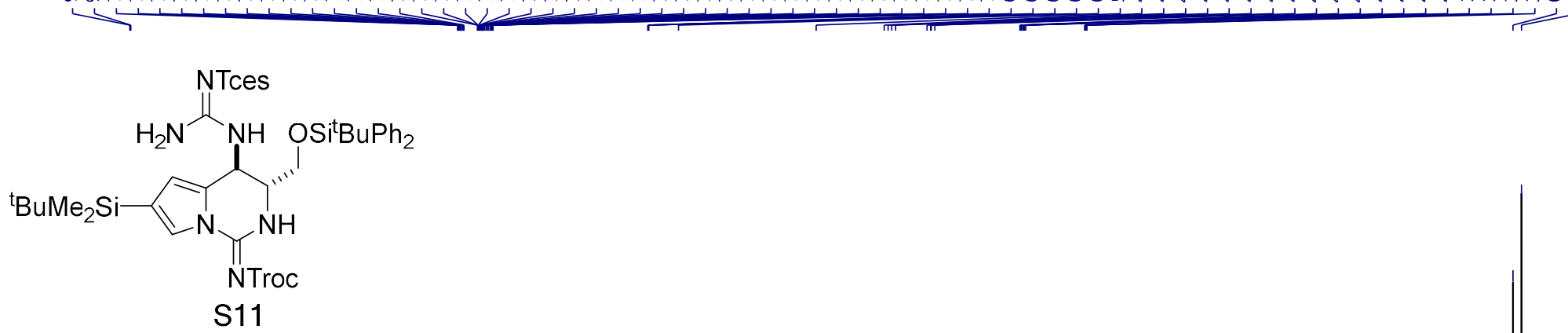
${ }^{13} \mathrm{C}\left\{{ }^{1} \mathrm{H}\right\}$ NMR for S11, $125 \mathrm{MHz}, \mathrm{CD}_{3} \mathrm{CN}$

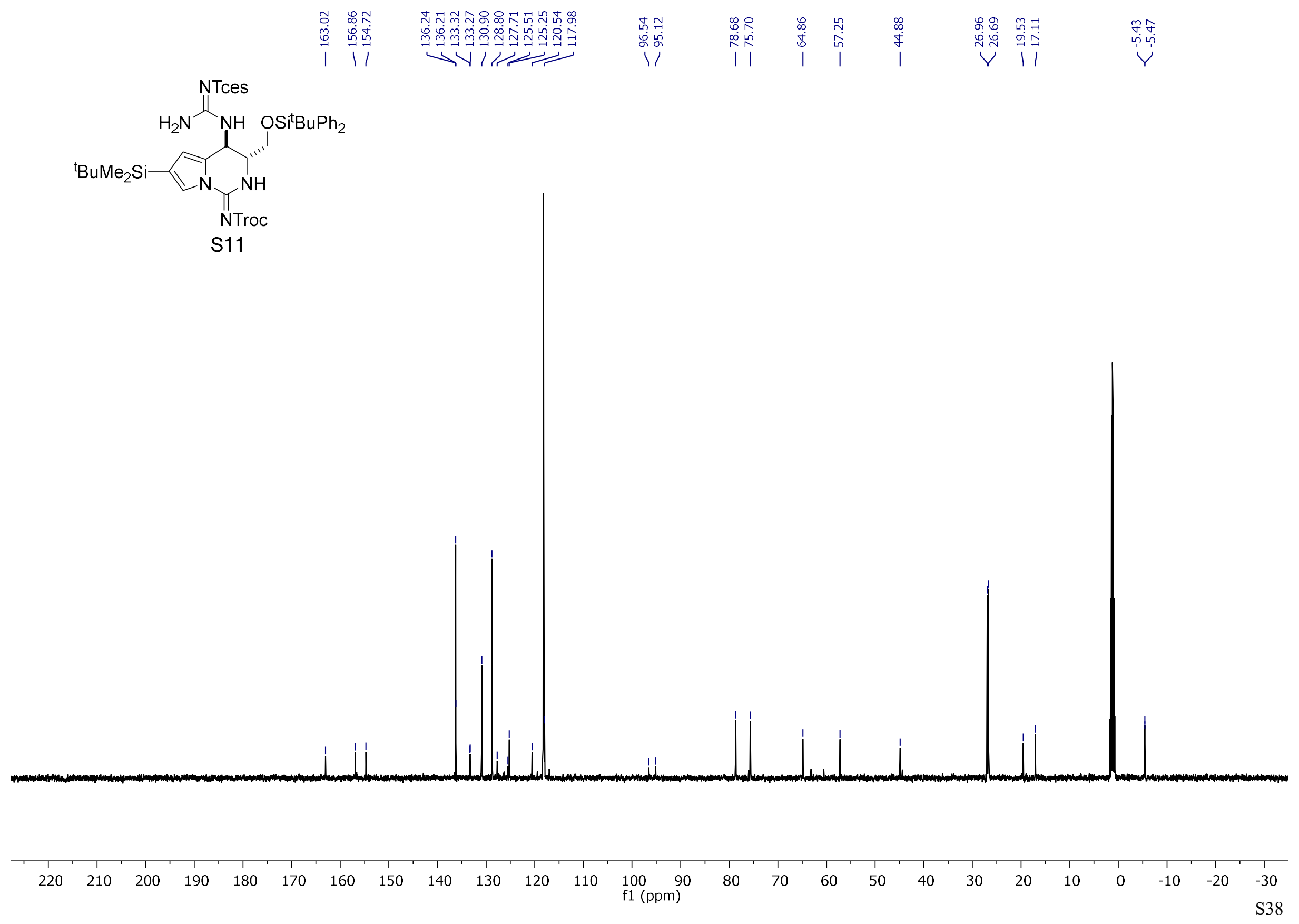




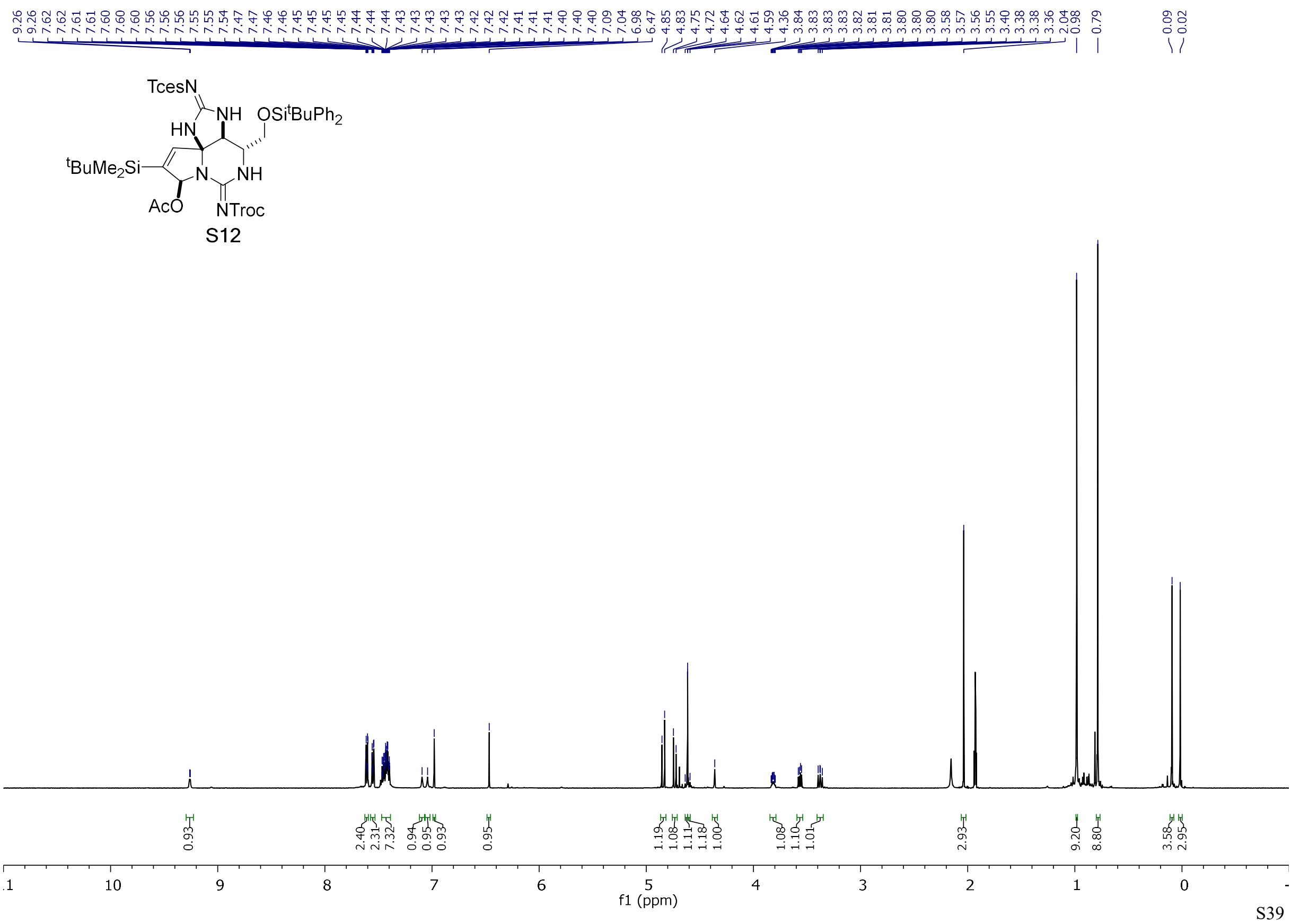


${ }^{13} \mathrm{C}\left\{{ }^{1} \mathrm{H}\right\}$ NMR for $\mathbf{S 1 2}, 125 \mathrm{MHz}, \mathrm{CD}_{3} \mathrm{CN}$

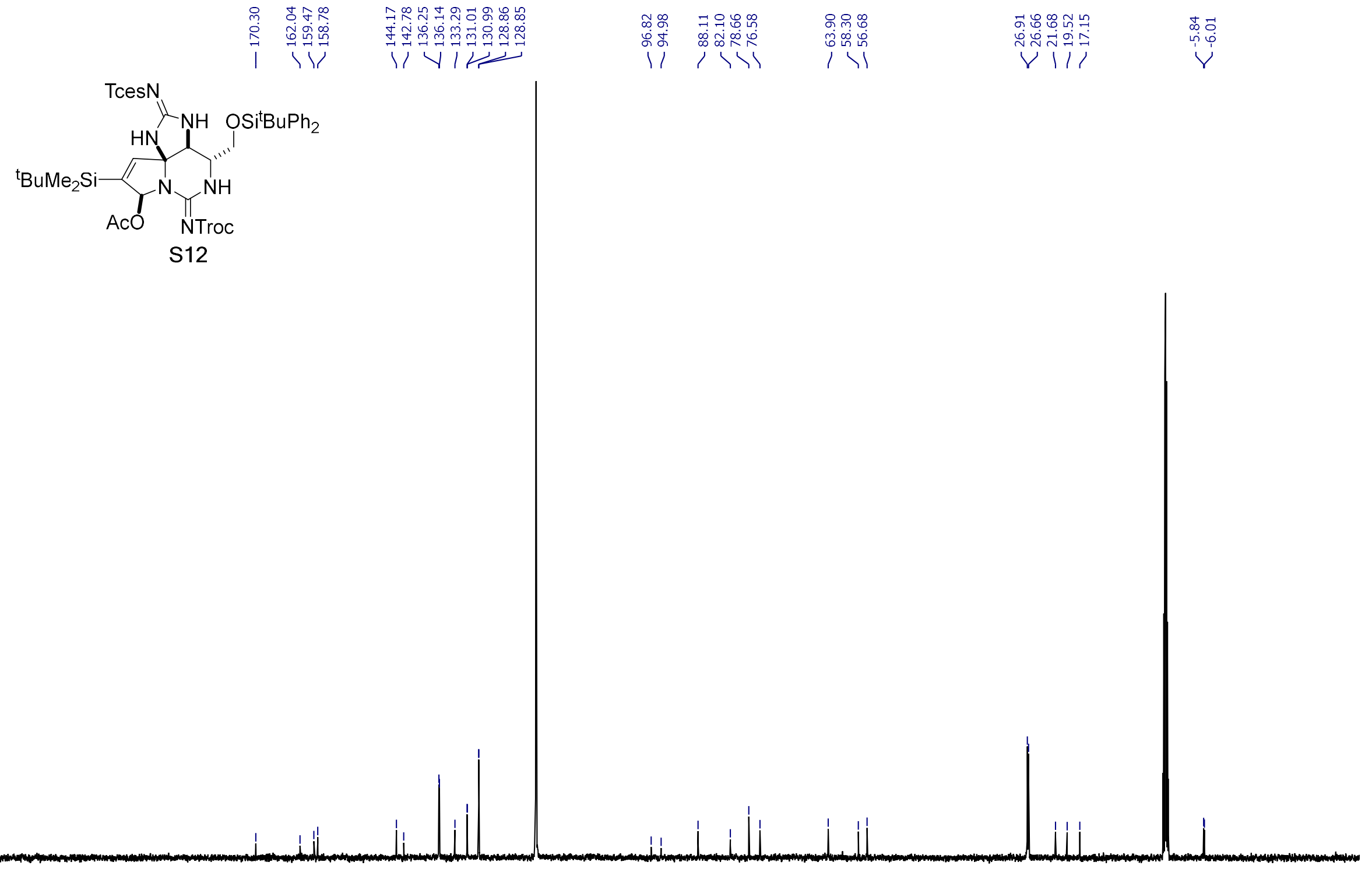




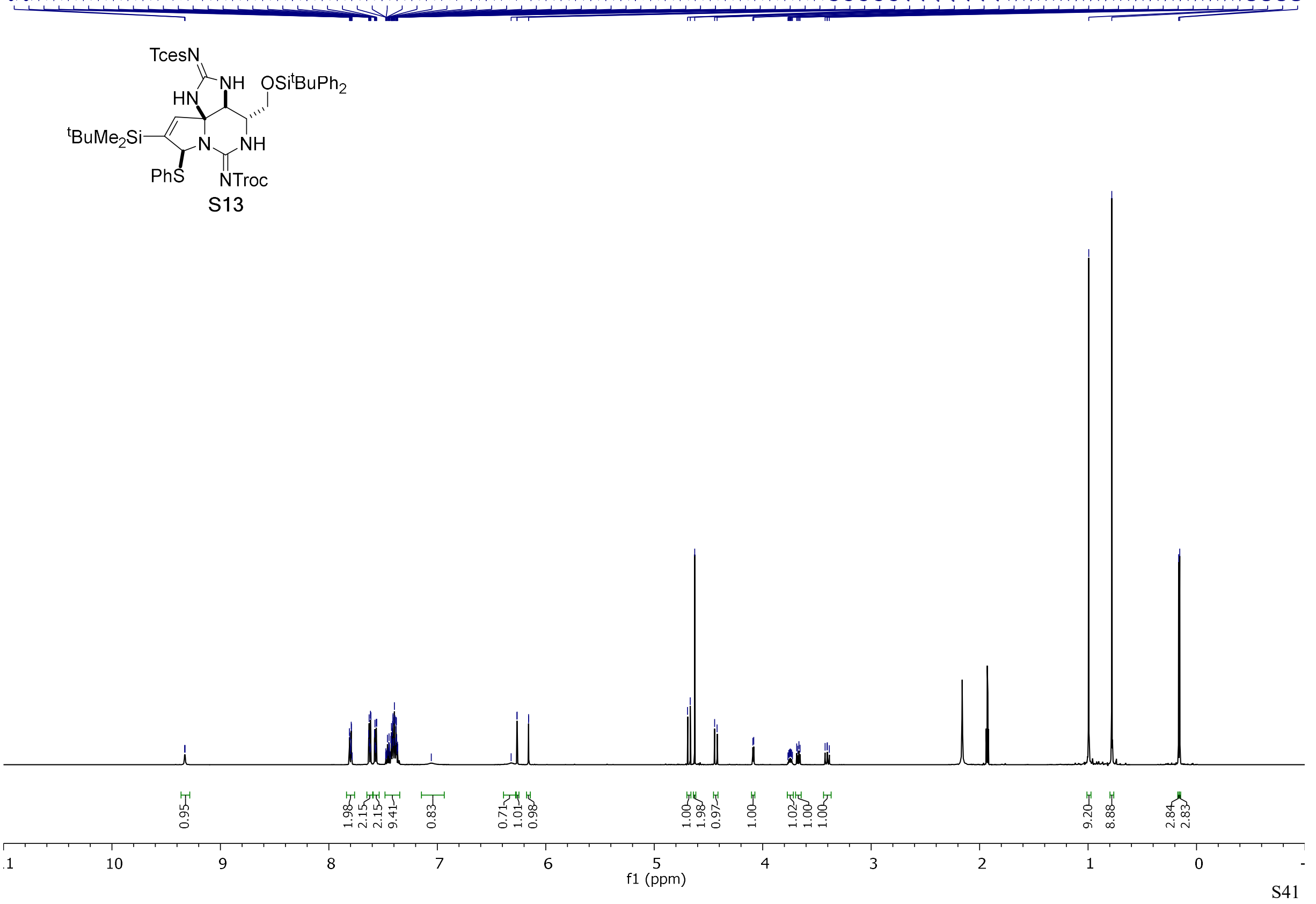


${ }^{13} \mathrm{C}\left\{{ }^{1} \mathrm{H}\right\}$ NMR for $\mathbf{S} 13,125 \mathrm{MHz}, \mathrm{CD}_{3} \mathrm{CN}$

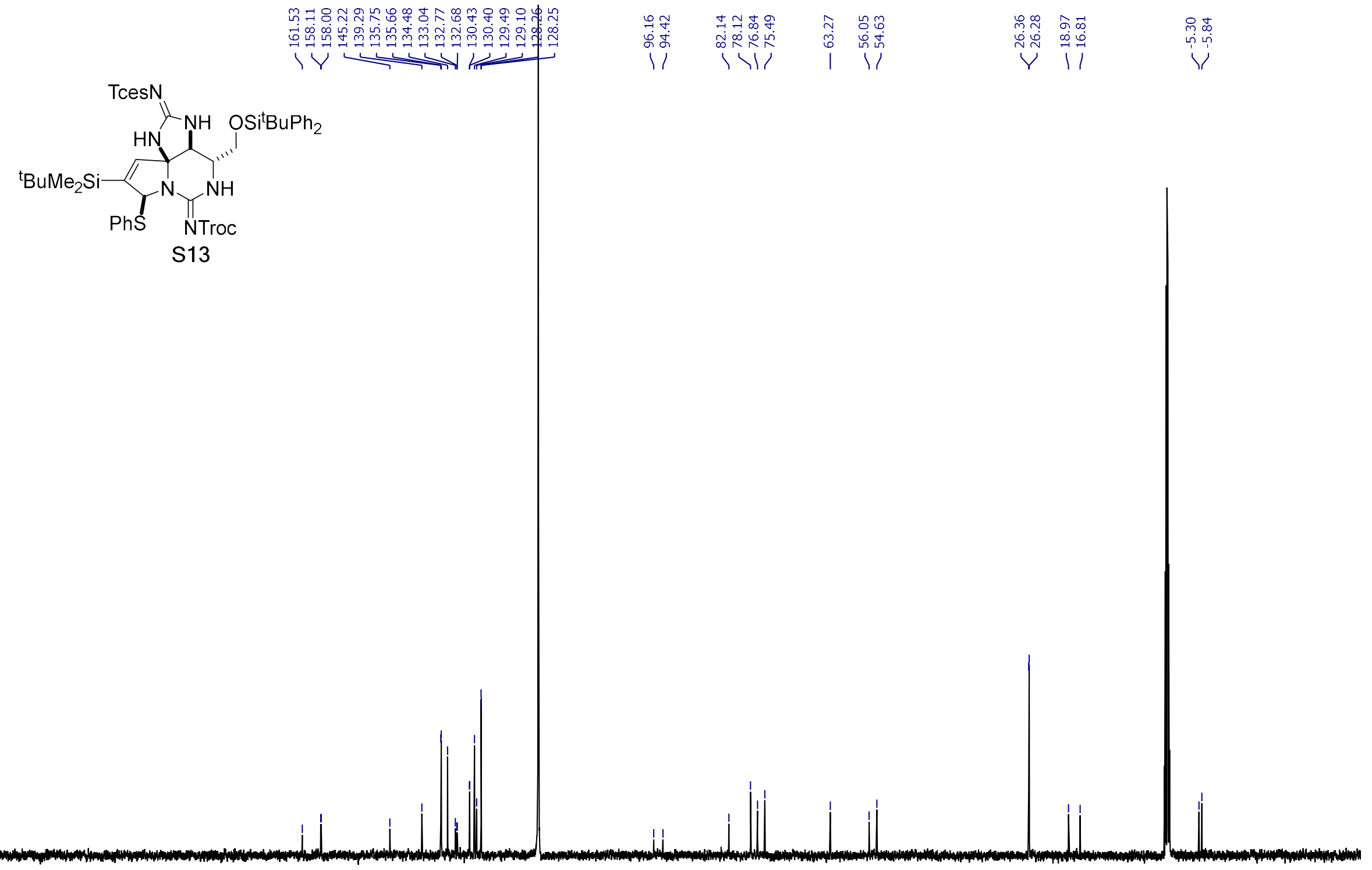



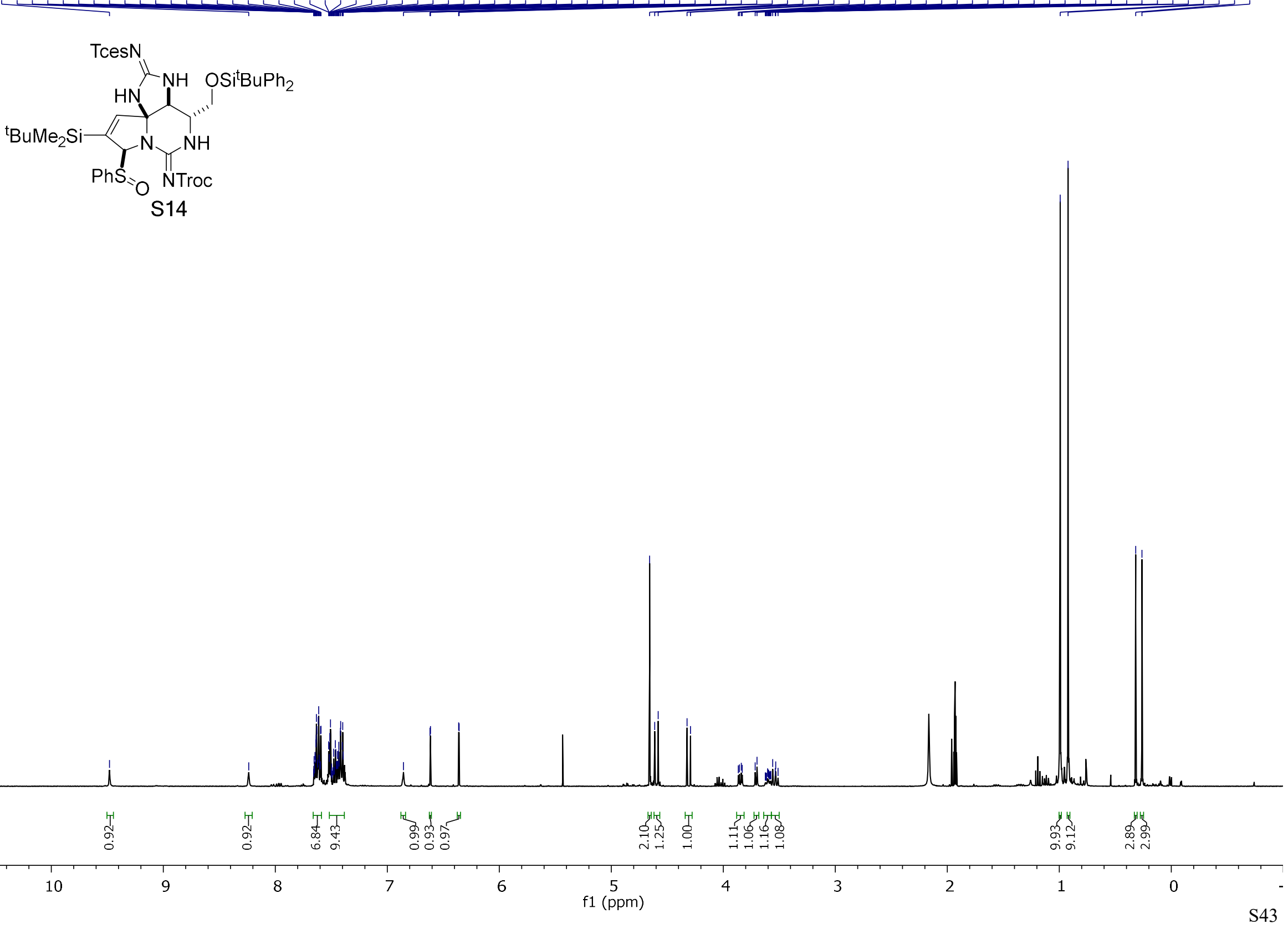


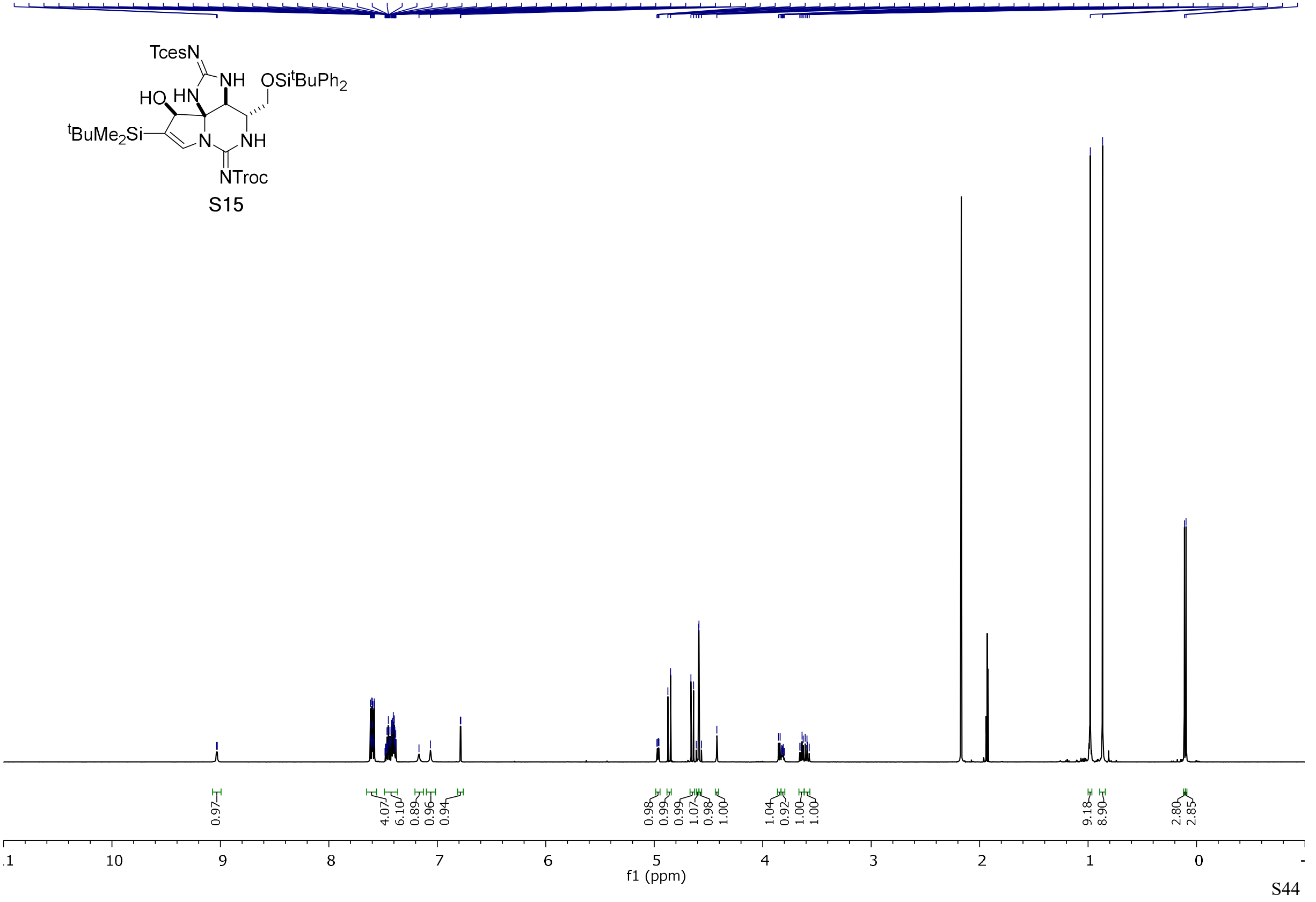


${ }^{13} \mathrm{C}\left\{{ }^{1} \mathrm{H}\right\}$ NMR for $\mathbf{S} 15,125 \mathrm{MHz}, \mathrm{CD}_{3} \mathrm{CN}$
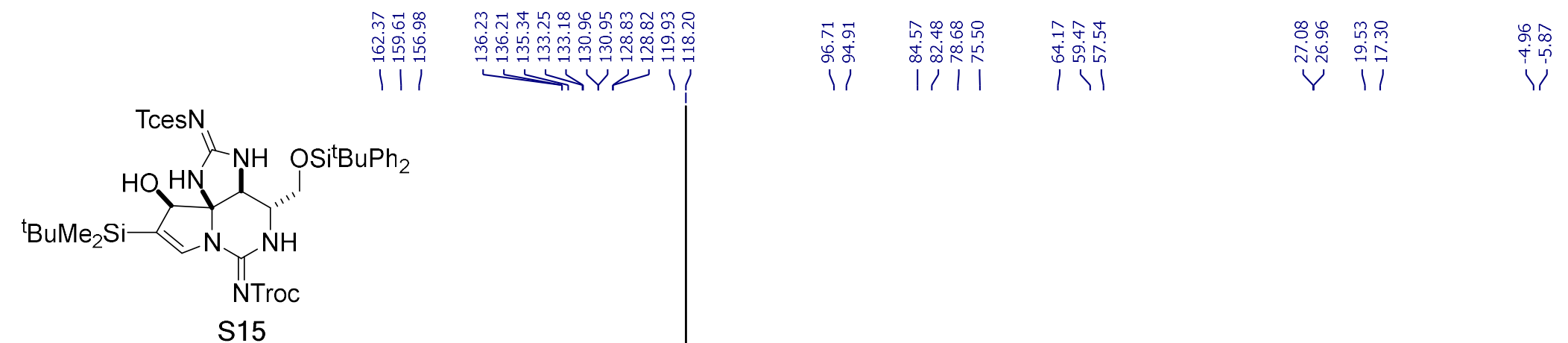
${ }^{1} \mathrm{H}$ NMR for $24,500 \mathrm{MHz}, \mathrm{CD}_{3} \mathrm{CN}$

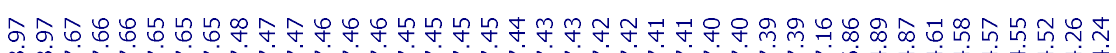
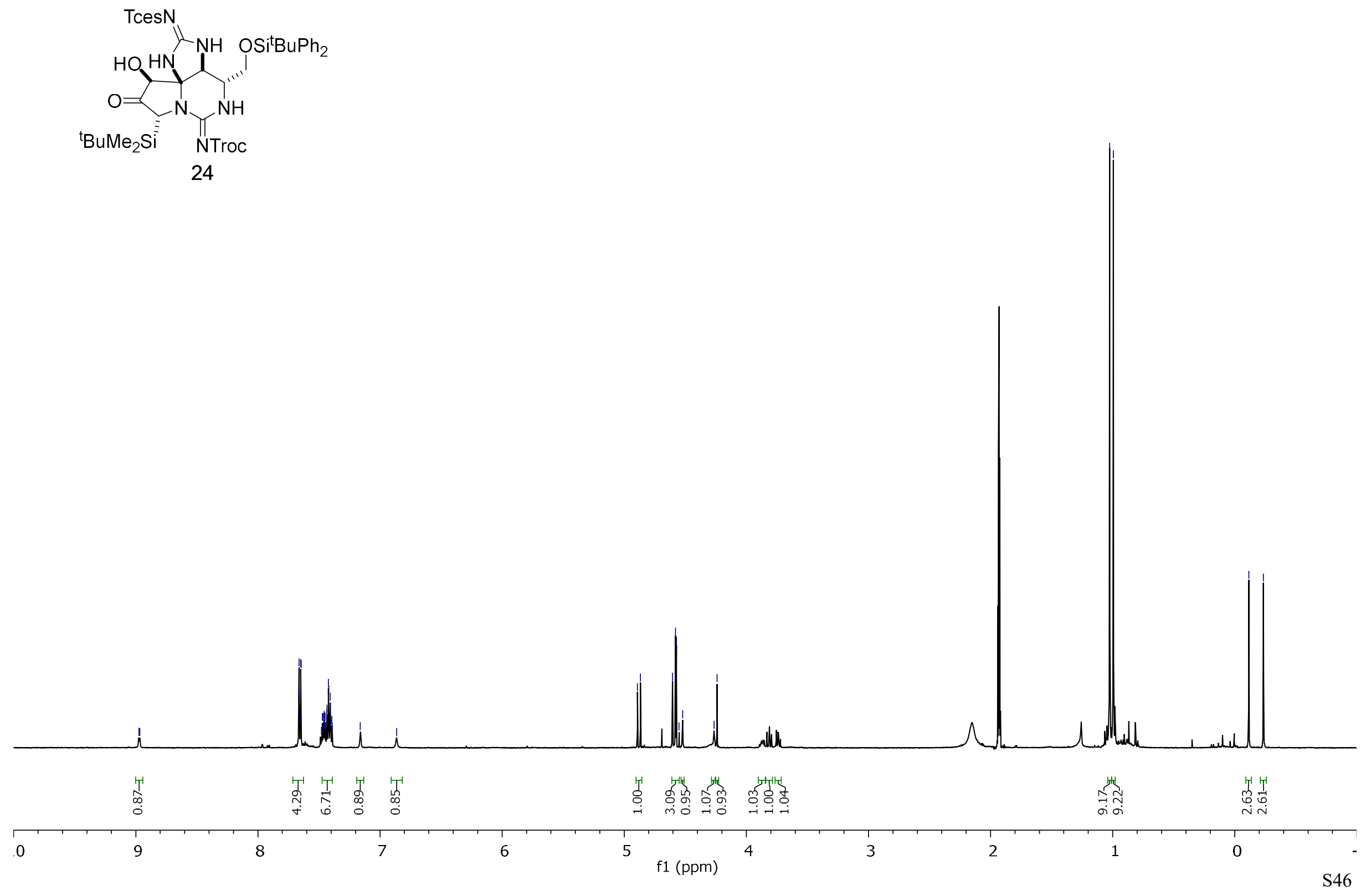
${ }^{1} \mathrm{H}-{ }^{13} \mathrm{C}$ HSQC for $24,600 \mathrm{MHz}, \mathrm{CD}_{3} \mathrm{CN}$

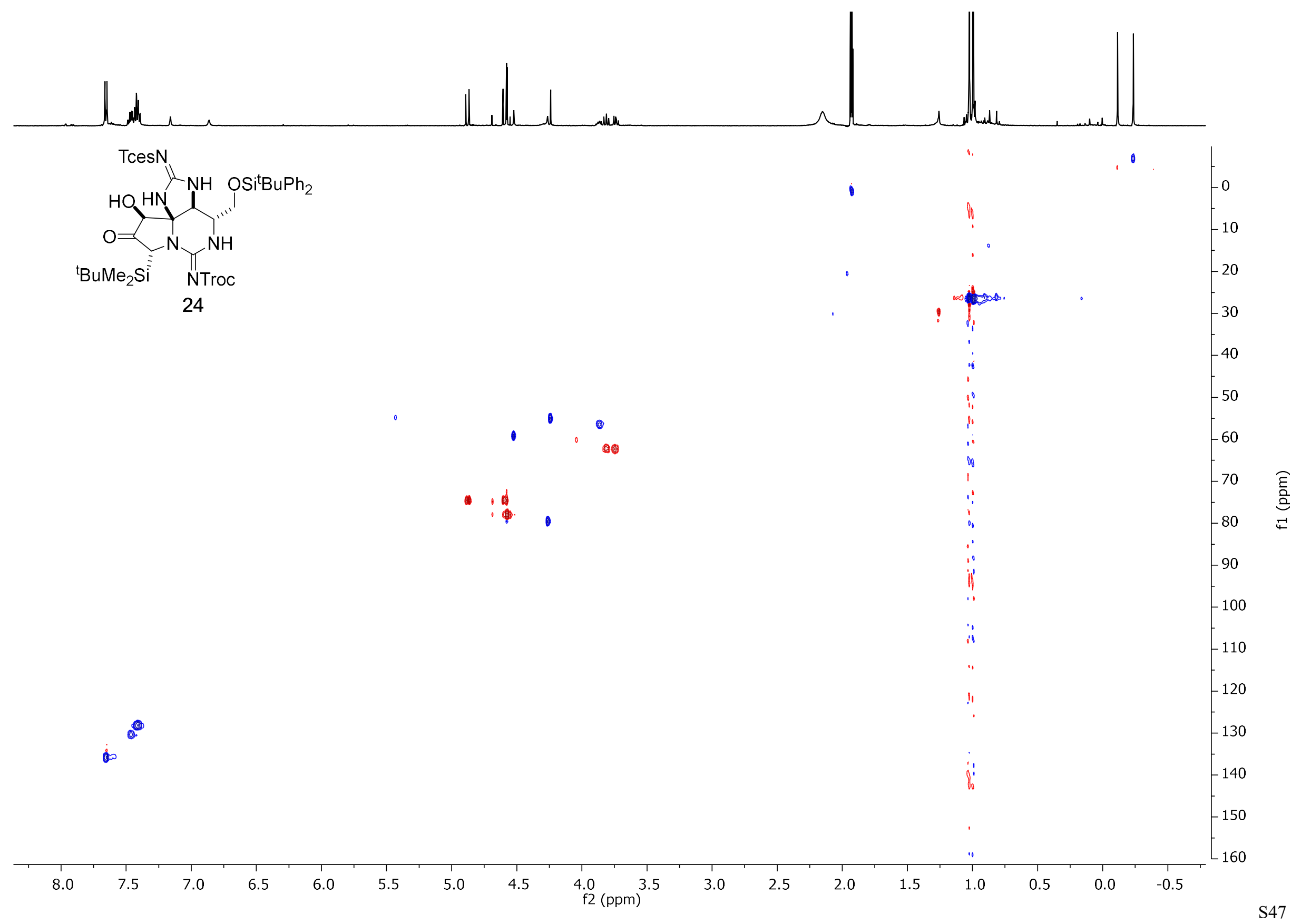


${ }^{1} \mathrm{H}-{ }^{13} \mathrm{C}$ HMBC for $24,600 \mathrm{MHz}, \mathrm{CD}_{3} \mathrm{CN}$

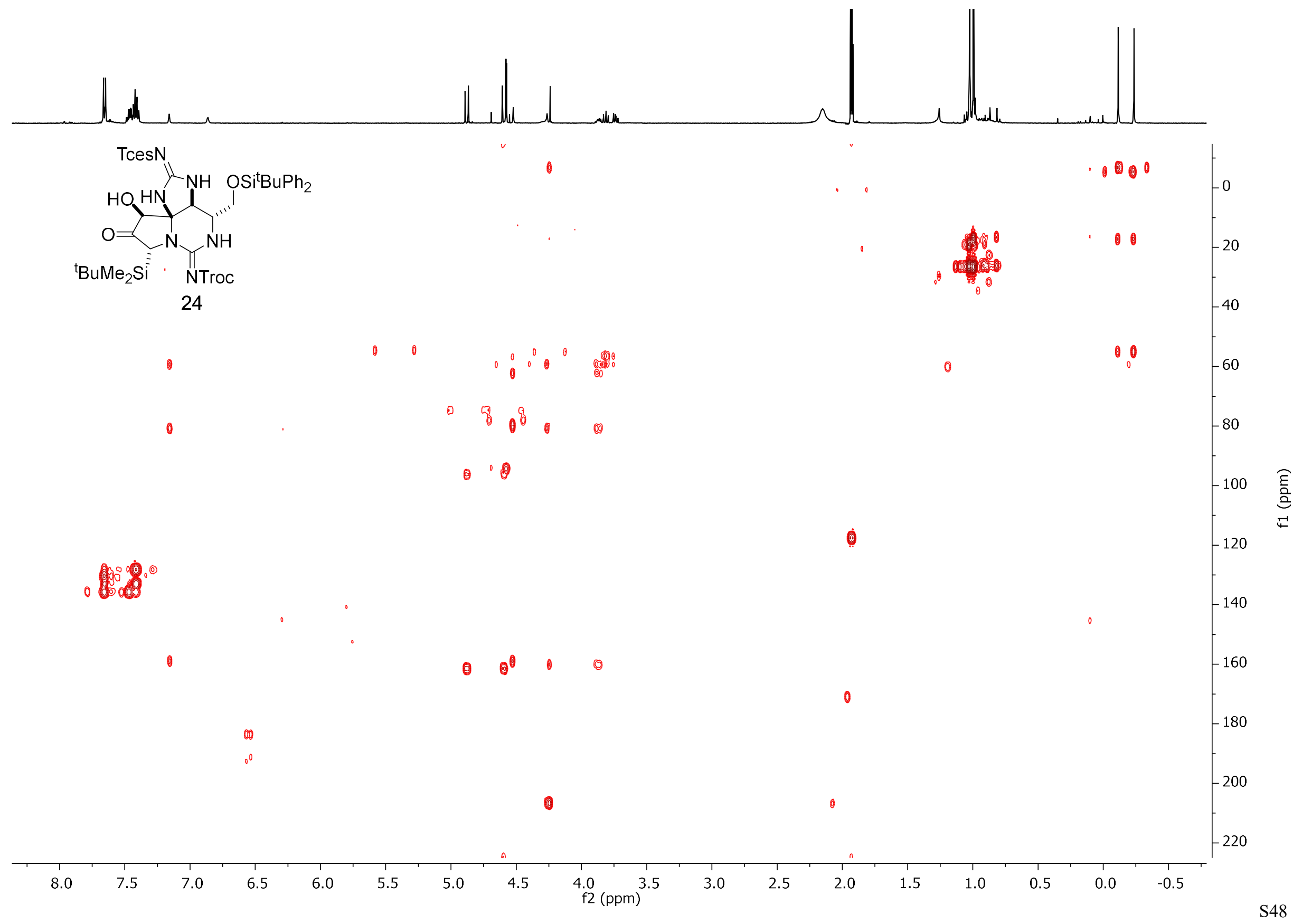


${ }^{1} \mathrm{H}$ NMR for $\mathbf{S} 16,600 \mathrm{MHz}, \mathrm{CD}_{3} \mathrm{CN}$

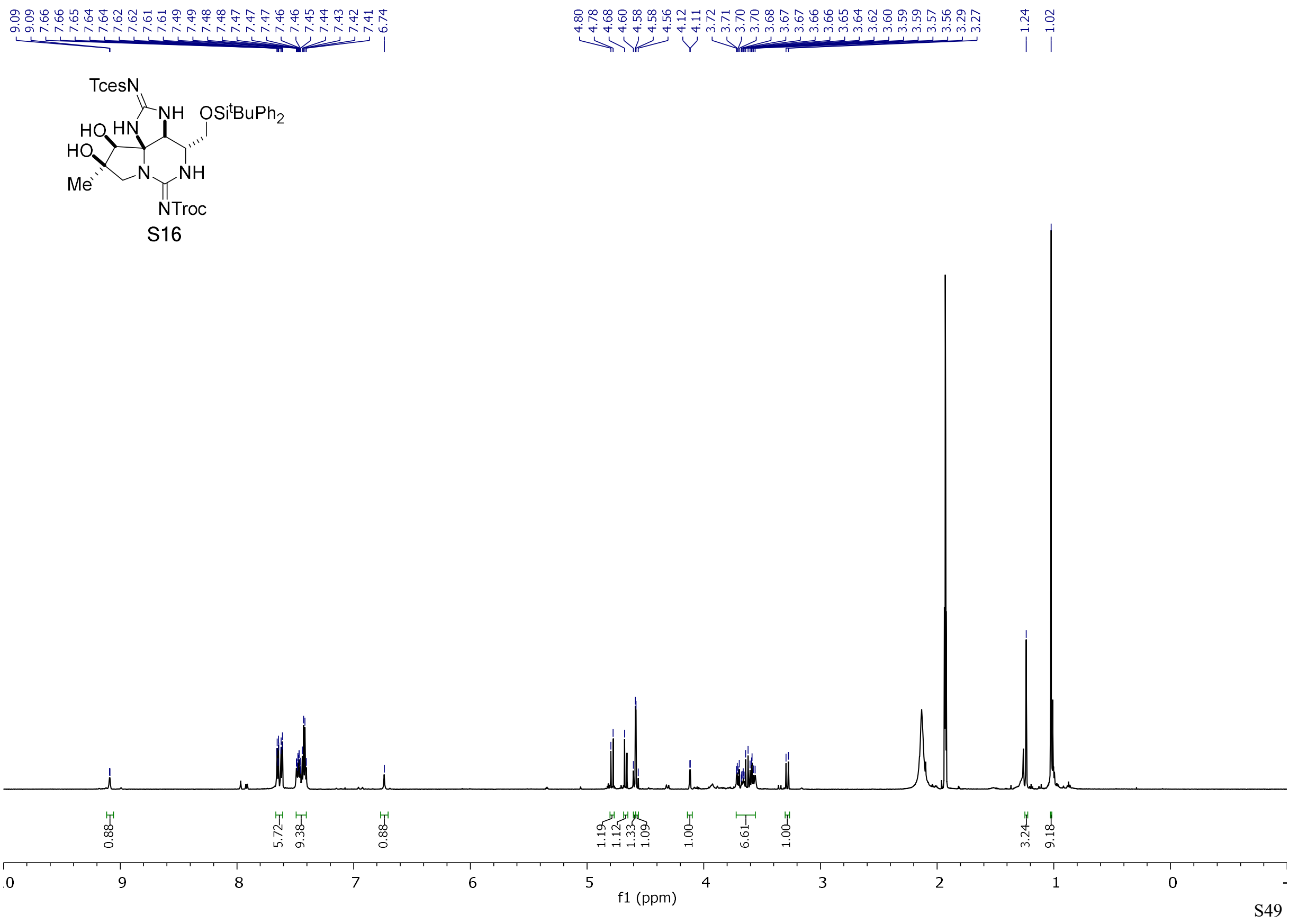


${ }^{1} \mathrm{H}-{ }^{13} \mathrm{C} \mathrm{HSQC}$ for $\mathbf{S} 16,600 \mathrm{MHz}, \mathrm{CD}_{3} \mathrm{CN}$

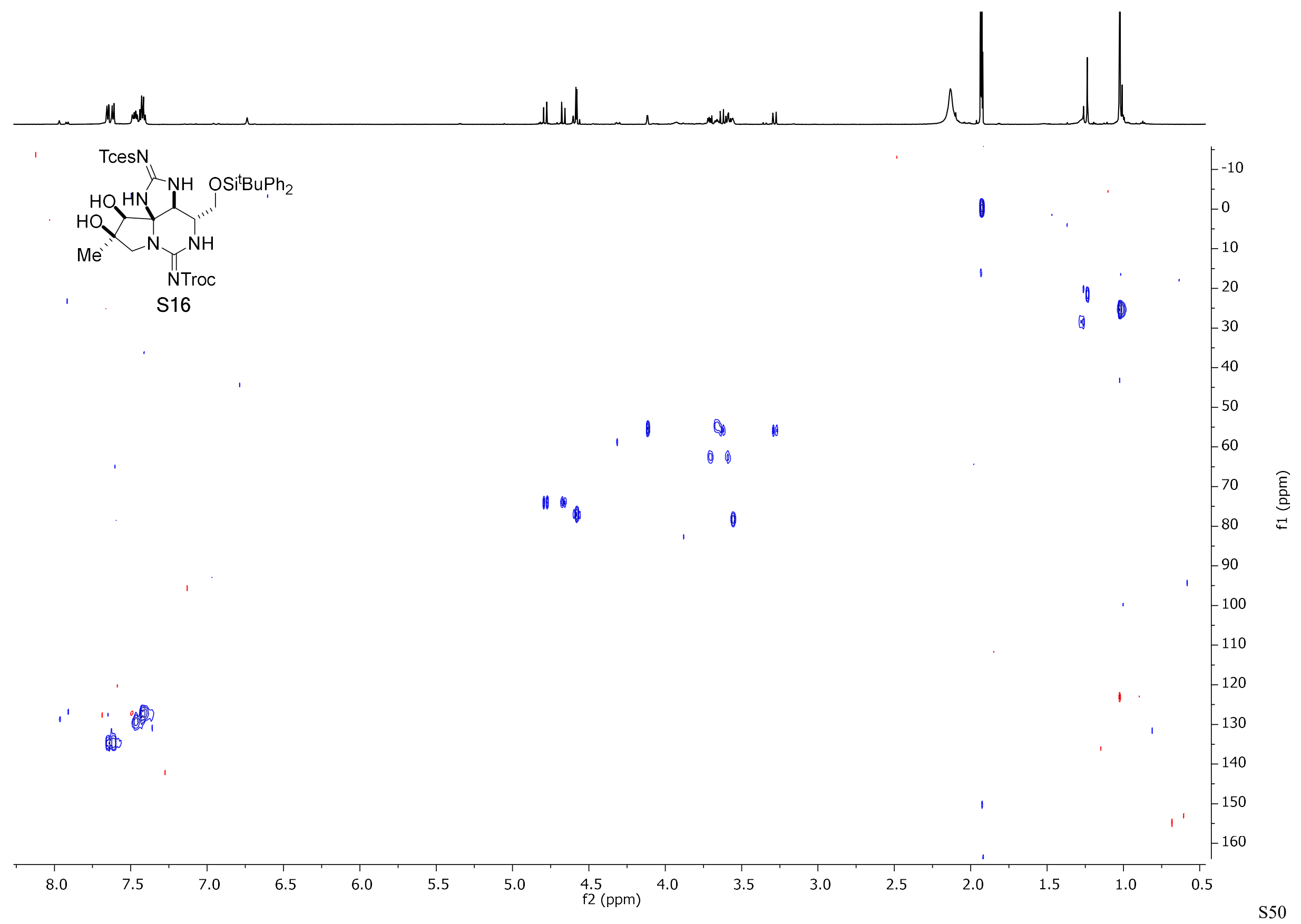


${ }^{1} \mathrm{H}-{ }^{13} \mathrm{C} \mathrm{HMBC}$ for S16, $600 \mathrm{MHz}, \mathrm{CD}_{3} \mathrm{CN}$

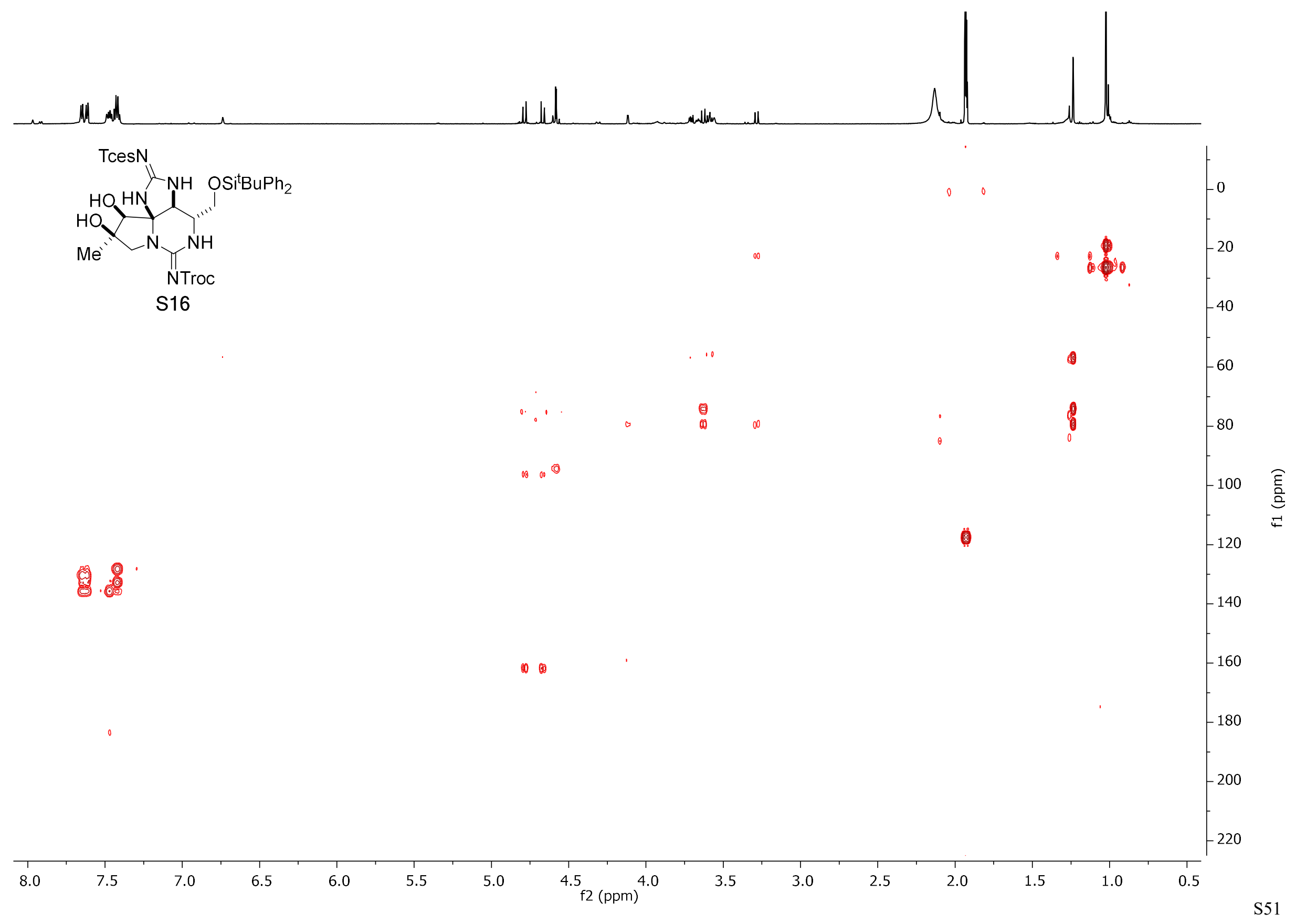




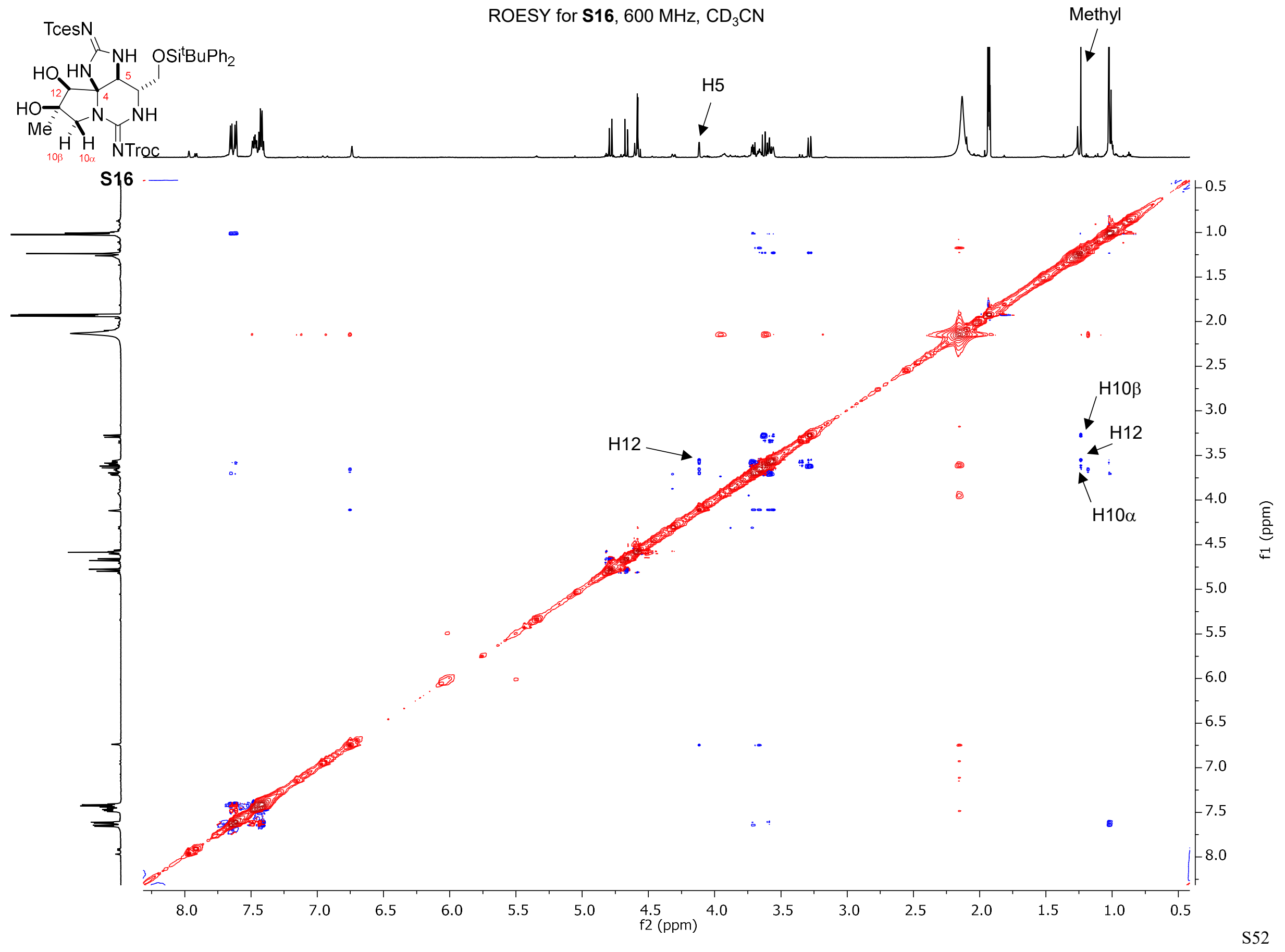




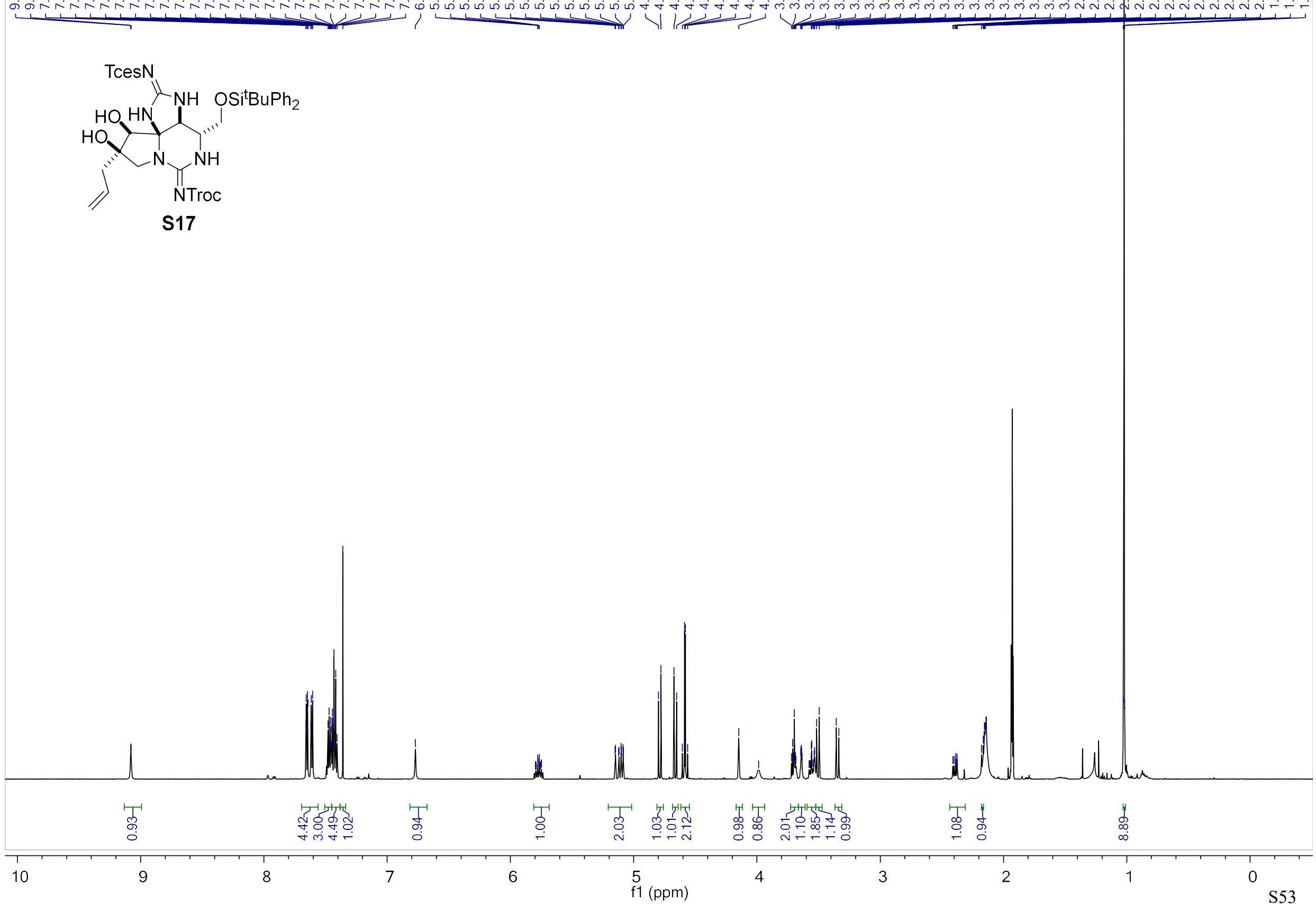


${ }^{1} \mathrm{H}-{ }^{13} \mathrm{C}$ HMBC for $\mathbf{S} 17,600 \mathrm{MHz}, \mathrm{CD}_{3} \mathrm{CN}$

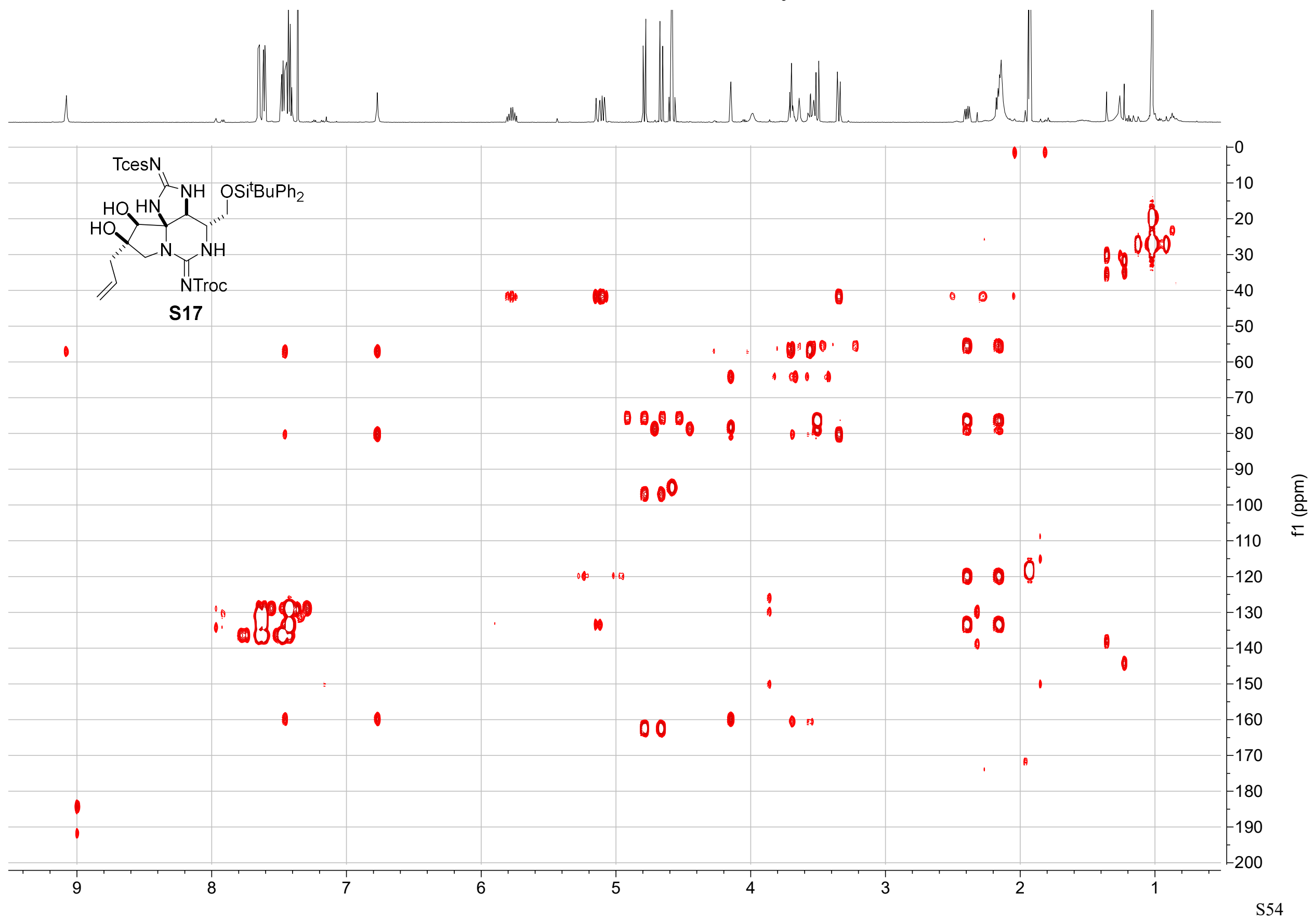


${ }^{1} \mathrm{H}-{ }^{13} \mathrm{C}$ HSQC for $\mathbf{S} 17,600 \mathrm{MHz}, \mathrm{CD}_{3} \mathrm{CN}$

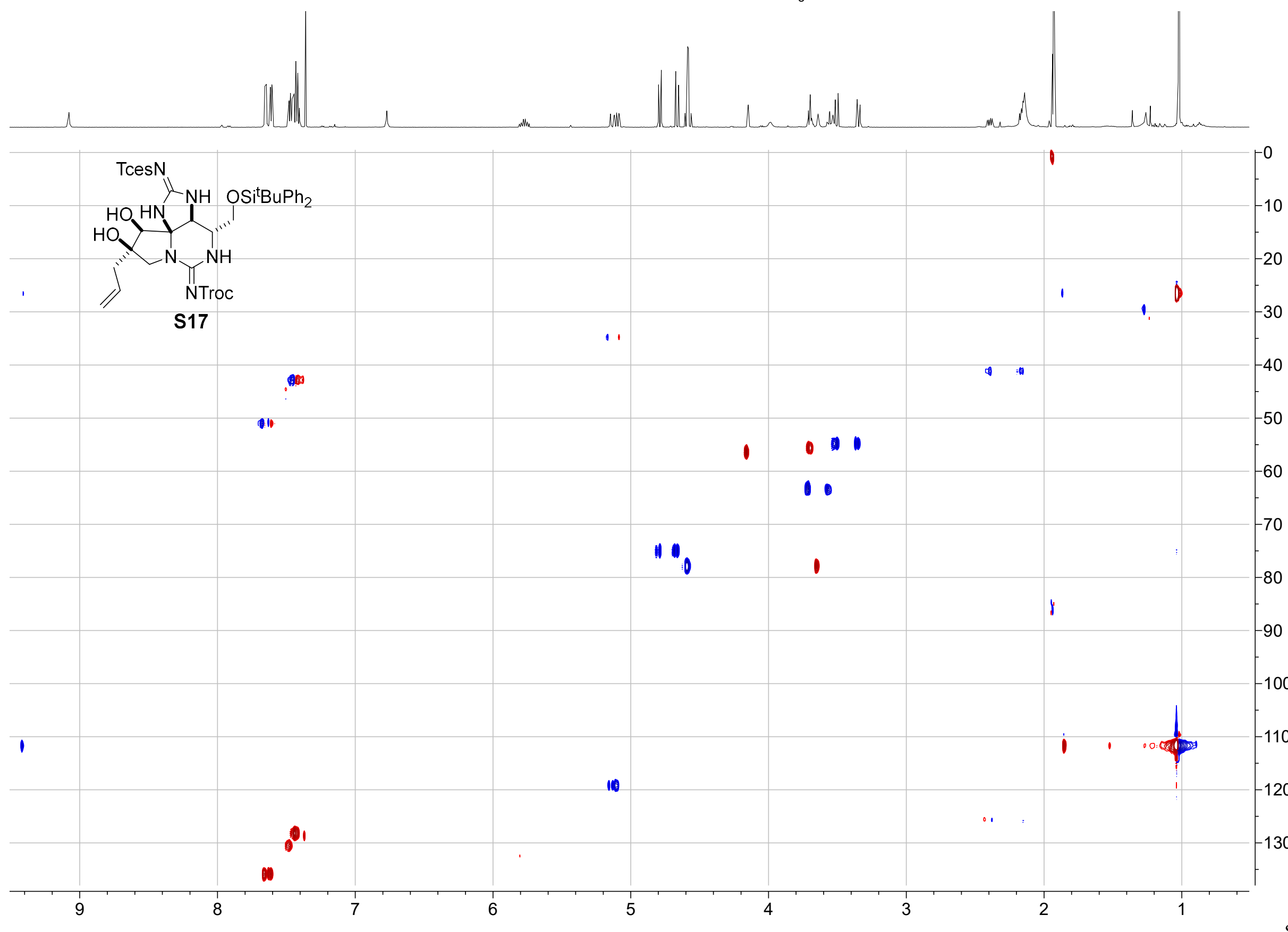

है
을
든 


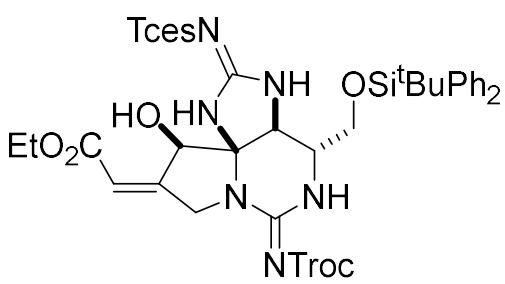

30

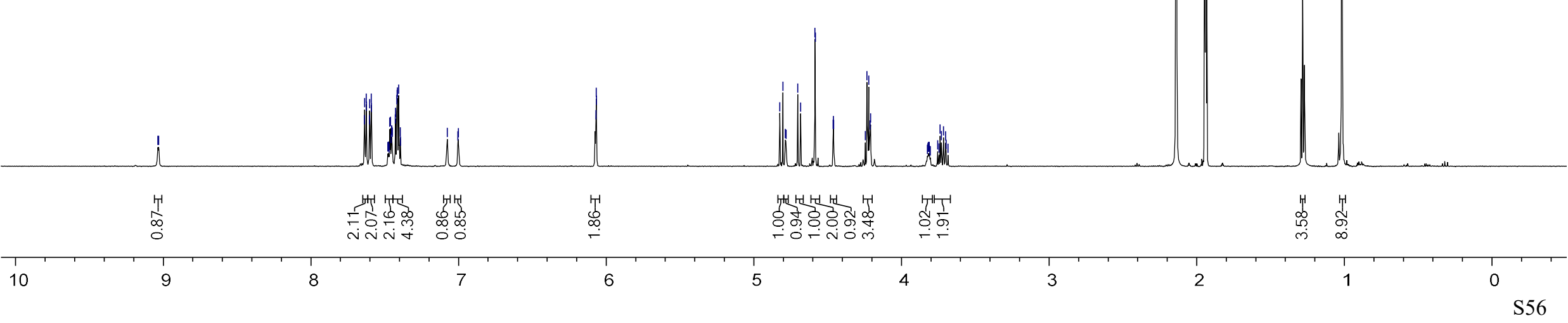


${ }^{13} \mathrm{C}\left\{{ }^{1} \mathrm{H}\right\}$ NMR for $30,125 \mathrm{MHz}, \mathrm{CD}_{3} \mathrm{CN}$

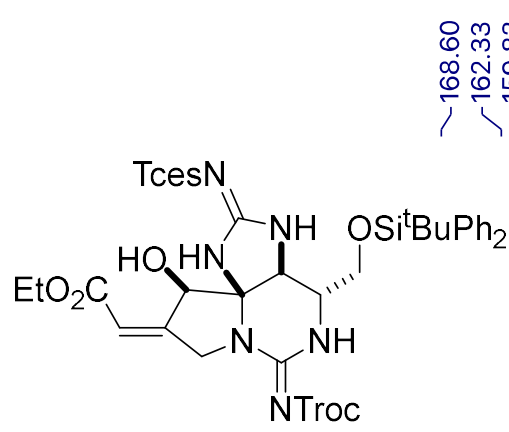

30

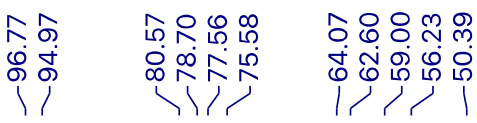

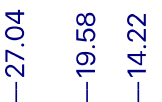

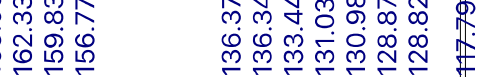



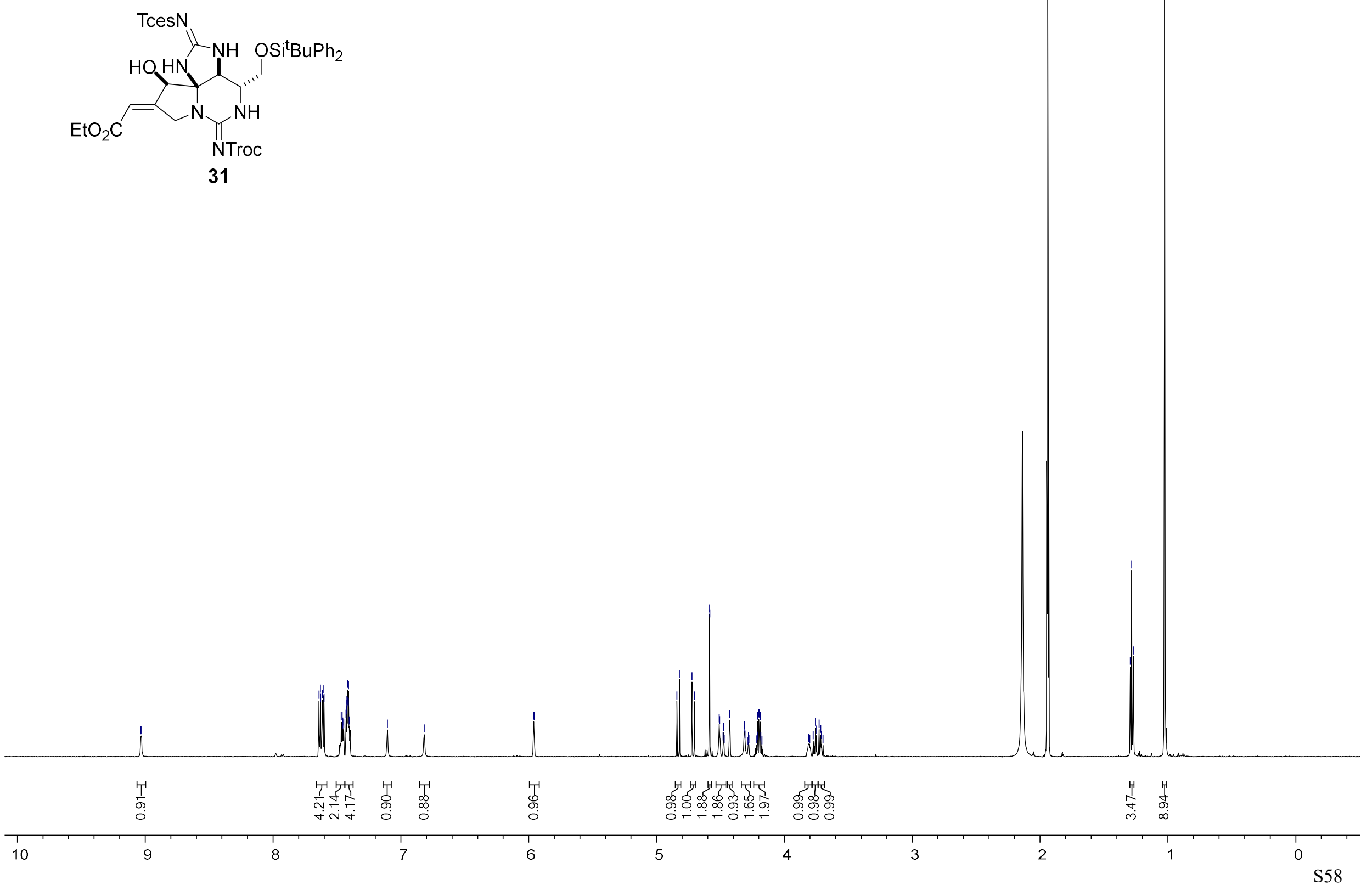
${ }^{13} \mathrm{C}\left\{{ }^{1} \mathrm{H}\right\}$ NMR for $31,125 \mathrm{MHz}, \mathrm{CD}_{3} \mathrm{CN}$
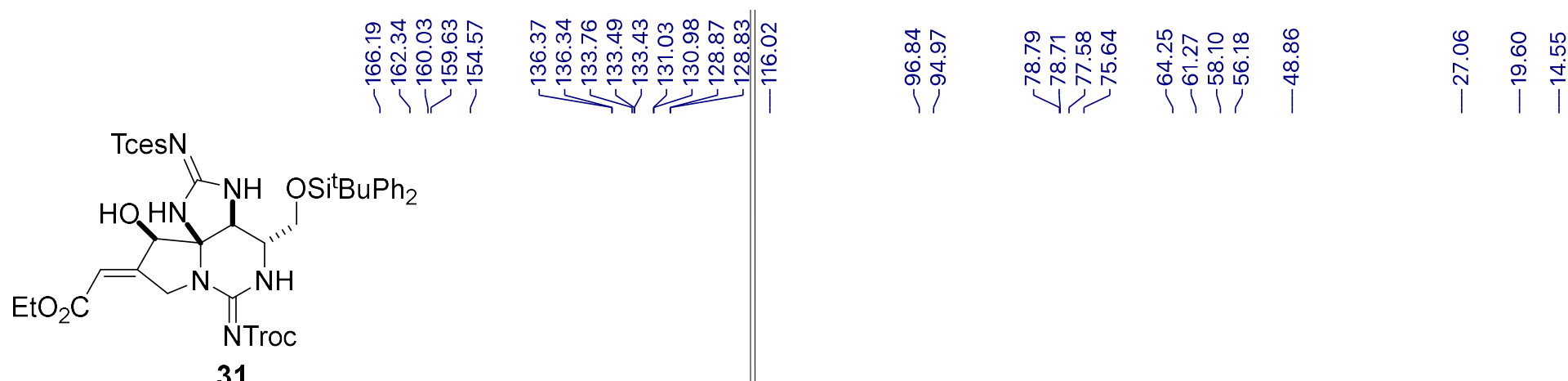

31 


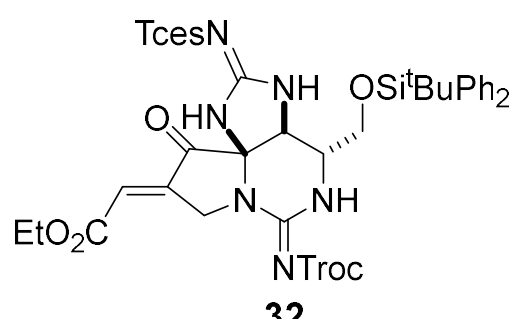

32

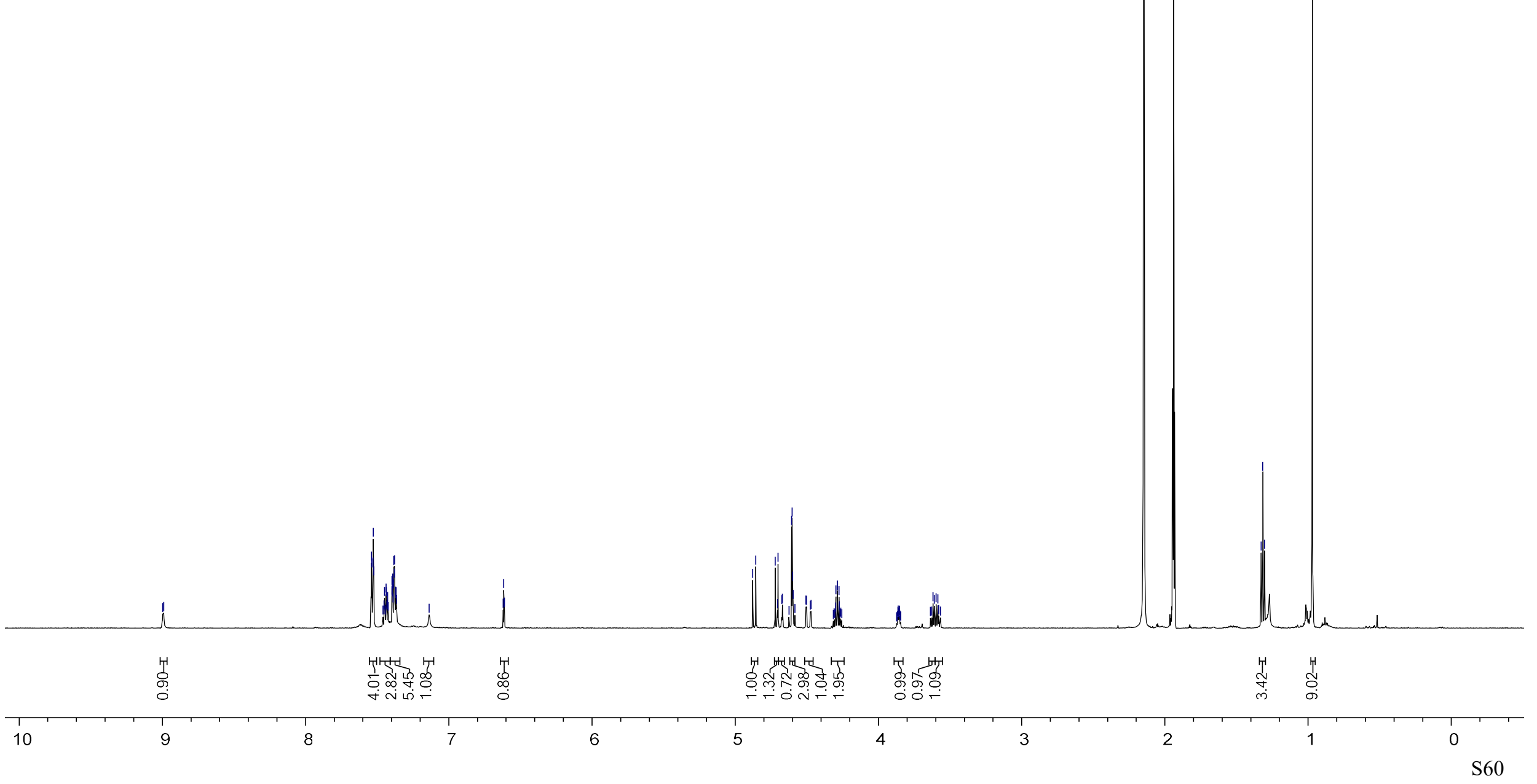


${ }^{1} \mathrm{H}-{ }^{13} \mathrm{C}$ HMBC for $32,600 \mathrm{MHz}, \mathrm{CD}_{3} \mathrm{CN}$

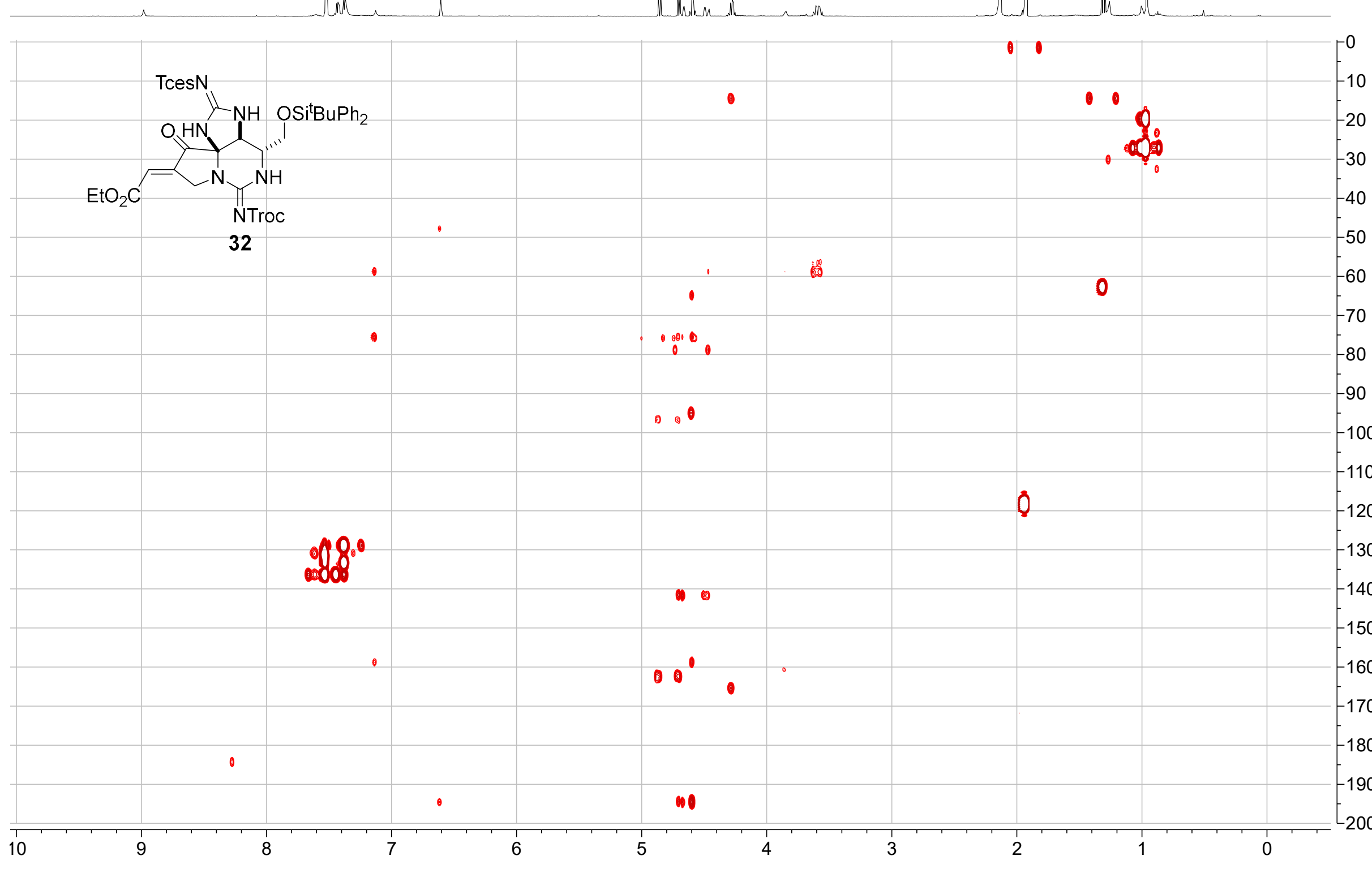


${ }^{1} \mathrm{H}-{ }^{13} \mathrm{C}$ HSQC for $32,600 \mathrm{MHz}, \mathrm{CD}_{3} \mathrm{CN}$

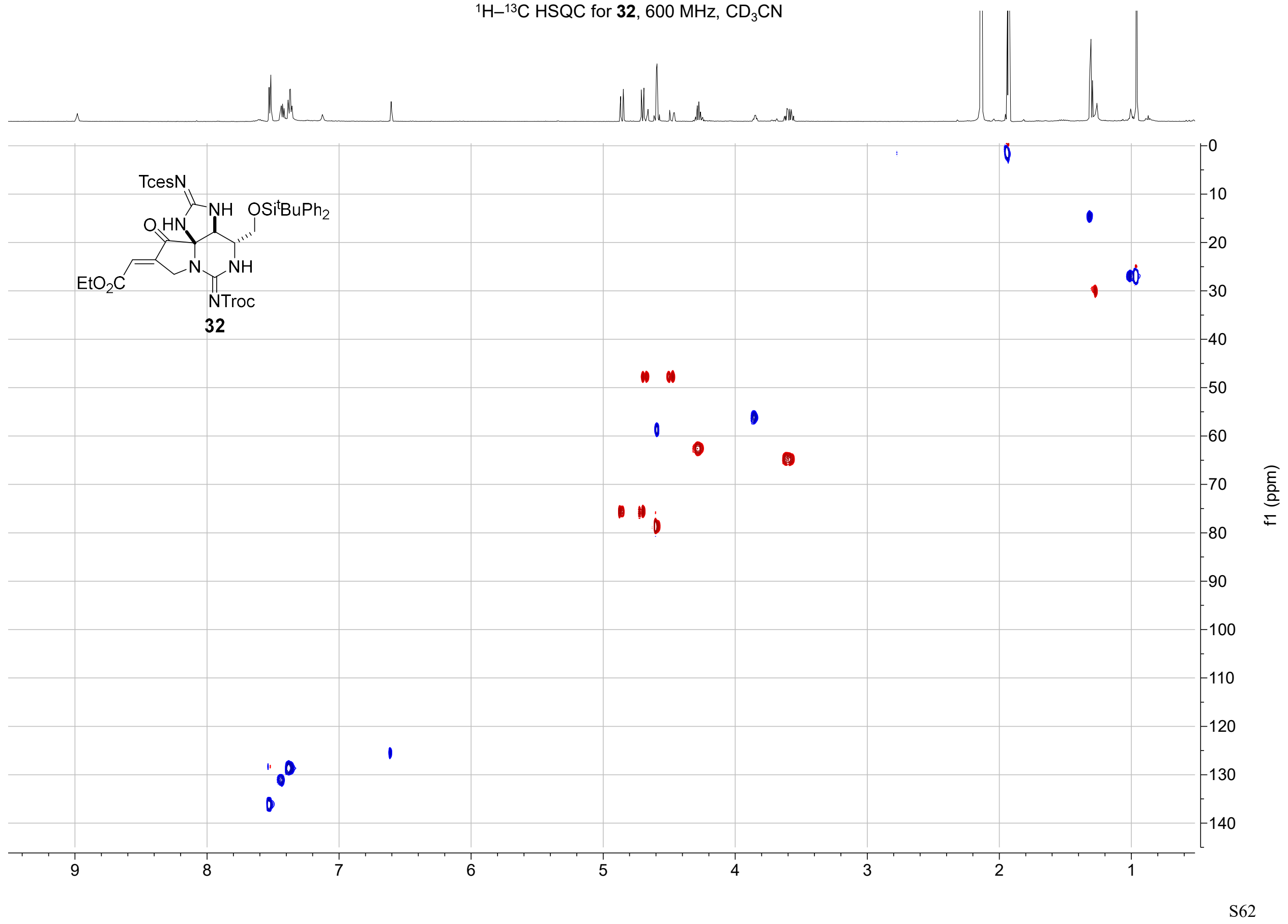




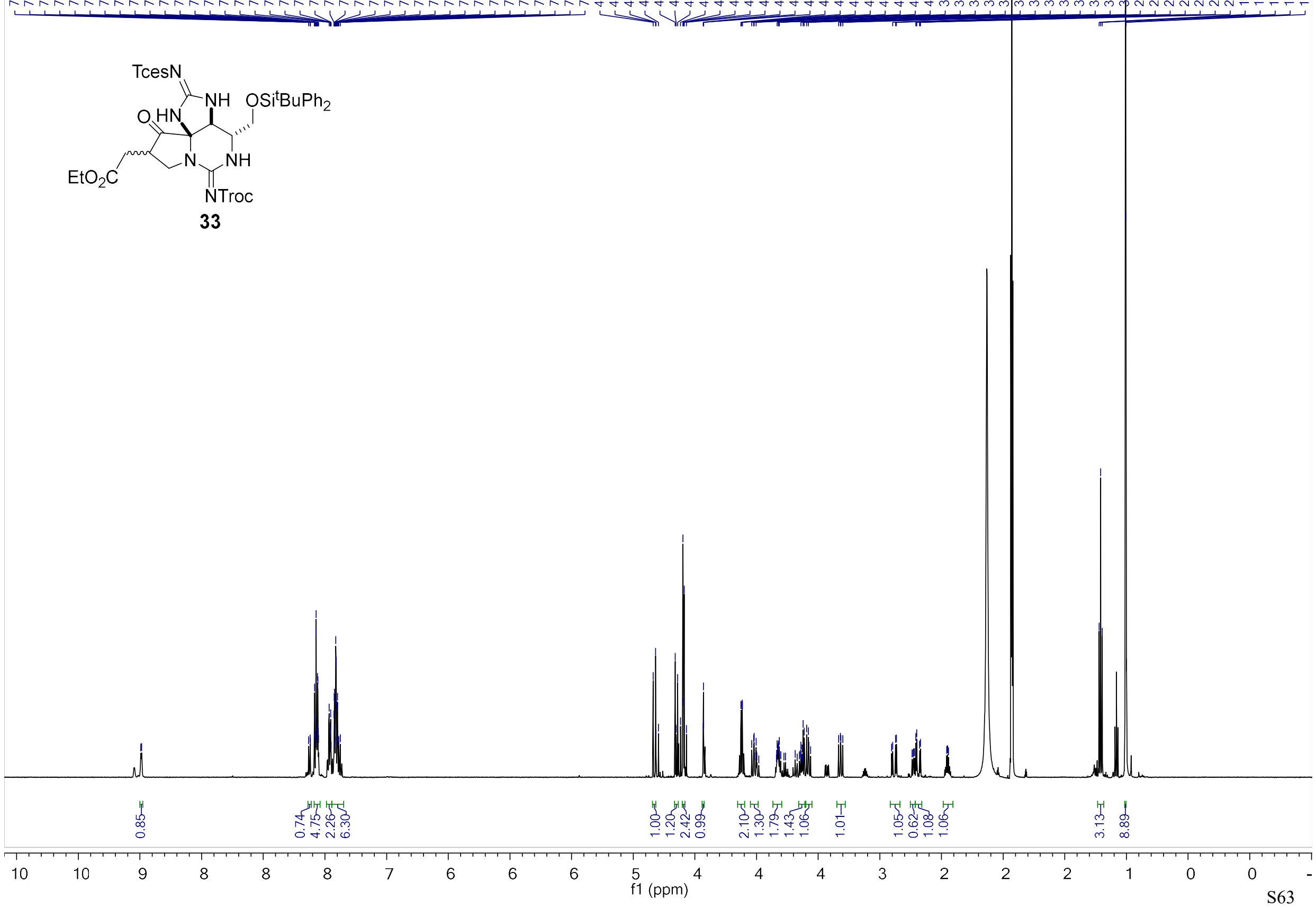


${ }^{1} \mathrm{H}-{ }^{13} \mathrm{C} \mathrm{HMBC}$ for $33,600 \mathrm{MHz}, \mathrm{CD}_{3} \mathrm{CN}$ 
${ }^{1} \mathrm{H}-{ }^{13} \mathrm{C} \mathrm{HSQC}$ for $33,600 \mathrm{MHz}, \mathrm{CD}_{3} \mathrm{CN}$

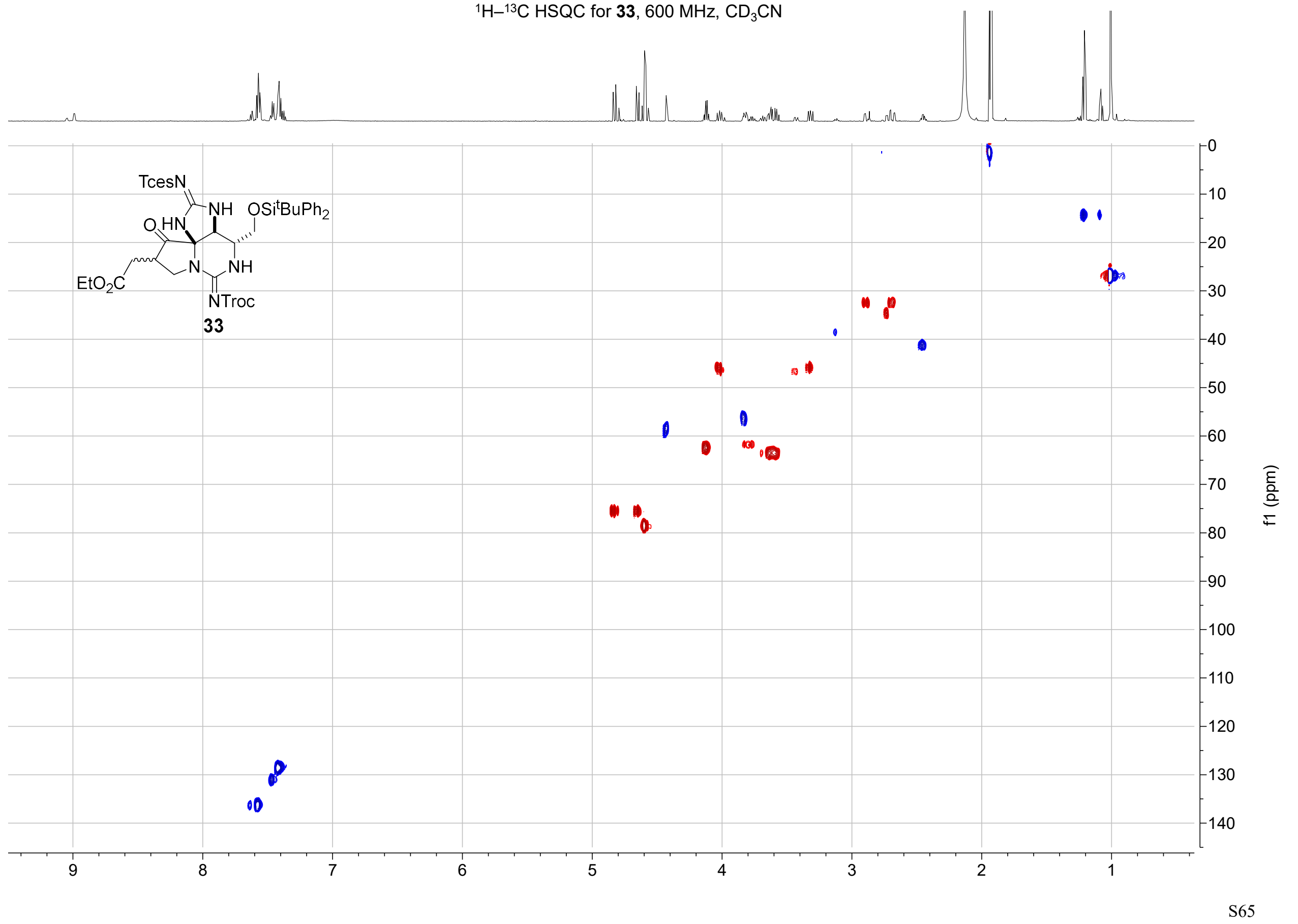


${ }^{1} \mathrm{H}$ NMR for $34,600 \mathrm{MHz}, \mathrm{CD}_{3} \mathrm{CN}$

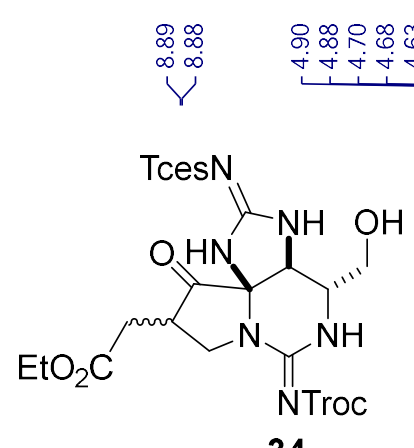

34

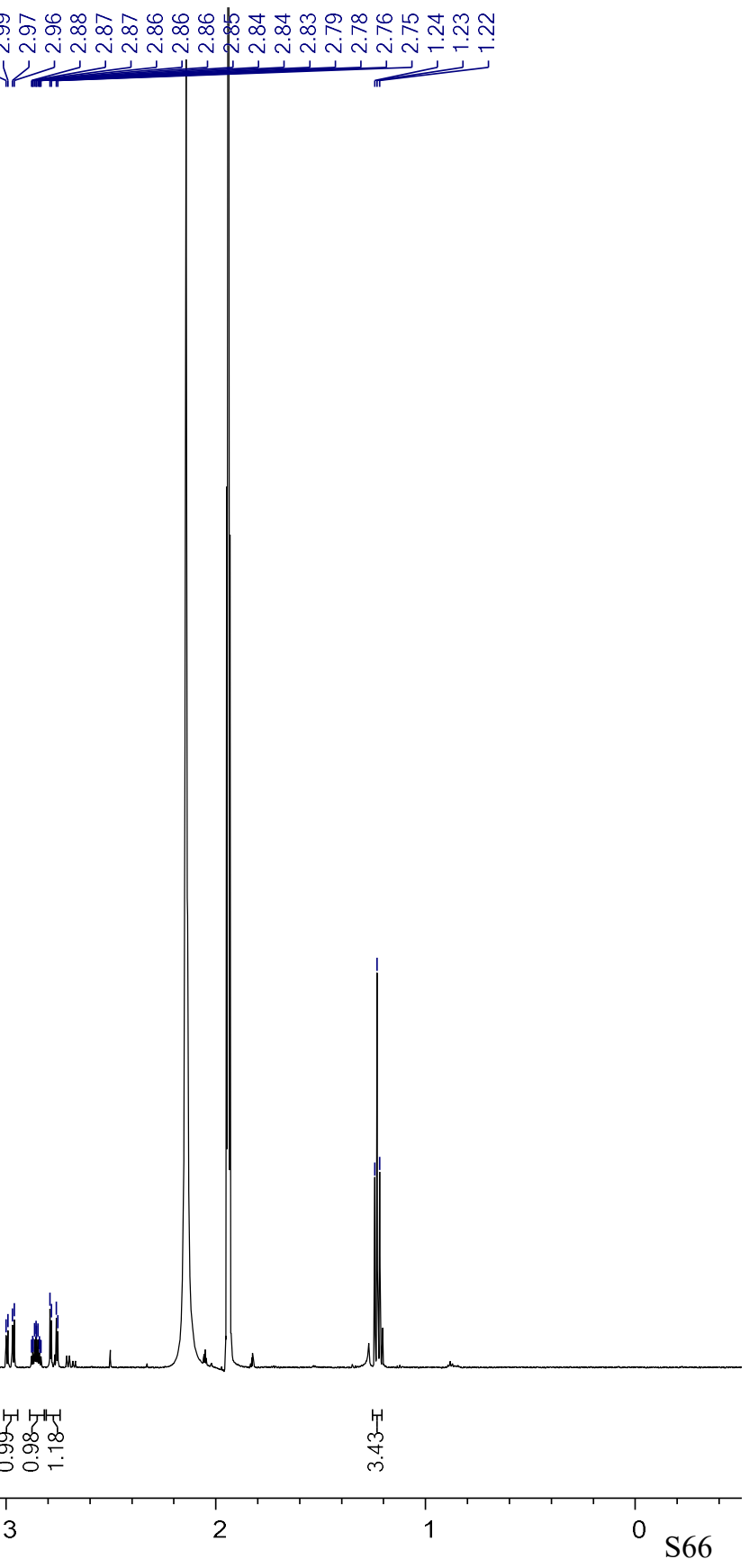


${ }^{13} \mathrm{C}\left\{{ }^{1} \mathrm{H}\right\}$ NMR for $34,125 \mathrm{MHz}, \mathrm{CD}_{3} \mathrm{CN}$
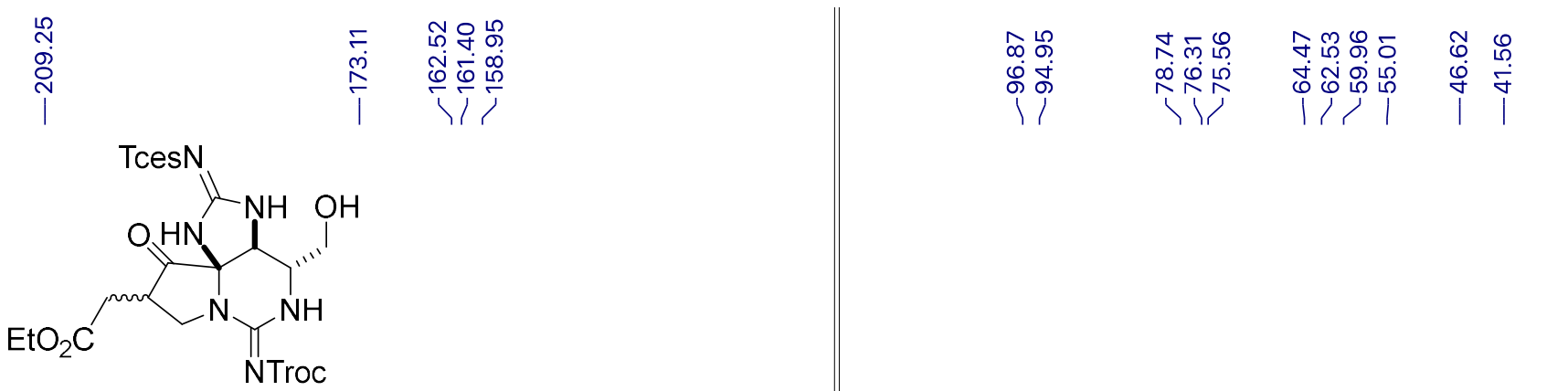



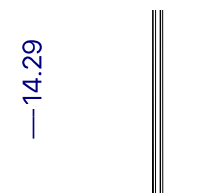

34 
${ }^{1} \mathrm{H}$ NMR for $\mathbf{S} 18,600 \mathrm{MHz}, \mathrm{CD}_{3} \mathrm{CN}$

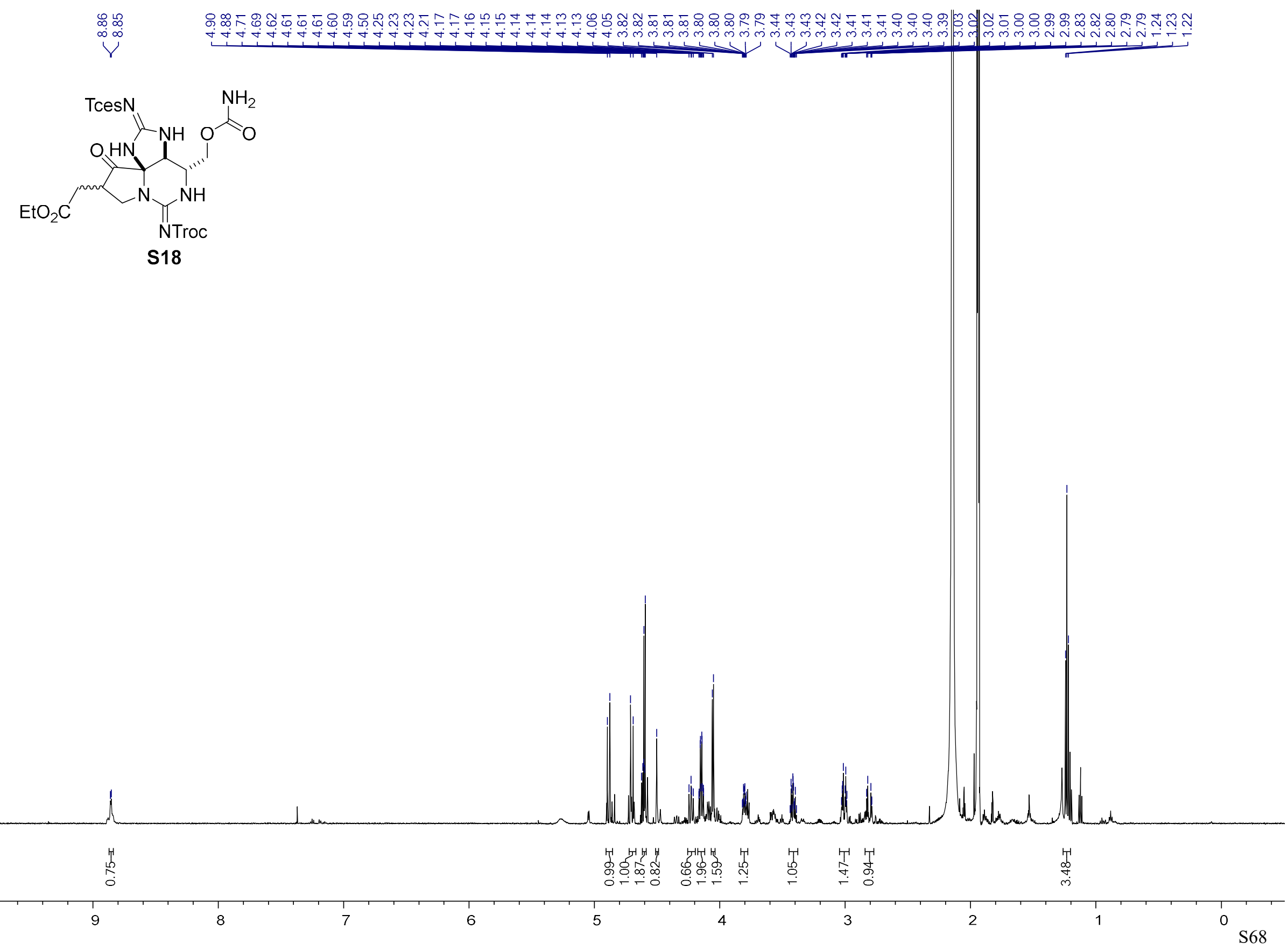


${ }^{1} \mathrm{H}-{ }^{13} \mathrm{C} \mathrm{HMBC}$ for $\mathbf{S} 18,600 \mathrm{MHz}, \mathrm{CD}_{3} \mathrm{CN}$

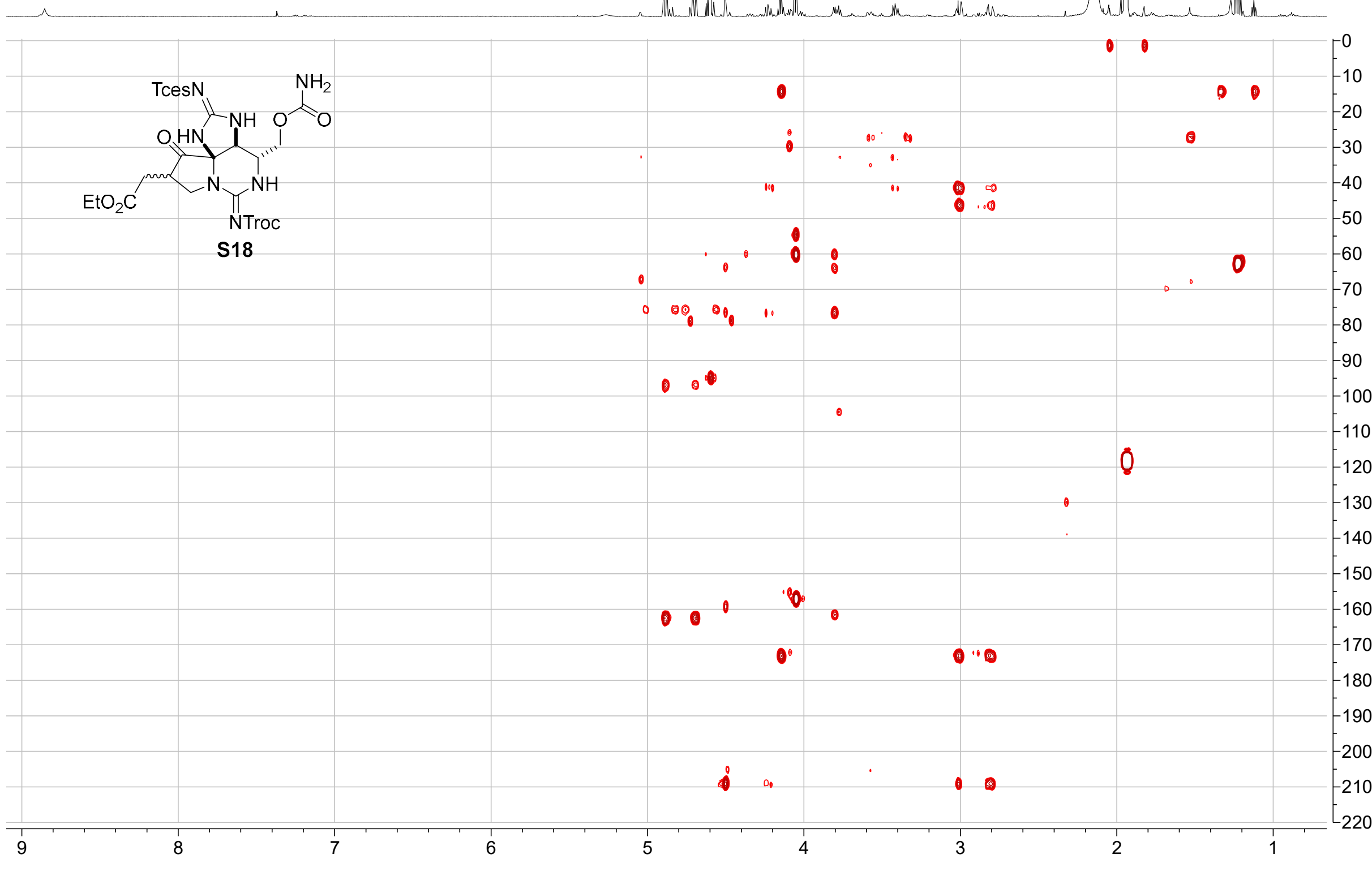


${ }^{1} \mathrm{H}-{ }^{13} \mathrm{C}$ HSQC for $\mathbf{S} 18,600 \mathrm{MHz}, \mathrm{CD}_{3} \mathrm{CN}$

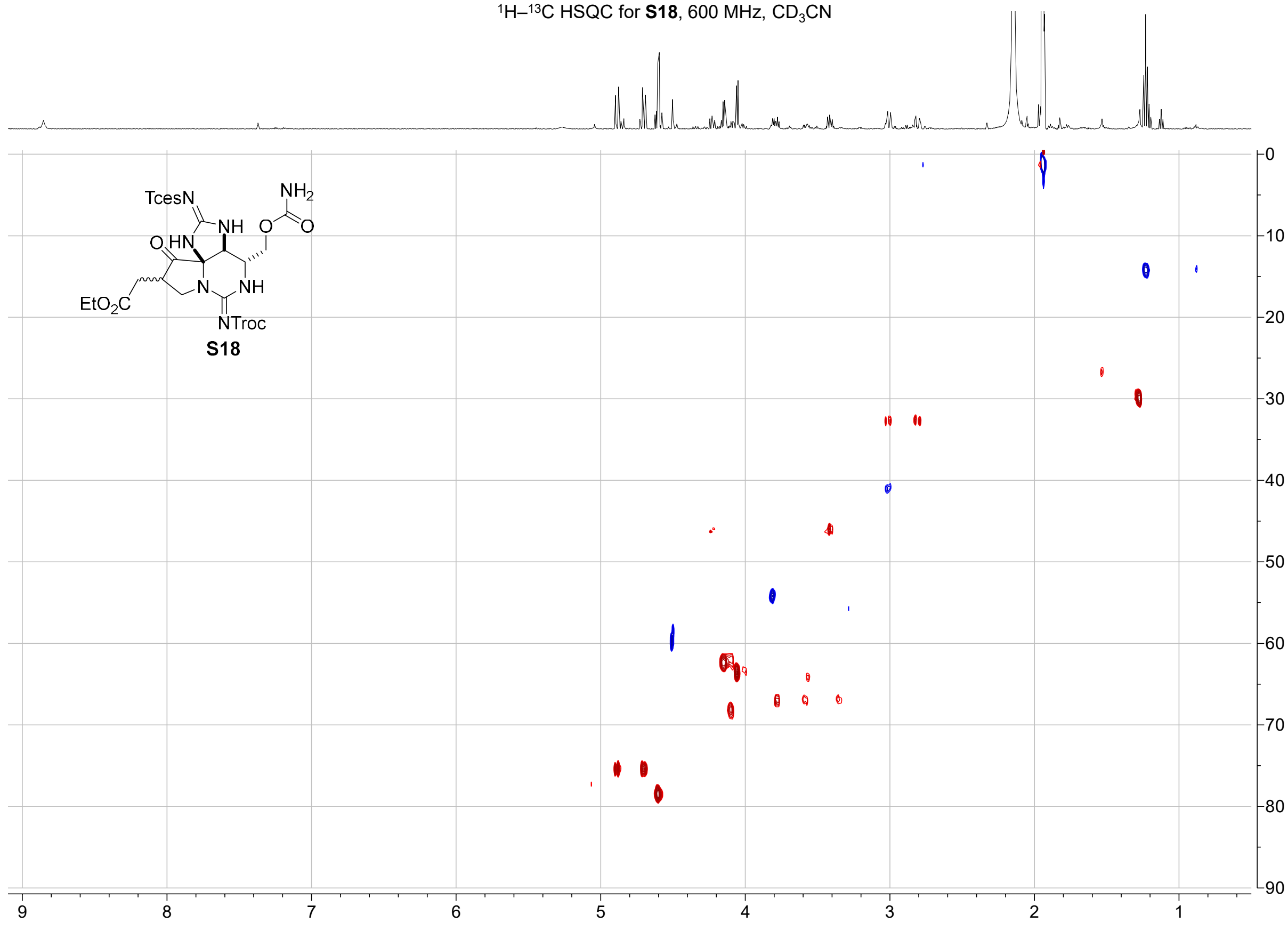

$\frac{\widehat{\varepsilon}}{\frac{\hat{\theta}}{2}}$ 
${ }^{1} \mathrm{H}$ NMR for 11-SEA, $600 \mathrm{MHz}, \mathrm{D}_{2} \mathrm{O}$

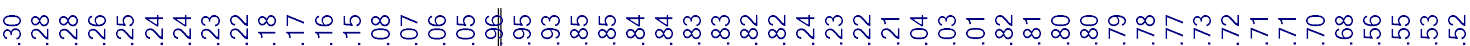

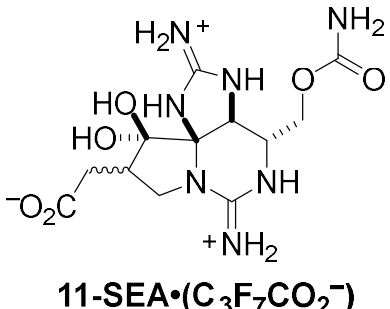

11-SEA $\cdot\left(\mathrm{C}_{3} \mathrm{~F}_{7} \mathrm{CO}_{2}^{-}\right)$

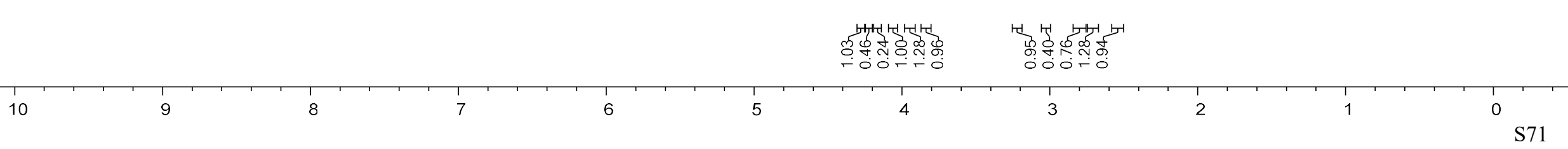


${ }^{1} \mathrm{H}$ NMR for 11-SEA, $600 \mathrm{MHz}, \mathrm{D}_{2} \mathrm{O}$

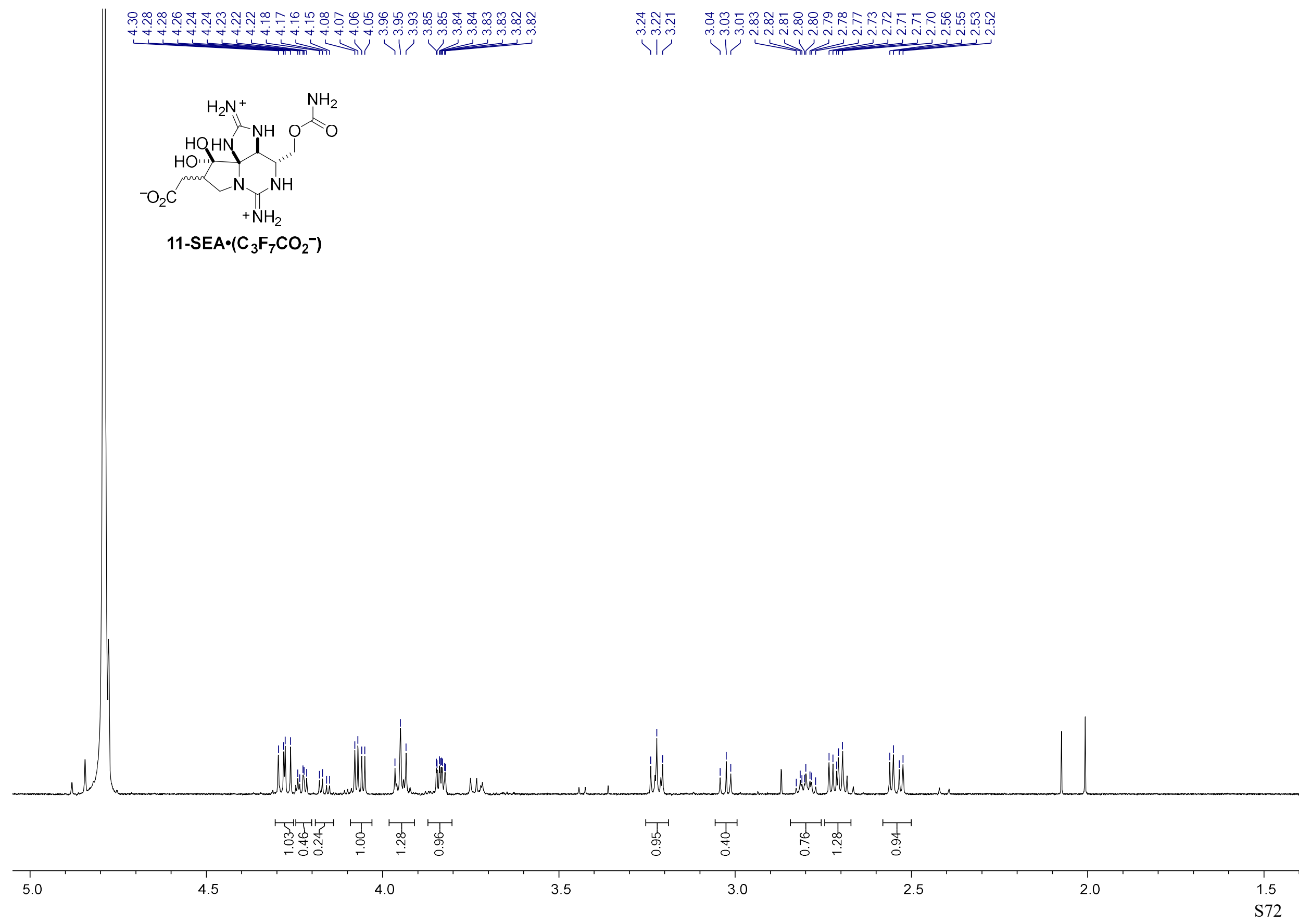


${ }^{1} \mathrm{H}$ NMR for 11-SEA, $600 \mathrm{MHz}, \mathrm{D}_{2} \mathrm{O}$

$$
\text { 11-SEA・ }\left(\mathrm{C}_{3} \mathrm{~F}_{7} \mathrm{CO}_{2}^{-}\right)
$$

Note: The sample allowed to

stand in $\mathrm{D}_{2} \mathrm{O}$ for $15 \mathrm{~h}$ before

spectrum was recorded

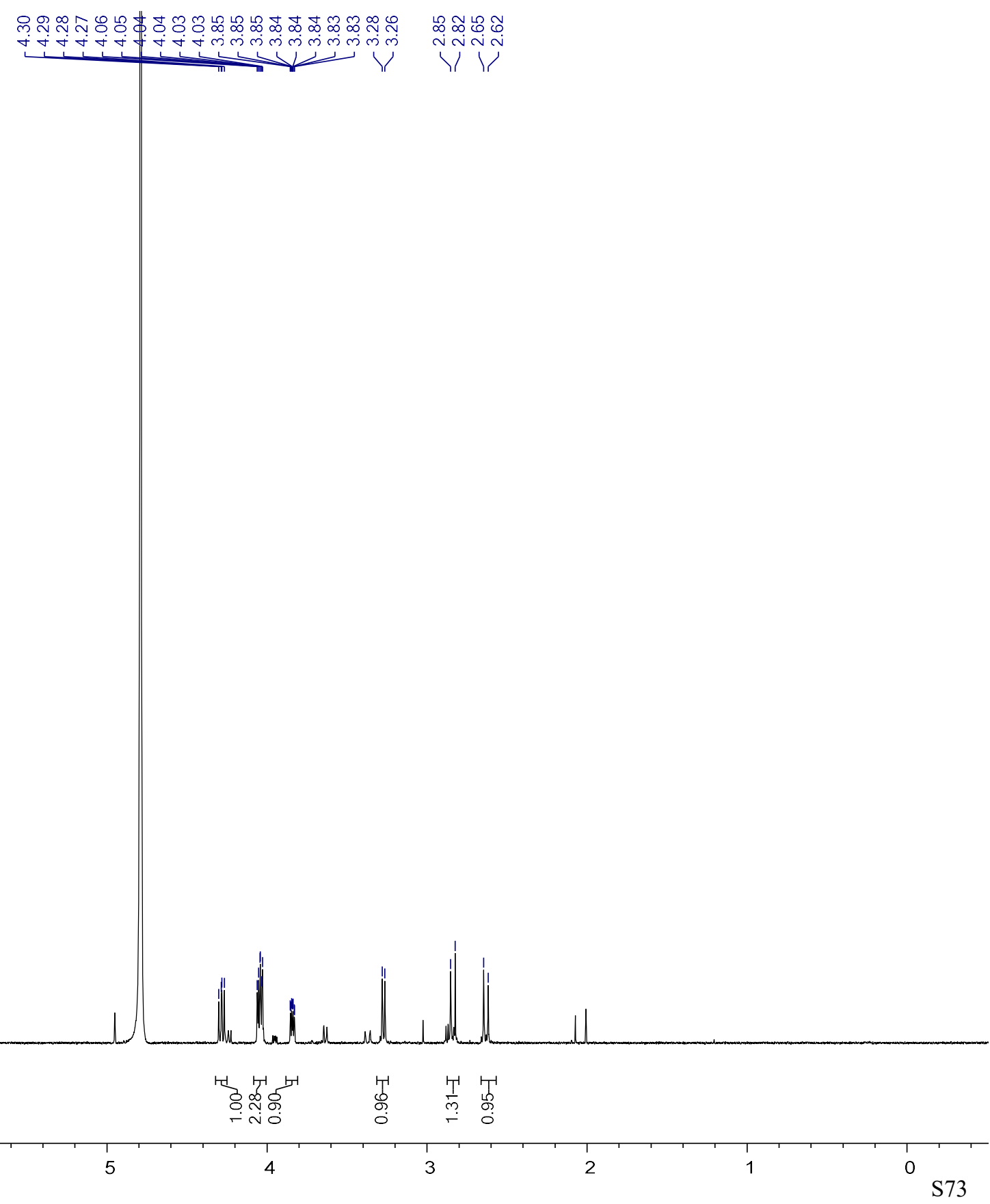

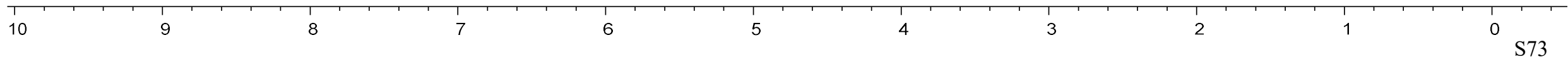


${ }^{1} \mathrm{H}$ NMR for 11-SEA, $600 \mathrm{MHz}, \mathrm{D}_{2} \mathrm{O}$

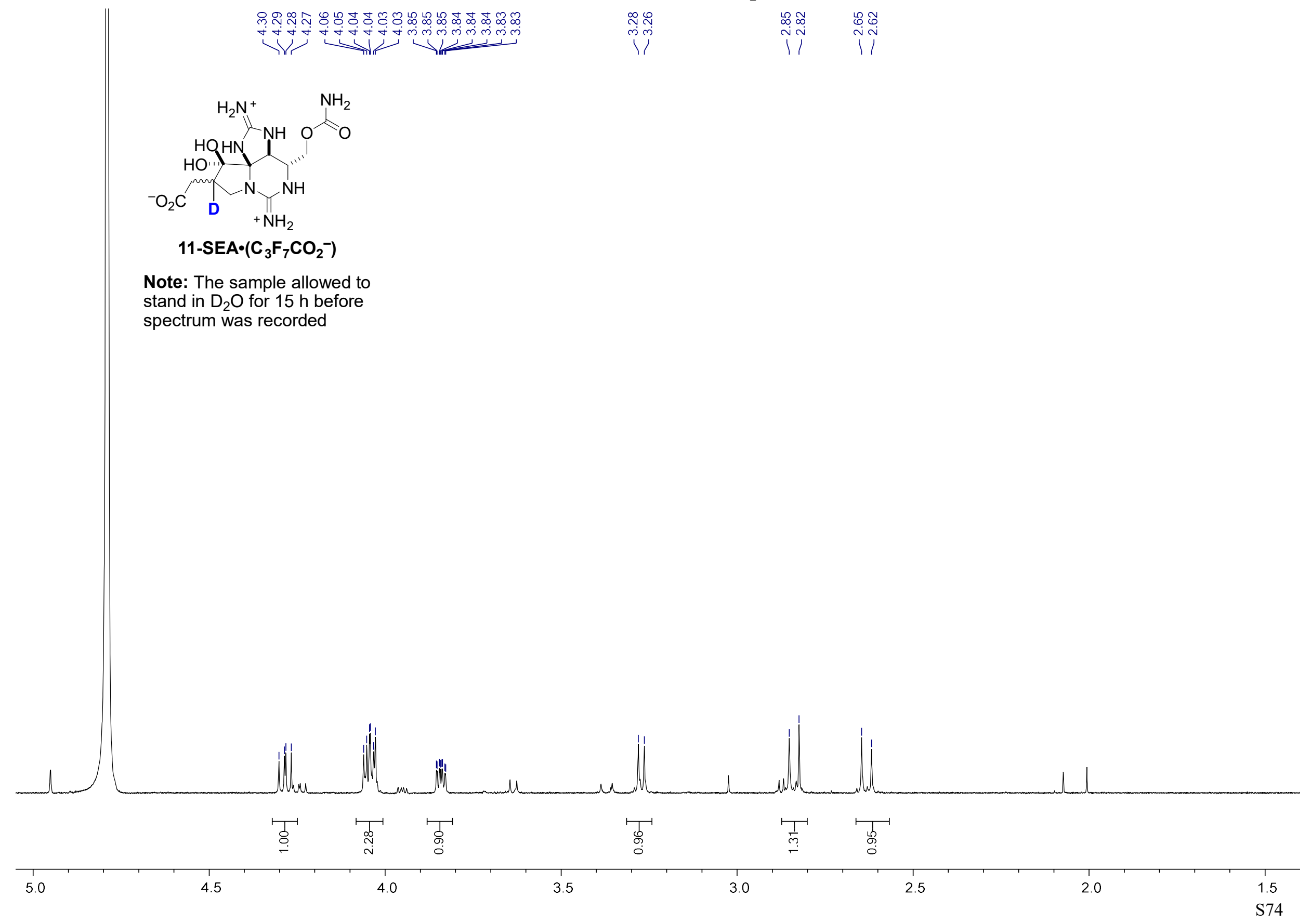


${ }^{1} \mathrm{H}-{ }^{13} \mathrm{C}$ HMBC for 11-SEA, $600 \mathrm{MHz}, \mathrm{D}_{2} \mathrm{O}$

(spectrum referenced to DMF)

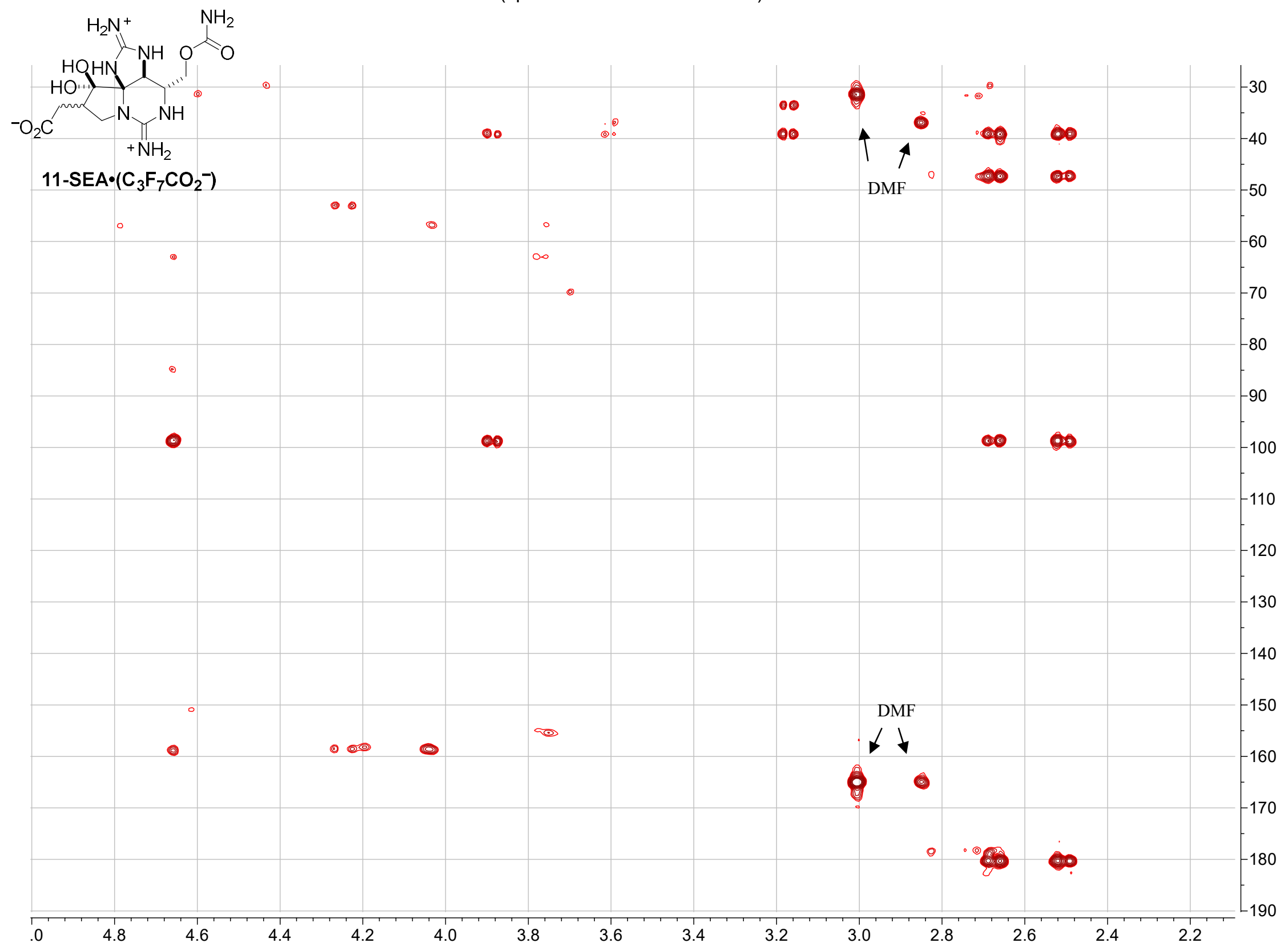


${ }^{1} \mathrm{H}-{ }^{13} \mathrm{C}$ HSQC for 11-SEA, $600 \mathrm{MHz}, \mathrm{D}_{2} \mathrm{O}$

(spectrum referenced to DMF)

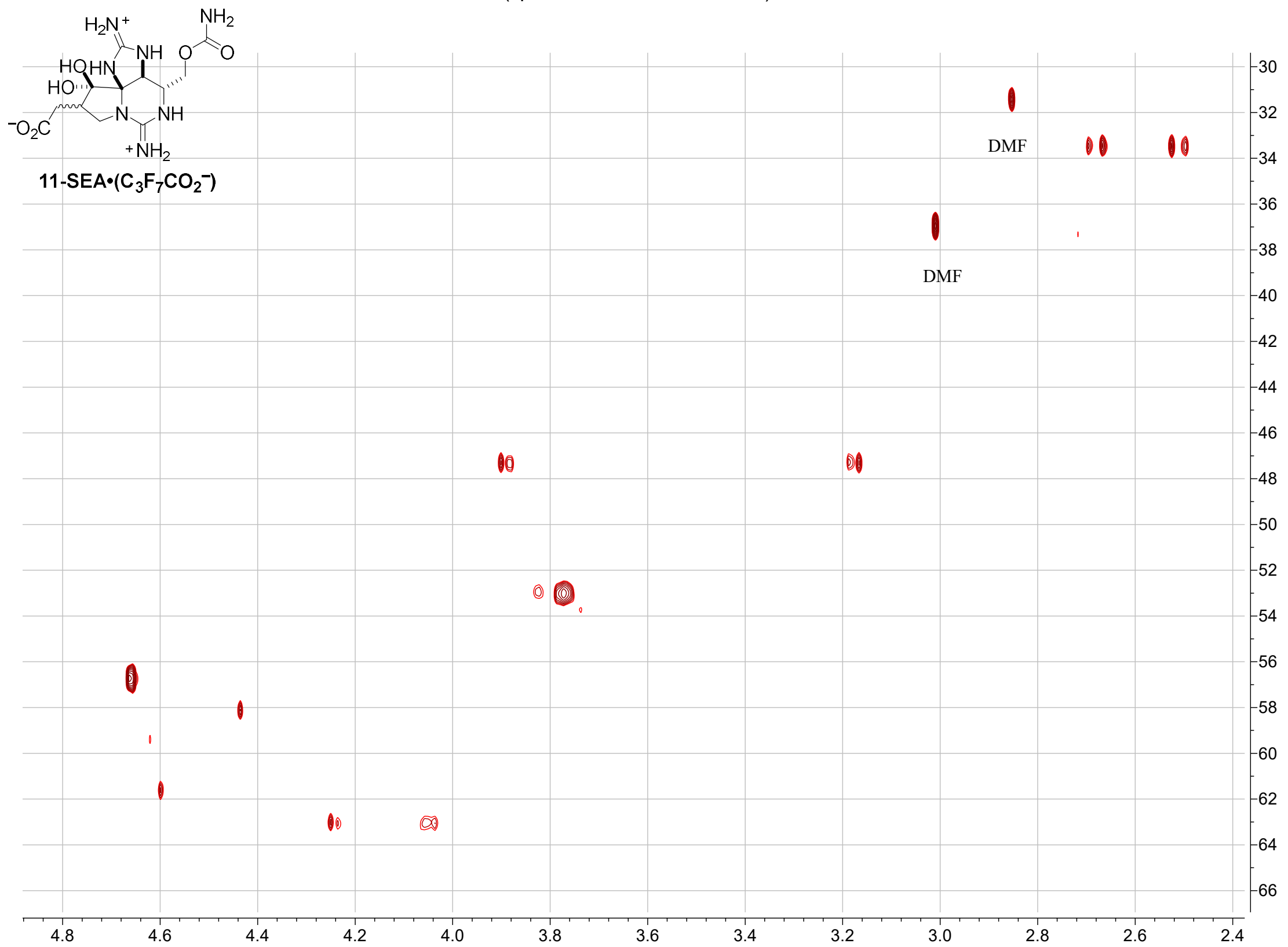

